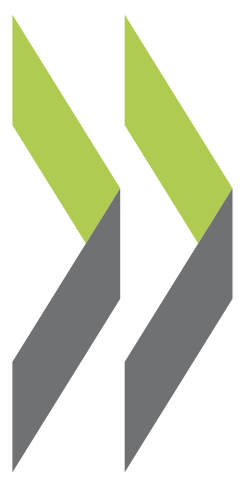

OECD Health Working Papers No. 63

Value in Pharmaceutical

Pricing

\title{
Valérie Paris,
}

\author{
Annalisa Belloni
}

https://dx.doi.org/10.1787/5k43jc9v6knx-en 
Organisation de Coopération et de Développement Économiques

Organisation for Economic Co-operation and Development

11-Jul-2013

DIRECTORATE FOR EMPLOYMENT, LABOUR AND SOCIAL AFFAIRS

English text only

HEALTH COMMITTEE

\section{Health Working Papers}

OECD Health Working Paper No. 63

VALUE IN PHARMACEUTICAL PRICING

Valérie Paris and Annalisa Belloni

JEL Classification: 118

All Health Working Papers are now available through the OECD's Internet Website at http://www.oecd.org/health/workingpapers

JT03342944

Complete document available on OLIS in its original format

This document and any map included herein are without prejudice to the status of or sovereignty over any territory, to the delimitation of international frontiers and boundaries and to the name of any territory, city or area. 


\title{
FOR EMPLOYMENT, LABOUR AND SOCIAL AFFAIRS
}

\author{
www.oecd.org/els
}

\section{OECD HEALTH WORKING PAPERS}

\author{
http://www.oecd.org/health/workingpapers
}

This series is designed to make available to a wider readership health studies prepared for use within the OECD. Authorship is usually collective, but principal writers are named. The papers are generally available only in their original language - English or French - with a summary in the other.

Comment on the series is welcome, and should be sent to the Directorate for Employment, Labour and Social Affairs, 2, rue André-Pascal, 75775 PARIS CEDEX 16, France.

The opinions expressed and arguments employed here are the responsibility of the author(s) and do not necessarily reflect those of the OECD.

\author{
Applications for permission to reproduce or translate \\ all or part of this material should be made to: \\ Head of Publications Service \\ OECD \\ 2, rue André-Pascal \\ 75775 Paris, CEDEX 16 \\ France
}

Copyright OECD 2013 


\section{ACKNOWLEDGEMENTS}

The authors wish to thank national experts for their input and review of health country profiles*; members of the Business and Industry Advisory Committee to the OECD for their contribution to the expert meeting and useful comments; Mark Pearson for careful reading and comments; Divya Srivastava, Jessica Farebrother and Delphine Rouilleault for various inputs on country profiles.

The authors remain responsible for any mistake.

* Forthcoming at http://www.oecd.org/els/health-systems/valueinpharmaceuticalpricing.htm 


\section{TABLE OF CONTENTS}

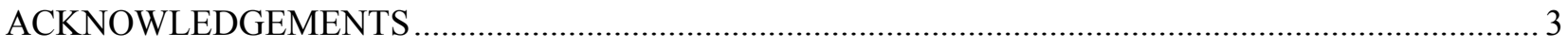

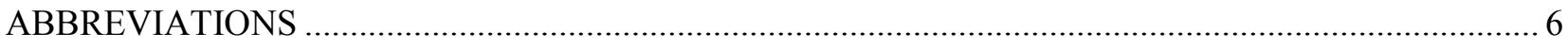

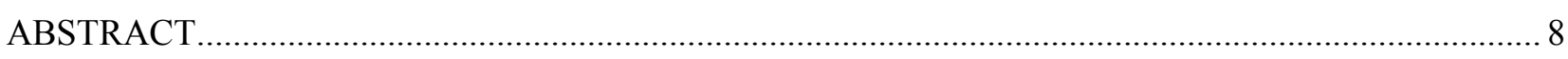

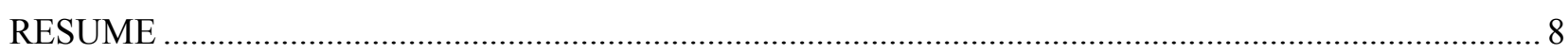

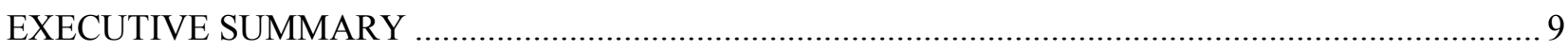

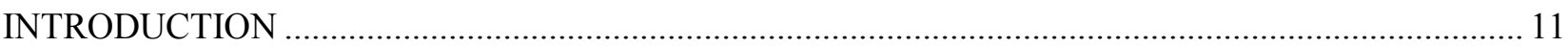

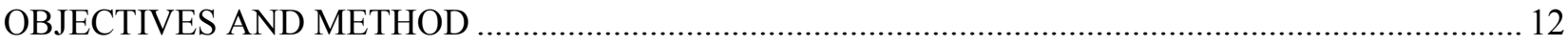

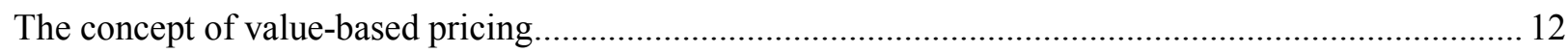

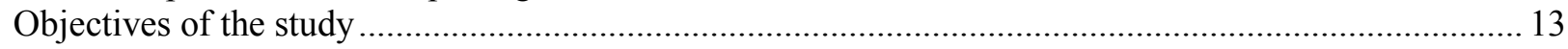

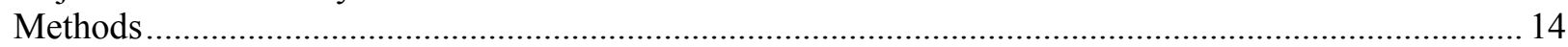

SECTION 1 AN OVERVIEW OF PHARMACEUTICAL COVERAGE AND PRICE REGULATION .. 17

Health systems characteristics and coverage for pharmaceutical care ............................................ 17

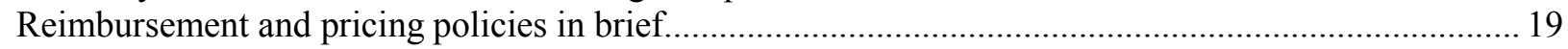

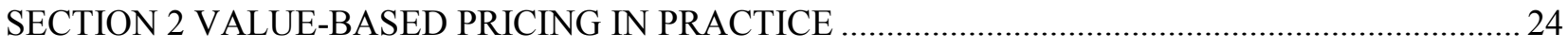

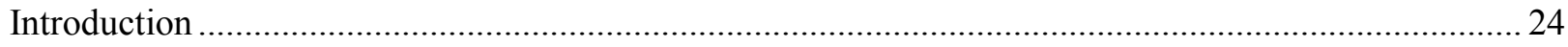

Economic evaluation for reimbursement and pricing decisions...............................................24

Principles and methods used for economic evaluation ...................................................... 25

Approaches for economic evaluation adopted by case-study countries ......................................26

The measure of therapeutic benefits and utility for patients .................................................... 28

Clinical outcomes: final endpoints, surrogate markers and intermediate outcomes ..........................28

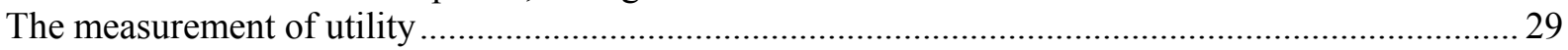

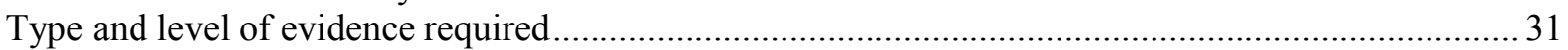

The choice of comparator to assess added therapeutic value .......................................................... 32

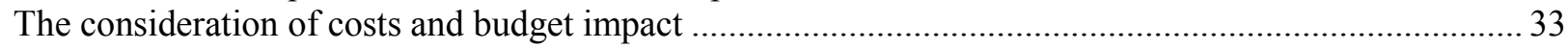

Costs considered in assessment for reimbursement or pricing ................................................. 34

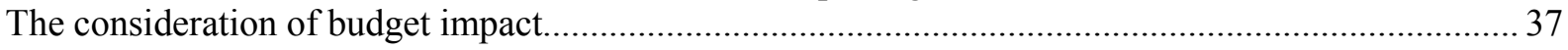

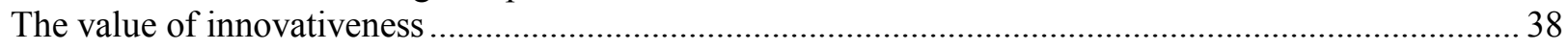

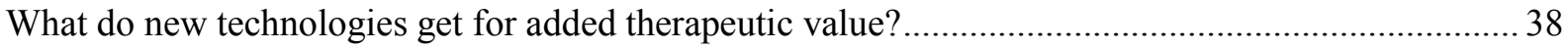

The assessment of added therapeutic value is not always consistent across countries ...................... 40

Innovation "beyond added therapeutic value" is generally not considered ......................................42

Positive changes in the process of care may be an exception .................................................42

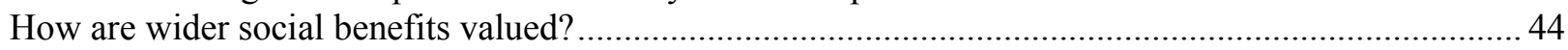

Is there a cost-effectiveness threshold? .............................................................................. 45

Are treatments for severe or rare diseases more valued than others? ............................................48

Treatments for severe diseases are more valued .................................................................. 48

Treatments for rare diseases are also often more valued .......................................................... 50

Paying for value through product-specific agreements ....................................................51

What happens when products have different indications with very different benefits?.......................54 
How does international benchmarking interfere with value-based pricing? .......................................... 55

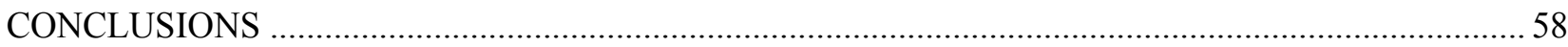

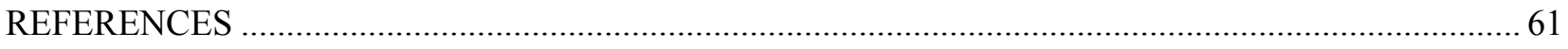

ANNEX 1: BACKGROUND INFORMATION ON CASE-STUDY COUNTRIES ................................65

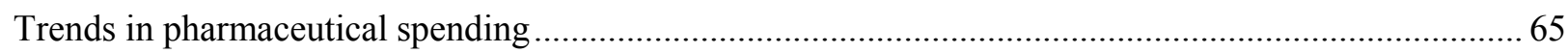

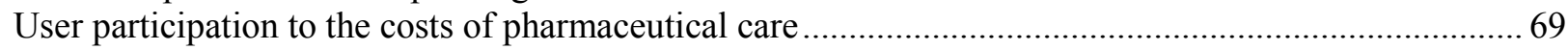

\section{Tables}

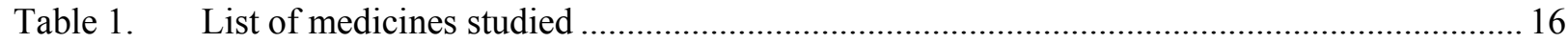

Table 2. Health systems characteristics and pharmaceutical coverage in case-study countries ......... 18

Table 3. Main criteria used to inform reimbursement decisions in case-study countries for products subject to assessment ................................................................................................... 20

Table 4. Regulation of prices or reimbursement prices of medicines(1) in case-study countries.......2 21

Table 5. Bodies in charge of assessment and decisions on reimbursement status and/or price .......... 23

Table 6. Analytical approaches for economic evaluation, as recommended by submission guidelines or recommendations issued by HTA bodies ...................................................................2. 27

Table 7. Summary of recommendations on data sources for the measurement of utility weights

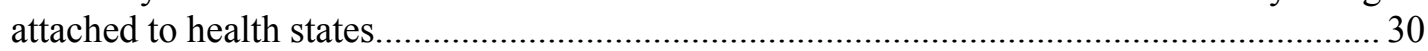

Table 8. The relationship between levels of evidence and grades of recommendation ..................... 31

Table 9. The choice of relevant comparator to assess added therapeutic benefit or incremental cost-

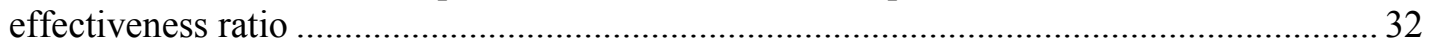

Table 10. The perspective adopted for economic evaluation and/or costs considered in case-study

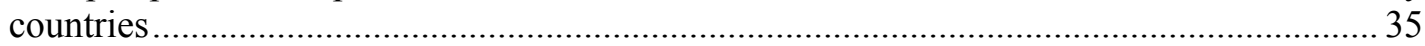

Table 11. Assessment of added therapeutic value and implications .................................................... 39

Table 12. Explicit and implicit ICER thresholds and values observed in our sample of products ....... 47

Table 13. International price benchmarking in OECD countries ........................................................ 55

Table 14. International benchmarking for price regulation............................................................ 57

Table 15. Annual growth in real total health expenditure and real pharmaceutical expenditure

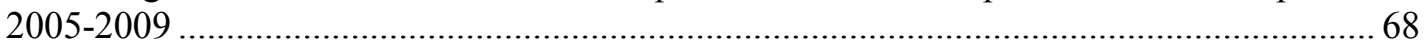

Table 16. Patient contributions to the costs of reimbursed pharmaceuticals in 2012 ......................... 70

\section{Figures}

Figure 1. Pharmaceutical spending as a share of total health expenditure and GDP, $2010 \ldots \ldots \ldots \ldots \ldots . .66$

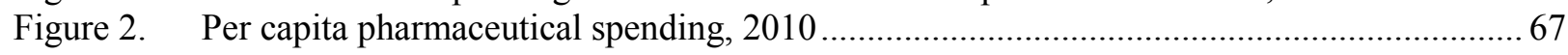

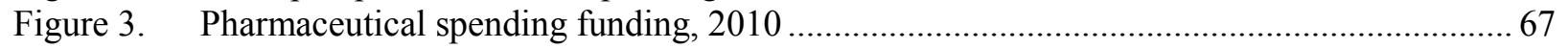

\section{Boxes}

Box 1. Analytic techniques used in the sample of surveyed products ..............................................28

Box 2. Health outcomes considered for the sample of selected products ............................................. 29

Box 3. Examples of instruments used to measure quality of life in the sample of selected products ....... 31

Box 4. The assessment of added therapeutic value differs across countries: the example of fingolimod. 41

Box 5. How improvement in the process of care is taken into account : the example of dabigatran........ 43

Box 6. The consideration of disease severity in the sample of products surveyed .................................50

Box 7. Product-specific agreements in the sample of products surveyed ............................................... 53 


\section{ABBREVIATIONS}

$\begin{array}{ll}\text { AIFA } & \text { Italian Medicines Agency } \\ \text { ASMR } & \text { Added Therapeutic Value (France) } \\ \text { ATC } & \text { Anatomical, Therapeutic, Chemical classification system } \\ \text { CADTH } & \text { Canadian Agency for Drugs and Technologies in Health } \\ \text { CBA } & \text { Cost-Benefit Analysis } \\ \text { CCA } & \text { Cost-Consequences Analysis } \\ \text { CDEC } & \text { Canadian Drug Expert Committee } \\ \text { CDR } & \text { Common Drug Review (Canada) } \\ \text { CEA } & \text { Cost-effectiveness analysis } \\ \text { CED } & \text { Coverage with Evidence Development } \\ \text { CFH } & \text { Pharmaceutical Care Committee (Netherlands) } \\ \text { CMA } & \text { Cost-Minimisation Analysis } \\ \text { CMR } & \text { Commission de Remboursement des Médicaments } \\ \text { CUA } & \text { Cost-Utility Analysis } \\ \text { CVZ } & \text { Health Care Insurance Board (Netherlands) } \\ \text { DACEHTA } & \text { Danish Centre for Health Technology Assessment } \\ \text { DALY } & \text { Disability-Adjusted Life-Year } \\ \text { DDD } & \text { Defined Daily Dose } \\ \text { DH } & \text { Department of Health (the United Kingdom) } \\ \text { EQ-5D } & \text { EuroQol 5D } \\ \text { ERP } & \text { External Reference Pricing } \\ \text { FDA } & \text { Food and Drug Administration } \\ \text { G-BA } & \text { Federal Joint Committee (Germany) } \\ \text { HAS } & \text { National Authority for Health (France) } \\ \text { HIRA } & \text { Health Insurance Review and Assessment Service (Korea) } \\ \text { HTA } & \text { Health Technology Assessment } \\ \text { HYE } & \text { Healthy Years Equivalent } \\ \text { ICER } & \text { Incremental Cost-Effectiveness Ratio } \\ \text { INESSS } & \text { National Institute for Excellence in Health and Social Services (Canada, Quebec) } \\ \text { IQWiG } & \text { Institute for Quality and Efficiency in Health Care (Germany) } \\ \text { KCE } & \text { Belgian Health Care Knowledge Centre } \\ \text { LYG } & \text { Life-Year Gained } \\ \text { MAUI } & \text { Multi-Attribute Utility instrument } \\ \text { MHLW } & \text { Ministry of Health, Welfare and Sport (Japan) } \\ \text { MoF } & \text { Ministry of Finance } \\ \text { MoH } & \text { Ministry of Health } \\ \text { NHS } & \text { National Health Service } \\ \text { NICE } & \text { National Institute for Health and Care Excellence } \\ \text { NoMA } & \text { Norwegian Medicines Agency } \\ \text { OFT } & \text { Office of Fair Trading } \\ \text { OOP } & \text { Out of Pocket } \\ & \end{array}$


PAG Provincial Advisory Group (Canada)

PAS Patient Access Schemes

PBAC Pharmaceutical Benefit Advisory Committee (Australia)

pCODR Pan-Canadian Oncology Drug Review

PMPRB Patented Medicines Price Review Board (Canada)

PPRI Pharmaceutical Pricing and Reimbursement Information

QALY Quality-adjusted life year

R\&D Research and development

R\&P Reimbursement and pricing

RCT Randomised Controlled Trial

SG Standard Gamble

SMC Scottish Medicine Consortium

SMR Therapeutic Value (France)

TLV Dental and Pharmaceutical Benefits Board (Sweden)

TTO Time Trade-Off

VAS Visual Analogue Scale

VAT Value Added Tax

VBP Value-based pricing

WHO World Health Organisation

WTP Willingness to pay 


\begin{abstract}
This study analyses how 14 OECD Countries refer to "value" when making decisions on reimbursement and prices of new medicines. It details the type of outcomes considered, the perspective and methods adopted for economic evaluation when used; and the consideration of budget impact. It describes which dimensions are taken into account in the assessment of "innovativeness" and the consequences of this assessment on prices; it confirms that treatments for severe and/or rare diseases are often more valued than others and shows how countries use product-specific agreements in an attempt to better align value and price.
\end{abstract}

\title{
RÉSUMÉ
}

Cette étude analyse comment 14 pays de l'OCDE prennent en compte la "valeur" dans leurs décisions concernant le remboursement et le prix des nouveaux médicaments. Elle décrit le type de " résultats » pris en compte, la perspective et les méthodes adoptées pour l'évaluation économique là où elle est utilisée, ainsi que la prise en compte de l'impact budgétaire. Elle décrit quelles dimensions sont prises en compte pour évaluer le caractère innovant et les conséquences de cette évaluation en termes de prix ; elle confirme que les pays accordent souvent une valeur plus élevée aux traitements pour les maladies sévères et/ou rares et montre comment les pays utilisent les accords «par produit » pour tenter de mieux adapter le prix à la valeur. 


\section{EXECUTIVE SUMMARY}

1. The objective of this study is to describe how OECD Member Countries refer to "value" when making decisions on reimbursement and prices of new medicines. The study scrutinised reimbursement and pricing policies in 14 OECD countries. In addition to describing the formal differences in how valuebased pricing is applied in these countries, a more detailed examination of the decisions made about 12 products brought to the market between 2005 and 2011 was conducted. These products were chosen to illustrate differences across countries in how value is assessed and how this might affect reimbursement decisions and pricing outcomes.

2. Ideally, information on prices actually paid by purchasers is needed to understand fully the impact of "value-based" reimbursement and pricing policies. Unfortunately, price information is not available for a number of products in our sample. Reliable price information was available only for a small number of products used in ambulatory care with list prices likely to correspond to actual prices. The project also tried to collect information on the use of all products, but such information was often not comparable or simply not available.

3. Despite these data limitations, this report does answer some of the questions about how valuebased pricing works in practice, and how much different conceptions of 'value' actually matter.

4. The first conclusion is that the types of health outcomes considered by assessment bodies to inform decisions on reimbursement have more in common with each other than differences. For example, all countries prefer final endpoints to surrogate markers to assess health outcomes where available. Countries using economic evaluation explicitly consider utility for patients when assessing incremental cost-utility ratios, while other countries do not systematically do so. This difference might be expected to have an impact on reimbursement decisions, price levels and relative prices of different categories of products. However, from the sample of countries and products scrutinized, it was not possible to identify such an impact.

5. Second, countries using economic evaluation are more sensitive to uncertainties attached to health outcomes or costs. They rejected funding applications on grounds of uncertainty more often than countries without economic evaluation. This may be due to the formal presentation of sensitivity analysis in economic assessments, which raises awareness of decision-makers.

6. Third, several countries have chosen a societal perspective to evaluate health technologies (e.g. Sweden and Norway). While this choice could, in principle, have a big impact on prices paid for products with a big social impact (such as increasing labour market productivity), in practice there is little evidence that it makes much difference.

7. Fourth, one of the objectives of value-based pricing is to reward innovation. This is mainly assessed through the added therapeutic value of new medicines over existing treatment alternatives. If assessment bodies confirm that a drug has some added therapeutic value, this influences the analytical method used in economic evaluation or the rules applying to price regulation in countries which do not use economic evaluation. Payers are in principle ready to pay a price premium or to allow incremental costs for an innovative product. However, establishing a clear link between the level of innovativeness and the price 
premium seems impossible. Assessing the implied value of a QALY is also difficult since there is little evidence of consistency across products.

8. Fifth, improvements in the process of care, without a direct impact on health, may have sometimes resulted in a higher price being paid for new products, although the evidence is not clear. By contrast, no evidence was found that innovation "beyond therapeutic value" is considered in practice to make reimbursement or price decisions.

9. The sixth conclusion is that the study confirmed that disease severity and rarity receive particular attention, justifying higher prices or incremental cost-effectiveness ratios (ICER) in case-study countries. While some countries have explicitly defined criteria that should be taken into account (e.g. NICE with the end-of-life criteria), others do not have pre-defined rules. Countries that do not use economic evaluations are also more likely to accept high prices in similar circumstances.

10. When medicines are approved for several indications which display very different costeffectiveness ratios, countries have adopted different attitudes. The seventh conclusion is that most often, the price of a medicine is unique, set at market entry, and countries make a "yes or no" decision for each new indication. The price may be reviewed (always downward in our sample) when a new indication is funded. In some occasions, product-specific agreements have been used to permit price discrimination across market segments defined for each indication.

11. Beyond these conclusions, it should be noted that price is not the only component of value. Very often, decision-makers have to trade-off prices against potential market sizes and are willing to extend indications in exchange for a lower price as long as benefits for patients are clearly shown. Negotiations of this type seem more likely to occur in systems not using a formal evaluation process.

12. Finally, international benchmarking is still widely used in price regulation, with several implications. The first is that it does not seem completely compatible with value-based pricing. The second is that the future implementation of value-based pricing in the most referenced countries will have an impact in other markets, which is difficult to predict at this stage. 


\section{INTRODUCTION}

13. Pharmaceutical reimbursement and pricing (R\&P) policies must balance static efficiency (keeping costs low relative to benefits) and dynamic efficiency (encouraging R\&D). There is no 'right' way of doing this. The OECD report published in 2008 "Pharmaceutical pricing policies in a global market" made an inventory of R\&P policies used by OECD Member Countries and analysed their impact on availability and affordability of medicines, both nationally and internationally, and on innovation. One of the main conclusions of this report was that countries should seek to pay for drugs in relation to the "value" they bring to their own health system and society.

14. Since the finalisation of that report, a number of major developments have occurred in some OECD countries which have left parts of the 2008 report outdated. Germany reformed its system in 2011, imposing maximum reimbursement prices for all new reimbursed products after the assessment of their added therapeutic value. France announced its intention to use economic evaluation in the pharmaceutical R\&P process from 2013. The United Kingdom announced its willingness to replace the 50-year old Pharmaceutical Pricing Regulation Scheme by value-based pricing for medicines from 2014. This means that pharmaceutical companies will no longer be able to set freely the prices of new products in Germany and the United Kingdom, as used to be the case. Hence, changes are likely to happen in the three countries (France, Germany and the United Kingdom) which are the most often referred to in international price benchmarking by other OECD countries (OECD, 2008). Either directly or indirectly, "value" will be influencing pricing decisions more prominently in the future.

15. The concept of value-based pricing has gained momentum, though there is no widely accepted definition of value in this specific context. However, many OECD countries already use some sort of "value-based pricing" in the sense that they regulate reimbursement or price of pharmaceuticals - at least in some circumstances - on the basis of their therapeutic value. The objective of this report is to describe current experiences in a sample of OECD countries using one of these two policies, or a mixture of both:

- The use of formal pharmaco-economic assessment to inform decisions on reimbursement and/or pricing;

- The practice of formal assessment of the added therapeutic value of new products over comparators, used to determine or negotiate price premiums.

16. Considering that economic conditions, health needs, citizens' preferences and health systems characteristics may legitimately differ across countries, the report does not seek to identify any 'best' practice but only to shed some light on how current practices in pharmaceutical reimbursement and pricing decisions actually work. 


\section{OBJECTIVES AND METHOD}

\section{The concept of value-based pricing}

17. Outside the area of health policy, value-based pricing happens when a price is set reflecting the value to the customer. This price may differ across market segments. Customer value is defined either by the customers' maximum "willingness-to-pay" or as "the cost of the customer's best alternative plus the value of any company-exclusive differentiating features" (Liozu et al., 2011). Though value-based pricing can be shown to be the most profitable strategy for a firm (subject to a series of assumptions), it is not (yet) widely used in practice. This may be due to misperceptions of managers about the role of price in purchasing decisions: they often think that predatory pricing is needed to gain market share, though the evidence suggest that this is not necessarily true (Hinterhuber, 2008). In the literature on strategic management and pricing, however, some pharmaceutical companies have been held up as examples because they have been able to charge a price premium over competitors when marketing new products with added therapeutic value.

18. In the health sector, the "value-based" terminology blossomed in the 2000's. It is used in different ways, from "value-based health systems" (Porter, 2009), to "value-based pricing" or "value-based benefit design" (see for instance, OFT, 2007; OECD, 2008; Health Affairs issue of November 2010). In a broad sense, "valued-based" means that activities of the health sector should be oriented, organised or funded so that the ultimate objective is to maximise health benefits for patients and the society as a whole. Although this does not sound as if it should be a novelty (has not improving health always been the objective of health systems?), it is, in the sense that it proposes to link payments for pharmaceuticals or health care services to evidence-based assessments of value for patients, their relatives and the society as a whole. But as the increasingly ubiquitous use of the term "value" suggests, "value-based pricing" for pharmaceuticals can also be seen as part of a wider movement in health systems involving health technology assessment, quality of care measurement and pay-for-performance payments for health professionals and institutions. All these policies aim to change resource allocation decisions on the basis of the respective values of health care interventions.

19. In the health sector, customer willingness-to-pay is not relevant to determine the price of a specific technology since the majority of health spending is financed by third-party payers and consumers often only pay a small share of expenditures for the consumption of health care services. Several authors have proposed definitions for value-based pricing in the pharmaceutical sector (hereafter VBP). In the context of the English National Health System, Claxton defined VBP as '(the price) that ensures that the expected health benefits [of a new technology] exceed the health predicted to be displaced elsewhere in the NHS, due to their additional cost' (Claxton, 2007). According to this definition, pharmaco-economic analysis is needed to determine whether a technology is cost-effective, by reference to a pre-defined costeffectiveness threshold. Husereau and Cameron (2011) propose a wider definition by saying that: "valuebased pricing consists of negotiating prices for new pharmaceuticals based on the value the new drug offers society, as assessed through HTA". VBP is expected to ensure in the short run that technologies are accepted for use in health systems only if they are cost-effective, while providing in the longer run clear signals and incentives for manufacturers to invest in the development of technologies which are more likely to be cost-effective (Claxton, 2007).

20. These definitions, however, do not provide simple recipes on how to determine value-based price in practice. Though some authors have strong views about the perspective to be adopted for economic evaluation and the way to determine cost-effectiveness thresholds in publicly funded health systems, these views are not consensual and these issues continue to be treated differently around the world. This report is 
an attempt to take stock of experience accumulated in a number of OECD countries which make decisions on reimbursement and prices based on an assessment of the therapeutic value of a new drug.

\section{Objectives of the study}

21. The primary objective of this study is to assess to what extent countries currently use "valuebased pricing". It describes how countries assess benefits or added therapeutic value of new products for reimbursement or pricing purpose. After marketing authorization, many countries perform a "second" assessment, in order to determine whether a new drug deserves to be reimbursed by public payers, at what price, and under what conditions (e.g. only for some of its indications, restrictions on prescribers). While a marketing authorization typically measures risks and benefits associated with a single product, this second assessment often compares the effectiveness of the new product with existing therapeutic alternatives (drug or non-drug). In some countries, it also includes information on cost-effectiveness. The study explores both institutional and methodological aspects of this second assessment. Case-studies include information on the institutions and stakeholders involved, as well as information on the decision process. This report undertakes a comparative analysis of methodological aspects. It shows the type of health outcomes considered (endpoint or surrogate outcomes, quality of life, etc.), the level of evidence required, the choice of comparators for comparative-effectiveness studies and other types of benefits considered in the evaluations.

22. An issue which receives particular focus is that of 'innovation'. For countries that formally assess the added value of a new drug over existing comparators and cluster products in different categories according to their level of innovativeness (e.g. Belgium, France and Italy), the study investigates the methods used to assess "innovativeness" over comparators and in particular the choice of comparators, health outcomes considered and valued (survival, patient comfort, etc.) in the clustering process. It also investigates whether other types of innovation (that do not translate into improved health) are taken into account.

23. To further explore what countries seek to value through their reimbursement or pricing decisions, this report describes the perspective adopted in pharmaco-economic assessments when performed for reimbursement purposes, especially the type of costs and non-health benefits considered. The study also explores how costs are considered in countries that do not use formal economic assessment to make pricing decisions.

24. A second objective of this report is to describe the rules and processes in place for appraisal and pricing of new medicines. The report looks at institutions involved in the process: Who is responsible for appraisal and who is finally responsible for making decisions of reimbursement and pricing? While some countries clearly separate advice and decision-making, other countries make the same body responsible for both appraisal and decisions. The study investigates the rules set to define eligibility to reimbursement status, with a focus on the following aspects: the existence of an explicit or implicit cost-effectiveness threshold beyond which drugs are less likely to be accepted, as well as possible variations of this threshold according to severity or rarity of the disease treated; the consideration of budget impact in the process; rules to define "price premiums" rewarding innovativeness; the treatment of medicines with several indications with very different added therapeutic value; and the role of product-specific agreements in the system (risk-sharing agreement, price-volume agreement, etc.).

25. The study also describes what happens after market entry, including what rules apply to reviewing reimbursement and pricing decisions. 


\section{Methods}

26. A sample of countries was initially selected as case-studies because they use one of the R\&P policy considered as "value-based":

- Australia, the Netherlands, Norway, Sweden and the United Kingdom (England and Wales and Scotland), because of their experience in using formal pharmaco-economic assessment to inform decision-making;

- Belgium, France, Germany, and Japan, which assess the added therapeutic value of new products - clustered in different categories -, and grant price premiums to innovative drugs.

27. In addition, some further countries were included: Italy for its system of innovation rating used in price negotiations and an advanced practice of performance-based agreements; and Canada, which uses both categorisation of innovativeness to regulate prices at federal level and centralised pharmaco-economic evaluation to inform decentralised decisions on reimbursement status, made for public coverage schemes. Denmark, Korea, and Spain were included because they use some elements of value-based pricing in their decisions.

28. The project's analyses and conclusions rely on two main streams of information: country profiles and analysis of assessments and decisions pertaining to a sample of medicines.

29. Country profiles were prepared using information published at national level (such as guidelines for submission, legislations, regulations, etc.), country profiles already published by the OECD (Germany, Sweden and Canada) or available from the WHO Collaborating Centre for Pharmaceutical Pricing and Reimbursement Policies website ${ }^{1}$ (Belgium, Denmark, France, the Netherlands, Norway, Spain); as well as comparative studies published recently (Sorenson et al., 2008; Le Polain et al., 2010; Wilsdon and Serota, 2011). In the majority of cases, country profiles were reviewed by country experts and written information was completed by interviews with stakeholders.

30. Descriptions of pricing and reimbursement policies can only go so far in providing a concrete understanding of what actually happens to products undergoing pricing and reimbursement processes in each country. Therefore, information has been collected on assessments and decisions made in case-study countries for a sample of products. This sample was selected after consultations with experts and does not pretend to be representative of the pharmaceutical market. Instead, it includes products with different characteristics to illustrate contrasting situations.

31. The sample of the 12 products selected is presented in table 1, with information on indications, date of first marketing authorisation in the sample of countries, and reasons for its selection. The sample includes products:

- With different "levels of innovativeness" (breakthrough, major improvement, moderate improvement and light improvement);

- With different types of outcomes: improvement in survival, in quality of life, in surrogate markers, in comfort of use for patients and/or caregivers, as well as other possible benefits;

- Used in the treatment of diseases with different levels of severity;

1. $\quad$ http://whocc.goeg.at/Publications/CountryReports, consulted in May 2012. 
- With different degree of uncertainty in available evidence of effectiveness;

- With different sizes of population targets (including one orphan drug);

- Used in different settings (hospital only, ambulatory care);

- Approved for several indications, with very different "therapeutic value" or incremental costeffectiveness ratios in their different uses.

32. Information was collected on the assessments performed and decisions made for reimbursement status and/or prices for these products. Almost all countries responded to this survey and this was supplemented by additional information drawn from publicly available assessment reports. The objective was to answer the following questions:

- Is reimbursement/funding granted with restrictions (e.g. restricted to some population groups, with or without prior authorisation, reserved to certain specialists or specialised settings, accepted only as a second-line treatment and/or for some indications)?

- What was the status of the drug before the decision was made: funded since market entry by default, or through a special access program, or not funded pending assessment and decision?

- In decentralised and/or pluralistic systems: do conditions and levels of funding or reimbursement differ across regions or insurers? On what grounds?

33. Information collected on pricing aimed to answer the following questions:

- What criteria were taken into account in pricing decision or price negotiations?

- Can purchasers negotiate lower prices than the list price? Does the price usually vary across purchasers?

- Is there any (non-confidential) product-specific agreement, and if so, what is its content? Could the product be subject to a confidential agreement, likely to reduce its list price? 
DELSA/HEA/WD/HWP(2013)4

Table 1. List of medicines studied

\begin{tabular}{|c|c|c|c|}
\hline $\begin{array}{l}\text { Active substance and } \\
\text { trade names }\end{array}$ & $\begin{array}{l}\text { Date of first } \\
\text { Marketing } \\
\text { authorization in } \\
\text { sample of } \\
\text { countries }\end{array}$ & Indications(1) & Criteria for selection \\
\hline $\begin{array}{l}\text { Bevacizumab, } \\
\text { Avastin } ®\end{array}$ & 2005 & $\begin{array}{l}\text { Metastatic cancer of the colon or rectum, } \\
\text { Metastatic breast cancer, } \\
\text { Advanced, metastatic or recurrent non-small cell } \\
\text { lung cancer that is unresectable } \\
\text { Advanced or metastatic kidney cancer }\end{array}$ & $\begin{array}{l}\text { Several indications with } \\
\text { different therapeutic value; } \\
\text { Disease severity } \\
\text { Hospital settings }\end{array}$ \\
\hline Cetuximab, Erbitux $®$ & 2004 & $\begin{array}{l}\text { Metastatic cancer of the colon or rectum } \\
\text { Squamous cell cancer of the head and neck }\end{array}$ & $\begin{array}{l}\text { Disease severity } \\
\text { Hospital settings }\end{array}$ \\
\hline Sunitinib, Sutent ${ }^{\circledR}$ & 2007 & $\begin{array}{l}\text { Gastrointestinal stromal tumour (GIST), } \\
\text { Metastatic renal cell carcinoma, } \\
\text { Pancreatic neuro-endocrine tumours (indication } \\
\text { adopted in 2010) }\end{array}$ & $\begin{array}{l}\text { Clinical step change } \\
\text { Disease Severity, End of } \\
\text { life treatment } \\
\text { Hospital settings }\end{array}$ \\
\hline Cabazitaxel, Jevtana ${ }^{\circledR}$ & 2011 & Hormone refractory metastatic prostate cancer & Disease Severity \\
\hline Fingolimod, Gilenya ${ }^{\circledR}$ & 2011 & Relapsing-remitting multiple sclerosis & $\begin{array}{l}\text { Disease Severity } \\
\text { Gains in quality of life } \\
\text { Wider social benefits }\end{array}$ \\
\hline Dabigatran, Pradaxa ${ }^{\circledR}$ & 2008 & $\begin{array}{l}\text { Prevent the formation of blood clots in the veins } \\
\text { in adults who have had an operation to replace } \\
\text { a hip or knee. } \\
\text { Prevent strokes and the formation of clots in } \\
\text { adults who have 'non-valvular atrial fibrillation' } \\
\text { and are considered to be at risk of stroke. }\end{array}$ & $\begin{array}{l}\text { Prevention } \\
\text { Hospital settings } \\
\text { Ambulatory care }\end{array}$ \\
\hline Eculizumab, Soliris ${ }^{\circledR}$ & 2007 & $\begin{array}{l}\text { Paroxysmal nocturnal haemoglobinuria }(\mathrm{PNH}) \\
\text { Atypical haemolytic uremic syndrome (aHUS }\end{array}$ & Orphan drug \\
\hline Boceprevir Victrelis ${ }^{\circledR}$ & 2011 & $\begin{array}{l}\text { Chronic (long-term) hepatitis C genotype } 1 \\
\text { Compensated liver disease }\end{array}$ & Disease severity \\
\hline Telaprevir, Incivo ${ }^{\circledR}$ & 2011 & $\begin{array}{l}\text { Chronic (long-term) hepatitis C } \\
\text { Compensated liver disease }\end{array}$ & Disease severity \\
\hline $\begin{array}{l}\text { Ranibizumab, } \\
\text { Lucentis }{ }^{\circledR}\end{array}$ & 2007 & $\begin{array}{l}\text { Neovascular (wet) age-related macular } \\
\text { degeneration (AMD) } \\
\text { Macular Oedema Following Retinal Vein } \\
\text { Occlusion (RVO) } \\
\text { The treatment of visual impairment due to } \\
\text { diabetic macular oedema (DME) }\end{array}$ & $\begin{array}{l}\text { Disease severity } \\
\text { Quality of life }\end{array}$ \\
\hline $\begin{array}{l}\text { Sitagliptin, Januvia } ₫ \text {, } \\
\text { Ristaben } ₫ \text {, Xelevia }{ }^{\circledR}\end{array}$ & $\begin{array}{l}2007 \text { for } \\
\text { Januvia }{ }^{\circledR} \text { and } \\
\text { Xelevia } \AA, 2010 \\
\text { for Ristaben } \AA\end{array}$ & $\begin{array}{l}\text { Type } 2 \text { diabetes, to improve the control of blood } \\
\text { glucose (sugar) levels }\end{array}$ & $\begin{array}{l}\text { Secondary prevention, } \\
\text { large population } \\
\text { Ambulatory care }\end{array}$ \\
\hline $\begin{array}{l}\text { Sitagliptin metformin } \\
\text { Ristfor } ₫, \text { Efficib } \AA \text {, } \\
\text { Janumet } \circledast \text { Velmetia } ®\end{array}$ & $\begin{array}{l}2010 \text { for } \\
\text { Ristfor } \AA, 2008 \\
\text { for Efficib } \AA \text {, } \\
\text { Janumet }{ }^{\circledR} \text { and } \\
\text { Velmetia }{ }^{\circledR}\end{array}$ & $\begin{array}{l}\text { Type } 2 \text { diabetes, to improve the control of blood } \\
\text { glucose (sugar) levels }\end{array}$ & $\begin{array}{l}\text { Secondary prevention, } \\
\text { Small added value, } \\
\text { change in patient comfort } \\
\text { Ambulatory care }\end{array}$ \\
\hline
\end{tabular}




\section{SECTION 1 \\ AN OVERVIEW OF PHARMACEUTICAL COVERAGE AND PRICE REGULATION}

34. This section describes the main characteristics of pharmaceutical coverage in the sample of countries selected for this study. It then presents a brief overview of the pricing and reimbursement process, as well as institutions involved in assessment and decision-making. It is an introduction to the more thorough description of criteria taken into account during this process in section 2 .

\section{Health systems characteristics and coverage for pharmaceutical care}

35. Countries selected for case studies offer a great variety of health systems characteristics, but all provide coverage for basic health needs to all or almost all residents through a tax-funded national health system or through mandatory social health insurance. Coverage for pharmaceutical care is included in the basic benefit package in all countries but Canada (see table 2). In Canada, the tax-funded health systemdoes not cover the costs of pharmaceuticals used in outpatient care. Canada's residents obtain pharmaceutical coverage through voluntary private health insurance (two thirds of the population) unless they are eligible for one of the public plans run by provinces and territories or by the federal government (one third of the population). The province of Québec is an exception since coverage for outpatient pharmaceuticals is mandatory, and must be primarily obtained through private health insurance or by the public system if it is not possible. However, in all provinces those over 65 years have public coverage, and in some provinces (Manitoba and Saskatchewan) all residents have coverage after the annual deductible has been reached.

36. In all countries other than Canada and the United Kingdom, the pharmaceutical benefit is defined at the central level (see Table 2). In Canada, each drug plan designs its own benefit package through drug formularies. In the United Kingdom, each country defines the covered benefit package for pharmaceuticals. In other decentralised countries -such as Australia, Italy, Spain and Sweden - the benefit package is defined at the central level and access to medicine is identical or similar, at least for pharmaceuticals used in ambulatory care. In Spain, autonomous communities can offer additional benefits. In countries where competing insurers are allowed to deviate from the centrally defined benefit package Germany and the Netherlands - health insurance providers are required to cover all active substances in the pharmaceutical benefit package, but not necessarily all brands. They can also cover drugs that are not included in the national benefit basket.

37. In almost all countries the pharmaceutical benefit package is defined through positive lists. Germany and the United Kingdom are the only countries where every product marketed is covered by default, unless it belongs to one of the categories excluded from reimbursement by Law or regulations. This feature is in principle expected to encourage the adoption of new technologies, at a price set freely by the manufacturer. In England and Wales, the National Institute for Health and Care Excellence was created in 1999 with the mission to conduct health technology assessment and inform decision-making at local level, in order to reduce what was known as the "postcode lottery" (the fact that access to expensive medicines depended on decisions made by local providers facing budget constraints). NICE does not systematically assess new products but mainly those with high prices and/or uncertain effectiveness. Since the creation of NICE, stakeholders have noted that providers tend to wait for NICE decisions to implement new technologies in their daily practice. In Germany, until recently, new products with added therapeutic 


\section{DELSA/HEA/WD/HWP(2013)4}

value (i.e. that could not be clustered in reference price groups) were adopted at manufacturers' prices at market entry.

38. In all case-study countries, patients have to contribute to the costs of pharmaceuticals, through copayments, co-insurance rates or deductibles (see table 17 in Annex).

Table 2. Health systems characteristics and pharmaceutical coverage in case-study countries

Coverage for basic health needs and for pharmaceutical care

\begin{tabular}{lll}
\hline Australia & $\begin{array}{l}\text { All residents are covered by the national health } \\
\text { system Medicare, which includes the Pharmaceutical } \\
\text { Benefits Scheme. The PBS covers drugs dispensed } \\
\text { in community pharmacies or in private hospitals, as } \\
\text { well as some highly specialised drugs in public } \\
\text { hospitals. States finance most medicines used in } \\
\text { public hospitals. }\end{array}$ & $\begin{array}{l}\text { Positive list (PBS schedule) for medicines } \\
\text { covered by the PBS. Public hospitals define their } \\
\text { own formularies. }\end{array}$ \\
& $\begin{array}{l}\text { Almost all residents (99\%) are covered by social } \\
\text { health insurance, which includes coverage for } \\
\text { pharmaceutical care. }\end{array}$ & $\begin{array}{l}\text { Positive lists for outpatient and inpatient } \\
\text { medicines }\end{array}$
\end{tabular}

Canada
All residents are covered by the national health
system Medicare. Medicare covers pharmaceutical
used in inpatient care, but not pharmaceuticals used
in outpatient care.
Pharmaceutical coverage for outpatient care is
obtained through private health insurance for about
$2 / 3$ of residents, and by public drug plans for the
remaining $1 / 3$. All residents over 65 years are
covered by provincial plans, as well as all residents in
Manitoba and Saskatchewan once deductibles have
been exceeded.
All residents are covered by the national health
system, which includes pharmaceutical coverage.

France
$\begin{aligned} & \text { All residents are covered by social health insurance, } \\ & \text { which includes pharmaceutical coverage. }\end{aligned}$
$\begin{aligned} & \text { All residents are covered either by social health } \\ & \text { insurance }(90 \% \text { of the population) or by private health } \\ & \text { insurance }(10 \%) \text {. In both cases, the basic benefit } \\ & \text { package includes pharmaceuticals. }\end{aligned}$
package includes pharmaceuticals.
Drug formularies defined by each drug plan public or private- with specific rules

Positive list for outpatient medicines; Hospital formularies for medicines used in hospitals (exclusively or not).

\section{Positive lists for outpatient and inpatient} medicines

All medicines marketed in Germany are covered by SHI, unless they belong to one of the categories excluded from reimbursement by Law or regulation. The law defines benefits covered by statutory health insurance on a general level and the Federal Joint Committee defines concrete benefits. Private health insurers have some latitude to define benefits covered but generally offer similar benefits.

Positive lists for outpatient and inpatient medicines.

Positive list for outpatient and inpatient medicines.

Positive list for outpatient medicines.

Health insurers compete with potential differences in benefits covered. However, they must provide coverage for medicines included in a centrally defined positive list. 


\begin{tabular}{lll}
\hline & \multicolumn{1}{c}{$\begin{array}{c}\text { Coverage for basic health needs and for } \\
\text { pharmaceutical care }\end{array}$} & \multicolumn{1}{c}{$\begin{array}{c}\text { Definition of the pharmaceutical benefit } \\
\text { package }\end{array}$} \\
\hline Norway & $\begin{array}{l}\text { All residents are covered by national health } \\
\text { insurance, which includes pharmaceutical coverage. }\end{array}$ & Positive list for out-patient drugs. \\
Spain & $\begin{array}{l}\text { All residents are covered by the national health } \\
\text { system, which includes pharmaceutical coverage. }\end{array}$ & $\begin{array}{l}\text { Positive lists for outpatient and inpatient } \\
\text { medicines. }\end{array}$ \\
Sweden & $\begin{array}{l}\text { All residents are covered by the } \\
\text { national health system, which includes } \\
\text { pharmaceutical coverage. }\end{array}$ & $\begin{array}{l}\text { Positive lists for outpatient and inpatient care. } \\
\text { United }\end{array}$ \\
Kingdom & $\begin{array}{l}\text { All residents are covered by national health systems, } \\
\text { managed by governments (England and Wales, }\end{array}$ & $\begin{array}{l}\text { In England and Wales, all medicines are in } \\
\text { principle covered by default, unless they belong } \\
\text { to a category excluded from NHS coverage } \\
\text { and/or are included in a negative list. Hospitals } \\
\text { draw their own formularies. }\end{array}$ \\
\hline
\end{tabular}

Source: Country profiles and Paris et al. (2010)

\section{Reimbursement and pricing policies in brief}

39. All case-study countries, with the exception of Germany and the United Kingdom, conduct a systematic assessment of all new drugs ${ }^{2}$ or new indications of existing products applying for reimbursement status before market entry (Table 3). Decisions on the reimbursement status are based on a pre-defined set of criteria. Seven out of fourteen case-study countries systematically use economic evaluation to make decisions and consider cost-effectiveness ${ }^{3}$ as the primary condition for listing (including Australia, Belgium, Canada's public plans, Korea, the Netherlands, Norway and Sweden). In France, Italy and Japan, reimbursement decisions are mainly based on clinical criteria related to the efficacy or effectiveness of the new product, the nature of the disease treated and the existence of therapeutic alternatives. If a medicine is considered to deserve public coverage along these criteria, price negotiation takes place. The medicine can only be reimbursed if there is an agreement on price. Costeffectiveness studies are sometimes used in Italy and Spain to inform price negotiations.

40. In Germany and in the United Kingdom, medicines are covered as soon as they enter the market unless they belong to a category a priori excluded from reimbursement. In England and Wales, NICE provides advice, on request, on the coverage of new medicines by the English NHS, generally after their market entry. In Germany, since January 2011, new drugs must be assessed three months after market entry to make sure their price ensures an efficient use of resources and set a maximum reimbursement price if needed.

2. Unless otherwise specified, new drugs in this report refer to products containing a new active ingredient or new presentations of an existing product, excluding minor changes in packaging without major influence on indications.

3. Apart from section 2, where all analytical methods are detailed, cost-effectiveness is often used as a generic term encompassing cost-effectiveness and cost-utility, as is often the case in the literature. 
DELSA/HEA/WD/HWP(2013)4

Table 3. Main criteria used to inform reimbursement decisions in case-study countries for products subject to assessment

\begin{tabular}{|c|c|}
\hline Therapeutic relevance only & Therapeutic relevance and economic considerations \\
\hline $\begin{array}{l}\text { France(1) (safety, effectiveness, severity of the disease, } \\
\text { preventive/curative nature of the product, interest in terms } \\
\text { of public health) } \\
\text { Germany (the drug must not belong to one of the } \\
\text { categories excluded from reimbursement by Law of the } \\
\text { Federal Joint Committee) } \\
\text { Italy(1) (clinical effectiveness, disease relevance) } \\
\text { Japan (clinical relevance) }\end{array}$ & $\begin{array}{l}\text { Australia (cost-effectiveness, budget impact, therapeutic } \\
\text { need) } \\
\text { Canada (criteria vary across drug plans but often include } \\
\text { cost-effectiveness) } \\
\text { Belgium (efficacy and disease relevance, cost- } \\
\text { effectiveness for innovative products, budget impact). } \\
\text { Denmark (reasonable price in relation to therapeutic } \\
\text { value) } \\
\text { Korea (cost-effectiveness, clinical benefit, budget impact, } \\
\text { coverage in other countries) } \\
\text { Netherlands (added therapeutic value; cost-effectiveness; } \\
\text { budget impact) } \\
\text { Norway (cost-effectiveness) } \\
\text { Spain (reasonable price in relation to therapeutic value, } \\
\text { cost-effectiveness, budget impact) } \\
\text { Sweden (cost-effectiveness; need and solidarity and } \\
\text { human value principles) } \\
\text { United Kingdom ( } 2 \text { ) (no systematic assessment, cost- } \\
\text { effectiveness when assessed). }\end{array}$ \\
\hline
\end{tabular}

Note: (1) In France and Italy, recommendations on listing are not based on economic considerations. However, if authorities and the company cannot agree on a price, the product cannot be listed. In France, new products with a claimed added therapeutic value of competitors will be subject to economic evaluation from October 2013. (2) NICE does not systematically evaluate medicines for funding in England and Wales, while the assessment body in Scotland evaluates all new products.

Sources: Country profiles, PPRI and PHIS profiles, Le Polain et al. (2010) and Wilsdon and Serota (2011)

41. The majority of case-study countries regulate the price of pharmaceuticals reimbursed for ambulatory care and some countries regulate the prices of expensive medicines used in inpatient care and paid on top of regular hospital payments. The United Kingdom, Denmark and Sweden are the only exceptions to this rule, since Germany implemented a regulation of maximum reimbursement prices in 2011. International benchmarking is widely used, especially in European countries. It is also adopted in Canada to set a cap to the manufacturer's selling price of innovative patented medicines (see table 4). 
DELSA/HEA/WD/HWP(2013)4

Table 4. Regulation of prices or reimbursement prices of medicines(1) in case-study countries

\begin{tabular}{|c|c|c|}
\hline Countries & Scope of price regulation & Method(s) \\
\hline Australia & $\begin{array}{l}\text { Maximum ex-factory price is set for listed medicines. } \\
\text { RP for classes of interchangeable products. }\end{array}$ & Therapeutic referencing and cost plus \\
\hline \multirow[t]{2}{*}{ Canada } & $\begin{array}{l}\text { At Federal level: Maximum ex-factory price for all patented } \\
\text { Medicines. }\end{array}$ & $\begin{array}{l}\text { Federal level: International benchmarking for most } \\
\text { innovative drugs and therapeutic referencing for } \\
\text { less innovative ones. }\end{array}$ \\
\hline & $\begin{array}{l}\text { Provinces and Territories level: Maximum prices set for } \\
\text { drugs covered by public drug plans. }\end{array}$ & Drug plan level: Therapeutic referencing \\
\hline Belgium & Maximum ex-factory price is set for listed medicines. & $\begin{array}{l}\text { Prices of innovative drugs set with a premium over } \\
\text { comparators. Prices of less innovative drugs set } \\
\text { using international benchmarking and therapeutic } \\
\text { referencing. }\end{array}$ \\
\hline Denmark & $\begin{array}{l}\text { No price regulation at market entry, but periodically price } \\
\text { cap agreements between the Ministry of Health and the } \\
\text { association of pharmaceutical companies. }\end{array}$ & $\begin{array}{l}\text { International benchmarking for hospital drugs } \\
\text { (Commitment of the industry) }\end{array}$ \\
\hline France & $\begin{array}{l}\text { Maximum statutory price for medicines listed for outpatient } \\
\text { care and for a list of expensive hospital medicines, set at } \\
\text { the time of listing }\end{array}$ & $\begin{array}{l}\text { International benchmarking for most innovative } \\
\text { drugs; Internal/therapeutic referencing for less } \\
\text { innovative ones }\end{array}$ \\
\hline Germany & $\begin{array}{l}\text { Since 2011: Statutory price negotiated after market entry } \\
\text { RP for clusters of equivalent products ( ATC } 4,5 \text { ) }\end{array}$ & $\begin{array}{l}\text { Therapeutic referencing (and international } \\
\text { benchmarking). }\end{array}$ \\
\hline Italy & $\begin{array}{l}\text { Maximum statutory ex-factory price for outpatient } \\
\text { reimbursed medicines and for expensive hospital } \\
\text { medicines, set at the time of listing. }\end{array}$ & Therapeutic referencing \\
\hline Korea & Maximum reimbursement price. & $\begin{array}{l}\text { Assessment of the reimbursement committee, } \\
\text { international benchmarking; Budget impact; R\&D } \\
\text { costs for drugs launched first in Korea. }\end{array}$ \\
\hline Japan & $\begin{array}{l}\text { Reimbursement price for medicines included in the positive } \\
\text { list. }\end{array}$ & Therapeutic referencing \\
\hline Netherlands & $\begin{array}{l}\text { Maximum wholesale price for outpatient prescription-only } \\
\text { medicines (listed or not) and expensive hospital drugs. } \\
\text { RP for groups of interchangeable products (ATC } 4 \text { \& 5) }\end{array}$ & International benchmarking \\
\hline Norway & $\begin{array}{l}\text { Maximum pharmacy purchase price set for all prescription- } \\
\text { only medicines, at the time of market entry }\end{array}$ & $\begin{array}{l}\text { International benchmarking and therapeutic } \\
\text { referencing for reimbursement price }\end{array}$ \\
\hline Spain & Maximum ex-factory prices for reimbursed medicines & $\begin{array}{l}\text { International benchmarking and therapeutic } \\
\text { referencing. }\end{array}$ \\
\hline Sweden & $\begin{array}{l}\text { In order to be reimbursed, the manufacturer must propose } \\
\text { a price at which the drug will be considered cost-effective. } \\
\text { Purchase and retail prices are regulated. }\end{array}$ & \\
\hline United Kingdom & $\begin{array}{l}\text { No direct price control, but possible price agreement } \\
\text { following NICE negative recommendation based on } \\
\text { economic assessment. }\end{array}$ & $\begin{array}{l}\text { In case of price negotiation, the ICER is used to } \\
\text { determine the acceptable price. }\end{array}$ \\
\hline
\end{tabular}

Note: (1) This table refers to price regulation potentially applicable to on-patent products. It only refers to Reference Prices (RP) policies when they have the potential to influence the price of new products (i.e. when RP are not limited to clusters of generic equivalents but can include patented products).

Source: Country profiles, PPRI and PHIS profiles, KCE (2010)

42. Countries have organised differently institutions responsible for assessment, decisions and reimbursement. Although this report does not focus on institutional arrangements, some characteristics are described below. 
43. In most countries, the scientific assessment (including or not economic aspects) is conducted by a separate body, which provides recommendations to decision makers. In some countries, this committee or commission only includes scientific experts (Australia, common drug review in Canada, the Netherlands, and Norway). In other countries, the institution conducting the assessment includes stakeholders, i.e. health insurance funds, governments, health professionals, pharmaceutical industry and/or patient organisations. The Reimbursement Commission in Belgium, the Transparency Commission in France, the G-BA in Germany and the Drug Reimbursement Evaluation Committee in Korea all include representatives of health insurance funds. In Denmark, Italy and Sweden, assessment bodies include representatives of regions (or country councils) in charge of financing medicines used in hospitals. In Canada, the Provincial Advisory Group (PAG) of representatives of provincial and territorial Ministries of Health and cancer agencies provides feedback to the Canadian expert committees. The pharmaceutical industry is represented in only two assessment bodies, in Belgium and France, but with no voting rights. The public, consumers or patients are represented or consulted by a few institutions. The Swedish TLV and the Danish Reimbursement Committee include one representative of patients' organisations, while the Korean Committee and the Australian PBAC have one consumer representative. The Canadian expert committee for cancer drugs and experts involved in the Common Drug Review consult patient organisation and the Dutch Commission (CFH) has the possibility to do so.

44. Assessment bodies are integrated in the Medicine Agency (also responsible for marketing authorisation) in Italy, Denmark and Norway. They are part of the institution responsible for health technology assessment in Canada (for the Common drug review), France, and Korea. In Spain, the Directorate of Pharmacy in the Ministry of Health and Inequalities performs the assessment. In Germany, the assessment is performed by the Joint Federal Committee (G-BA), composed of representatives of health insurers, physicians and hospitals associations.

45. Assessment bodies also differ according to the scope of their activities. Wilsdon and Serota (2011) compared the number of assessments performed by several assessment bodies in 2009: while the French transparency commission and the Australian PBAC showed very high numbers (respectively 657 and 228, of which 73 major submissions), the Scottish Medicine Consortium assessed 82 medicines, the Dutch CVZ 41 and NICE only 17.

46. In a few countries, a single body is responsible for assessment and appraisal (decision-making), as is the case for NICE in England and Wales and for TLV in Sweden (for outpatient drugs). More often, the Ministry of health is responsible for decision-making (for instance Quebec, France, Japan, the Netherlands and Spain, and in Australia when expected budget impact does not require a decision from the Cabinet). The medicine agencies make decisions in Denmark, Italy and Norway. In France, health insurers decide on the reimbursement rate.

47. In countries with "separate" price negotiations, negotiations are most often conducted (or informed) by committees composed of representatives of several Ministries (Health, Finance, Industry) and third-party payers (health insurance funds). This is the case for instance in Belgium, France, Italy and Spain. 
DELSA/HEA/WD/HWP(2013)4

Table 5. Bodies in charge of assessment and decisions on reimbursement status and/or price

\begin{tabular}{|c|c|}
\hline & Body responsible for assessment \\
\hline Australia & $\begin{array}{l}\text { Pharmaceutical Benefits Advisory } \\
\text { Committee (PBAC) }\end{array}$ \\
\hline Belgium & $\begin{array}{l}\text { Commission de remboursement des } \\
\text { médicaments (CMR) }\end{array}$ \\
\hline \multirow[t]{3}{*}{ Canada } & $\begin{array}{l}\text { Common Drug Review (CDR), part of } \\
\text { the Canadian Agency for Drugs and } \\
\text { Technologies in Health (CADTH), } \\
\text { pCODR for cancer drugs }\end{array}$ \\
\hline & $\begin{array}{l}\text { + Committees for public plans at } \\
\text { federal, provincial and territorial level } \\
\text { (e.g.: Ontario: Committee to evaluate } \\
\text { drugs). }\end{array}$ \\
\hline & $\begin{array}{l}\text { In Quebec: National institute for } \\
\text { excellence in health and social } \\
\text { services (INESS). }\end{array}$ \\
\hline
\end{tabular}

\begin{tabular}{|c|c|c|c|}
\hline Denmark & $\begin{array}{l}\text { Danish Centre for Evaluation and } \\
\text { Health Technology Assessment } \\
\text { (DACEHTA). }\end{array}$ & $\begin{array}{l}\text { Danish Health and Medicines } \\
\text { Authority regarding drugs for } \\
\text { outpatient use. The Coordinating } \\
\text { Council on the introduction of hospital } \\
\text { medicines (KRIS) and the regional } \\
\text { Pharmaceutical and Therapeutic } \\
\text { Committee for hospital drugs. }\end{array}$ & $\begin{array}{l}\text { Not relevant for outpatient drugs. } \\
\text { For hospital drugs, Amgros } \\
\text { (purchasing agency) carries out } \\
\text { tenders. }\end{array}$ \\
\hline France & $\begin{array}{l}\text { Transparency Commission (part of } \\
\text { the High Authority on Health) }\end{array}$ & $\begin{array}{l}\text { Ministry of health decides on listing } \\
\text { and Union of social health insurance } \\
\text { funds (UNCAM) decides on } \\
\text { reimbursement rate. }\end{array}$ & $\begin{array}{l}\text { Committee on Health Products } \\
(\mathrm{MoH}, \mathrm{MoF}, \mathrm{SHI} \text { and } \mathrm{PHI})\end{array}$ \\
\hline Germany & $\begin{array}{l}\text { The Federal Joint Committee (G-BA) } \\
\text { and the Institute for Quality and } \\
\text { Efficiency in Health Care (IQWiG) }\end{array}$ & The Federal Joint Committee (G-BA) & $\begin{array}{l}\text { Reimbursement prices negotiated } \\
\text { with manufacturers if needed } \\
\text { after G-BA assessment }\end{array}$ \\
\hline Italy & $\begin{array}{l}\text { Technical Scientific Committee, part } \\
\text { of the Italian Medicines Agency } \\
\text { (AIFA) }\end{array}$ & AIFA's Technical Scientific Committee & $\begin{array}{l}\text { Committee for Pricing and } \\
\text { Reimbursement (AIFA) }\end{array}$ \\
\hline Japan & $\begin{array}{l}\text { Central Social Health Insurance } \\
\text { Council (Chuikyo) }\end{array}$ & $\begin{array}{l}\text { Ministry of Health, Labour and } \\
\text { Welfare (MHLW) }\end{array}$ & $\begin{array}{l}\text { Ministry of Health, Labour and } \\
\text { Welfare (MHLW) }\end{array}$ \\
\hline Korea & $\begin{array}{l}\text { Drug Benefit Coverage Assessment } \\
\text { Committee }\end{array}$ & Health Insurance Policy Council & $\begin{array}{l}\text { National Health Insurance Drug } \\
\text { Price negotiation team }\end{array}$ \\
\hline Netherlands & $\begin{array}{l}\text { Pharmaceutical Care Committee } \\
\text { (CFH) of the Dutch Health Care } \\
\text { Insurance Board (CVZ) }\end{array}$ & Ministry of Health, Welfare and Sport & $\begin{array}{l}\text { Ministry of Health, Welfare and } \\
\text { Sport }\end{array}$ \\
\hline Norway & Norwegian Medicines Agency & $\begin{array}{l}\text { Norwegian Medicines Agency; } \\
\text { MoH when budget impact is high }\end{array}$ & Norwegian Medicines Agency \\
\hline Spain & $\begin{array}{l}\text { Ministry of Health. General } \\
\text { Directorate of Pharmacy }\end{array}$ & Ministry of Health & $\begin{array}{l}\text { Inter-ministerial Pricing } \\
\text { Committee }\end{array}$ \\
\hline Sweden & $\begin{array}{l}\text { Dental and Pharmaceutical Benefits } \\
\text { Board (TLV) }\end{array}$ & $\begin{array}{l}\text { Dental and Pharmaceutical Benefits } \\
\text { Board (TLV) }\end{array}$ & TLV for purchase and retail price. \\
\hline $\begin{array}{l}\text { United } \\
\text { Kingdom }\end{array}$ & \multicolumn{2}{|c|}{$\begin{array}{l}\text { England and Wales: There is no systematic assessment of new medicines. } \\
\text { The National Institute for Health and Care Excellence (NICE) assesses } \\
\text { technologies and health strategies on request. } \\
\text { Scotland: Scottish Medicine Consortium (SMC) }\end{array}$} & \\
\hline
\end{tabular}

Notes: abbreviations: P\&T= Canadian provinces and territories, MoH= Ministry of Health, MoF= Ministry of Finance,

$\mathrm{SHI}=$ Statutory/Social health insurance, $\mathrm{PHI}=$ Private health insurance (1) The Cabinet is a group of the Australian executive government consisting of the Prime Minister and top-level ministers. It is the pre-eminent policy-making body.

Source: Country profiles, PPRI and PHIS country profiles 


\section{SECTION 2 \\ VALUE-BASED PRICING IN PRACTICE}

\section{Introduction}

48. This section analyses in detail which criteria are taken into account in reimbursement and pricing decisions in the sample of OECD countries selected for this study. It is based on two sets of information: general information on the case-study country's policies, mainly drawn from country profiles; and information on assessments conducted and decisions made for a sample of products, provided by country experts or found in summary assessment reports.

49. The analysis of this information was organised around questions raised by the Department of Health (DH) of England and Wales in the consultation document posted in 2010 "A new value-based approach to the pricing of branded medicines". In this paper, the DH made proposals to reform its 50-year old Pharmaceutical Pricing Regulation Schemes by "value-based pricing" as recommended by the Office of Fair Trading in 2007 (OFT, 2007). The reform proposal's objectives are to "get better patient outcomes and greater innovation, a broader and more transparent assessment and better value for money for the NHS". Some of the questions raised in this consultation are indeed of great interest for other OECD Member countries, since they address the challenging dilemma that all countries face in their own practices.

50. The DH proposes to use pharmaco-economics to define value and define a basic cost-effective threshold, reflecting the benefits displaced elsewhere in the NHS when funds are allocated to medicines. It then proposes to set higher thresholds when the "burden of illness is high", i.e. when there is an unmet medical need or when the disease is particularly severe; to set higher thresholds for medicines that can demonstrate greater therapeutic innovation and improvements over existing products; and to set higher thresholds for medicines that can demonstrate wider societal benefits (Department of Health, 2010).

51. In addition to these consultations on broad principles, the consultation document raised a number of more practical questions. The first of them is: how should "value" be measured? The first part of this section does not seek to answer this normative question, but explores practices in case-study countries, initially selected because their system was deemed to be based on some sort of value-based pricing. It then reviews health outcomes considered in products' evaluations, costs taken into account in economic evaluation and analytical methods used by countries. Other practical questions are: What is the appropriate approach when a single drug delivers significantly different benefits in different indications? How should "disease burden", "innovation" and "wider social benefits" be measured? The second part of this section reports on experiences of case-study countries in addressing these questions. Finally, the last section examines the prominent role played by international benchmarking in several case-study countries.

\section{Economic evaluation for reimbursement and pricing decisions}

52. The English Department of Health proposes the use of economic evaluation as the founding principle for value-based pricing reflecting the current trends in health economics. Many countries in our sample use economic evaluation for pricing and reimbursement decisions, more or less systematically. They have, however, adopted different perspectives and analytical methods. This section presents a short introduction to principles used in economic evaluation, with the main objective to establish a common understanding of the concepts and words used in the following sections of this report. It then describes the perspective and analytical methods recommended and used in the sample of case-study countries. 


\section{Principles and methods used for economic evaluation}

53. Economic evaluation consists of the comparative analysis of alternative treatments in terms of both costs and consequences. The most common analytic techniques are cost-consequence analysis (CCA), cost-minimization analysis (CMA), cost-effectiveness analysis (CEA), cost-utility analysis (CUA), and cost-benefit analysis (CBA). These techniques correspond in principle to different approaches for the role of economic evaluation, which can be briefly summarised as follows (according to Drummond et al., 2005; Hurley, 2000):

- In the welfarist approach, the amount individuals are willing to pay for a programme or a service is the best way to measure the outcome of a programme. If willingness to pay (WTP) is higher than costs, the programme should be implemented or the service supplied. However, countries are generally reluctant to use WTP for various reasons (e.g. because they reflect inequalities of income or are not relevant for subsidized services). The other two alternative approaches are preferred.

- The extra-welfarist approach aims to maximize health outcomes from a constrained health care budget. It rejects WTP as an appropriate measure for outcomes since it could be influenced by non-health characteristics of the program. Health improvements are the only relevant outcome taken into account, which might be weighted by health states preference scores.

- A third approach also rejects WTP but suggests adopting a broader social perspective -not limited to health system and budget- and considering a wider range of costs and consequences. This approach is referred to as the "decision-maker" approach (Drummond at al., 2005).

54. The perspective adopted affects the implementation of a value-based pricing approach and has therefore been the subject of animated debates in the academic community and among stakeholders. Johannesson et al. (2009) advocated for the adoption of a societal perspective. Their first argument is that if cost-benefit is used for other public investments (such as environment or traffic safety), it should also be used for the health sector in order to be able to compare alternative investments across sectors ${ }^{4}$. They admit that health budgets often appear to be limited, with no possible re-allocation from other sectors (and viceversa) and do not underestimate the potential distributional effects of a societal perspective (which could for instance discriminate against older people). However, they consider that these elements can be taken into account in an economic evaluation with a societal perspective. Consequently, they recommend the inclusion of all costs and benefits related to reductions in mortality and improved survival, noting that only Sweden has taken these costs on board, at least in its guidelines for economic evaluation.

55. Both the perspective adopted and information available at the time of assessment participate to the choice of the analytical method chosen for economic evaluation, the most common being: costeffectiveness analysis, in which outcomes are expressed in terms of health improvements (years or life gained for instance); cost-utility analysis, in which health outcomes are weighted by their utility for patients, and cost-benefit analysis, in which both costs and outcomes are expressed in monetary units. Cost-minimisation is a particular technique, adapted to cases where health effects of the new intervention are comparable to those of the best alternative option.

4. Authors provide an estimate of an Incremental Cost-effectiveness threshold, which would be derived from different Values of a Statistical Life (VSL) officially used in CBA for other sectors in several countries and show that current cost-per-QALY-gained thresholds are below this estimate. They conclude that current ICER thresholds underestimate the social value of health care technologies. 


\section{Approaches for economic evaluation adopted by case-study countries}

56. Guidelines published by assessment bodies show countries' preferred analytical methods; these depend on available information and added therapeutic benefit of the drug assessed over its comparator (see table 6). All countries recommend cost-effectiveness or cost-utility analysis when the new drug has a higher effectiveness then the comparator. Cost-minimisation or simple cost comparisons are recommended when effectiveness is not higher than that of the comparator. Germany adopted a singular approach, which generated lots of debate since costs and benefits are only compared within a therapeutic area in which an efficiency frontier is built from available therapeutic alternatives (IQWiG, 2009). However, with the implementation of the 2010 Act (AMNOG), this approach is expected to play a minor role in the German system. 
Table 6. Analytical approaches for economic evaluation, as recommended by submission guidelines or recommendations issued by HTA bodies Perspective adopted and preferred analytical technique

\begin{tabular}{l}
\hline $\begin{array}{l}\text { Country and Authors of } \\
\text { guidelines }\end{array}$ \\
\hline Australia \\
Pharmaceutical Benefits \\
Advisory Committee (PBAC, \\
2008) \\
Belgium \\
Health Care Knowledge Centre \\
(KCE, 2012)
\end{tabular}

Canada
Canadian Agency for Drugs and
Technologies in Health (CADTH,
2011)

Perspective: public payer

Analytical methods: CMA, CEA, CUA are accepted but the technique adopted must be justified.

\section{Perspective: health care payer (social insurance and patients)}

Analytical methods: If improving life expectancy is the main objective of the treatment and the most important outcome for the patient: CEA;

if the treatment has an impact on health-related quality of life that is significant to the patient or if there are multiple patient-relevant clinical outcome parameters expressed in different units that cannot be translated into one common unit in a valid way: CUA (CBA not accepted)

Perspective: several perspectives accepted but should be presented separately

Analytical methods: Where clinical outcomes are final (an event that is relevant and noticeable to patients): CEA/CUA

Where clinical outcomes are intermediate (subjective clinical measures where extrapolation of health benefits to life-years or QALY is more difficult, non clinical endpoints, or surrogate endpoints): CEA/CUA

If data are not available to support the relationship between surrogate and final clinical outcomes a CCA is required

\section{Italy}

No guidelines

Korea

Perspective: public payer or societal

Analytical methods: CEA/CUA

\section{Norway}

The Norwegian Medicines

Control Authority (NoMA, 2005)

\section{Sweden}

Pharmaceutical Benefits Board

(TLV, 2003)

\section{Netherlands}

Foundation for Health Care and University (2006)

UK: Scotland

Scottish Medicine Consortium

(SMC, 2007)

\section{UK: England \& Wales}

National Institute for Health and

Clinical Excellence (NICE, 2008)

France

Haute Autorité en Santé (HAS, 2011)

\section{Germany}

Institute for quality and efficiency

in health care (IQWiG, 2009)
Perspective: Limited Societal perspective

Analytical methods: CMA, CEA, CUA, CBA are accepted but the choice of technique must be justified.

\section{Perspective: Societal}

Analytical methods: CEA/CUA is recommended,

CBA where QALY are difficult to use. If the effects of the new products are comparable to those of the best comparable treatment, then a cost comparison is sufficient.

Perspective: societal

Analytical methods: CEA, CUA, no CMA

Perspective: National health system and patients

Analytical methods: CMA, CEA, CCA, CUA, CBA accepted, choice needs to be justified.

Perspective: National Health System and Personal Social Services (PSS)

Analytical methods: CEA or CUA for the reference case are the preferred forms of economic evaluation.

Pharmaco-economic assessment is not yet used in R\&P process but will be from October 2013.

Perspective: all financing agents

Analytical methods: CEA/CUA

Pharmaco-assessment is not used in the R\&P process.

Perspective: statutory health insurance and patients

Analytical methods: Efficiency frontier method based on a CEA, but CUA also possible.

Sources: Country profiles, National Guidelines

57. In the sample of products surveyed for this report, CEA and CUA were the analytical methods the most frequently used. Incremental costs per life year gained (LYG) and incremental costs per QALY are often both presented in assessment reports. The so-called 'incremental cost-effectiveness ratio' on which decisions are based is in fact the incremental costs per QALY gained (i.e. an incremental cost-utility ratio). 


\section{Box 1. Analytic techniques used in the sample of surveyed products}

Case-study countries who reported detailed information on analytic methods used in economic evaluations for the sample of products reviewed are Australia, Belgium, Canada, Norway and Spain. Across the sample of products, the most-often used analytical techniques were: cost-utility analysis and cost-effectiveness analysis. In some cases, countries used the two methods. For the oncology drug Sunitinib for instance, Australia, Canada and Norway reported both incremental cost per life year gained and incremental cost per QALY.

Several countries (Australia, Belgium, the Netherlands, Norway and Spain) used a CMA for the anti-coagulant Dabigatran in the prevention of venous thrombotic events because they considered that the drug had no added therapeutic value over competitors (see box 5 for further details).

Several countries logically used CMA to assess the anti-diabetic combination of sitagliptin and metformin since this product just combines two active substances which are otherwise administrated separately. There is no expected impact on effectiveness of the treatment.

Source: OECD Survey on assessments and decisions for a selected sample of products

\section{The measure of therapeutic benefits and utility for patients}

58. The concept of value is primarily based on therapeutic advantages procured by new products or new indications over existing products. If a new product or indication has no added therapeutic benefits for patients, payers usually accept to pay for it only if it reduces the cost of treatment. It is therefore important to examine how case-study countries assess and measure the added therapeutic value in terms of health outcomes, which is the subject addressed in the following paragraphs. Countries using economic evaluation often go a step further by considering utility for patients. The text highlights commonalities and differences in the utility measurement methods adopted by case-study countries. Finally, it discusses the evidence of health benefits that different countries expect to see.

\section{Clinical outcomes: final endpoints, surrogate markers and intermediate outcomes}

59. Experts and decision-makers usually prefer final end-point data on which to make their decisions (such as life-years gained or overall survival). However, collecting data on final endpoints often requires a long period of time and such results cannot always be drawn from clinical trials. In practice, decisionmakers sometimes have to rely on intermediate outcomes or surrogate markers (e.g. reduced cholesterol level) to make decisions.

60. A surrogate end point, or marker, is a laboratory measurement or physical sign that is used in therapeutic trials as a substitute for a clinically meaningful endpoint that is a direct measure of how a patient feels, functions or survives and is expected to predict the effect of the therapy. It can also be described as "a biomarker that is intended to substitute for a clinical endpoint. [It] is expected to predict clinical benefit (or harm or lack of benefit or harm) based on epidemiologic, therapeutic, pathophysiologic, or other scientific evidence" (definitions from FDA and from the Biomarkers Definitions Working Group, respectively, both quoted in the 2010 report of the Institute of Medicine on biomarkers and surrogate end points in chronic diseases). Usually, surrogate markers are only accepted when data on final outcomes are not available and when a clear link can be established between the surrogate marker and the final outcome. This link is usually established in epidemiological models, whose results are publicly available. Guidelines for economic evaluation or manufacturers' submissions generally express their preference for final outcomes and define the conditions in which intermediate outcomes are accepted (see for instance in Canada and Australia). 
61. In practice, the type of outcomes considered differs across therapeutic areas, reflecting what can be measured in clinical trials (Drummond et al., 2005). This appears clearly from assessment reports for the sample of products surveyed (Box 2). Although the set of outcomes accepted to assess effectiveness differs slightly across countries, there are more commonalities than differences. Countries using formal cost-effectiveness or cost-utility analysis to make decisions need measures of final outcomes (life years gained), should they be estimated by modelling when not available from clinical trials, while other countries accept assessments of effectiveness only on surrogate markers.

\begin{tabular}{|c|c|c|}
\hline \multicolumn{3}{|c|}{ Box 2. Health outcomes considered for the sample of selected products } \\
\hline Product & Therapeutic area & Outcomes considered \\
\hline $\begin{array}{l}\text { Fingolimod } \\
\text { (Gilenya®) }\end{array}$ & Multiple sclerosis & $\begin{array}{l}\text { Annual relapse rate (all countries) } \\
\text { T2 lesions on MRI (NICE, England and CDR, } \\
\text { Canada) }\end{array}$ \\
\hline Boceprivir (Victrelis $®)$ & Hepatitis C & Sustained virological response (all countries) \\
\hline Sunitinib (Sutent $囚$ ) & $\begin{array}{l}\text { Oncology } \\
\text { (gastrointestinal stromal } \\
\text { tumour; metastatic renal } \\
\text { cancer; pancreatic neuro- } \\
\text { endocrine tumour) }\end{array}$ & $\begin{array}{l}\text { Time to tumour progress (all countries) } \\
\text { Progression Free Survival (all countries) } \\
\text { Risk of death for pancreatic tumour (pCODR, } \\
\text { Canada) } \\
\text { Overall objective response (tumour shrinkage) for } \\
\text { renal cancer (Spain) }\end{array}$ \\
\hline
\end{tabular}

\section{The measurement of utility}

62. OECD countries using economic evaluation to inform their decisions usually prefer cost-utility analysis, which takes into account patient preferences or utility derived from different health states. The most common measure of outcome in cost-utility analysis is the Quality-Adjusted Life Year (QALY). QALYs capture both gains from reduced morbidity (increased quality of life) and reduced mortality (quantity of life years gained) in a single metric. Other generic outcomes measures are Healthy Years Equivalent (HYE) and the Disability-Adjusted Life-Year (DALY) (Drummond, 2005).

63. Agencies responsible for health technology assessment which publish guidelines for cost-utility analysis usually accept three alternative methods to estimate utility weights used for QALYs (Mauskopf, 2011; National guidelines for economic evaluation):

- A multi-attribute utility instrument (MAUI) survey submitted to patient during the clinical trials or as part of an observational study, with preference weights applied to the health states using a time trade-off (TTO) or standard gamble (SG) approach;

- A direct elicitation of utility for relevant health states, using a visual analogue scale (VAS), TTO or SG approach within the clinical trials or in a separate study;

- A systematic review of the published literature to identify utility weights estimated using a TTO or SG approach.

64. OECD countries using cost-utility analysis generally express a preference for utility weights elicited via a multi-attribute survey instrument (MAUI) used in randomised clinical trials (see Table 7). Other methods can be used by applicants to measure utility derived from quality of life (PBAC, 2008). In the United Kingdom, NICE and Scottish guidelines express a preference for the Euro Qol 5D instrument 
(EQ-5D), with utility weights applied using the TTO approach (Mauskopf, 2011). EQ-5D consists of five items relating to mobility, self-care, main activity, pain/discomfort and anxiety/depression. On the basis of their responses to the five items, patients are classified into a health state with a preference weight attached. Preferences for health states are derived from general population surveys using techniques such as the rating scale, standard gamble, and time trade-off.

Table 7. Summary of recommendations on data sources for the measurement of utility weights attached to health states

\begin{tabular}{|c|c|c|c|c|c|}
\hline \multirow[b]{2}{*}{ Country } & \multicolumn{3}{|l|}{ Data sources } & \multicolumn{2}{|l|}{ Measures } \\
\hline & $\begin{array}{l}\text { Multi-attribute } \\
\text { utility instrument } \\
\text { (MAUI) }\end{array}$ & $\begin{array}{l}\text { Direct elicitation of } \\
\text { utility }\end{array}$ & $\begin{array}{l}\text { Systematic } \\
\text { Literature Review }\end{array}$ & QALY & $\begin{array}{l}\text { Clinical } \\
\text { endpoints }\end{array}$ \\
\hline Australia (PBAC) & ++ & + & ++ & ++ & \\
\hline Belgium & & & ++ & ++ & ++ \\
\hline Canada (CADTH) & ++ & ++ & & ++ & + \\
\hline Netherlands & ++ & + & + & ++ & \\
\hline Norway (NoMA) & ++ & + & ++ & ++ & ++ \\
\hline Sweden (TLV) & ++ & ++ & & ++ & \\
\hline UK (NICE) & ++ & + & + & ++ & \\
\hline Scotland (SCM) & ++ & + & + & ++ & + \\
\hline
\end{tabular}

Note: ++ , preferred approach or strongly recommended; +, acceptable approach; blank cell, no guidelines provided.

Source: Mauskopf (2011) and National guidelines for economic evaluation

65. In practice, assessments performed by authorities rely on information provided by the applicant. Information collected for the sample of products surveys suggests that utility weights differ across countries, but above all, across therapeutic areas (see box 3). Pharmaceutical companies commonly use both generic instruments and disease-specific multi-attribute instruments to evaluate changes in quality of life, the latter being more sensitive than standard instruments. The sensitivity of economic analyses to QALY weights is higher when the assessed product improves the quality of life without any gain in terms of survival. In the assessment produced for cabazitaxel in November 2011, the Australian PBAC recognised that the use of another set of utilities (the one used by NICE) would reduce the ICER to a lower level. 


\begin{tabular}{|c|c|c|}
\hline Product & Therapeutic area & Outcomes considered \\
\hline $\begin{array}{l}\text { Fingolimod } \\
\left.\text { (Gilenya }{ }^{\circledR}\right)\end{array}$ & Multiple sclerosis (MS) & $\begin{array}{l}\text { NICE considered quality of life reported by patients with } \\
\text { EQ-5D, as well as MS-specific instruments, known as } \\
\text { PRIMUS Qol (outcome measures), PRIMUS-Activities } \\
\text { (activity limitations) and UFIS (measure of fatigue } \\
\text { impact). }\end{array}$ \\
\hline Sitagliptin & Diabetes & $\begin{array}{l}\text { Canada considered quality of life measured with the } \\
\text { Psychological General Well-Being survey and EQ-5D. }\end{array}$ \\
\hline Sunitinib (Sutent $\circledast$ ) & $\begin{array}{l}\text { Oncology } \\
\text { GIST(gastrointestinal stromal } \\
\text { tumour) } \\
\text { mRCC (metastatic renal cancer) } \\
\text { pNET (pancreatic neuro- } \\
\text { endocrine tumour) }\end{array}$ & $\begin{array}{l}\text { For renal cancer, Canada considered quality of life } \\
\text { measured with the European Organisation for Research } \\
\text { and Treatment of Cancer (EORTC) Quality of life } \\
\text { questionnaire; } \\
\text { Norway considered health-related quality of life } \\
\text { measured with FACT (Functional Assessment of Cance } \\
\text { Therapy), FKSI (Functional Assessment of Cancer } \\
\text { Therapy- Kidney Symptom Index), and EQ-5D. } \\
\text { For GIST, the model assessed by Norwegian authorities } \\
\text { only used EQ-5D. }\end{array}$ \\
\hline Dabigatran & $\begin{array}{l}\text { Cardiology } \\
\text { Prevention of stroke and } \\
\text { systemic embolism }\end{array}$ & $\begin{array}{l}\text { NICE assessment relied on quality of life estimates } \\
\text { based on HRQoL. }\end{array}$ \\
\hline
\end{tabular}

\section{Type and level of evidence required}

66. The type and level of evidence required by authorities in charge of assessing the benefits of new technology can play a role in the outcome of the assessment. In some countries, guidelines for economic evaluation specify the level of evidence required and in which circumstances assessment bodies are ready to consider lower levels of evidence (see CADTH, 2009, for instance). A major source of effectiveness data is the existing medical literature, in which clinical data are assessed according to evidence levels. One example of level of evidence ranking is proposed by Cook et al. in 1992 and used by PBAC in Australia (see table 8).

Table 8. The relationship between levels of evidence and grades of recommendation

\begin{tabular}{lll}
\hline Level of evidence & Available information & $\begin{array}{l}\text { Grade of } \\
\text { recommendation }\end{array}$ \\
\hline Level I & Well conducted, suitably powered RCT & Grade A \\
\hline Level II & Well conducted, but small and under powered RCT & Grade B \\
\hline Level III & Non-randomized observational studies & Grade C \\
\hline Level IV & Non-randomized study with historical controls & Grade C \\
\hline Level V & Case series without controls & Grade C \\
\hline Source: Bagshaw S \& Bellomo R (2008) Adapted from Cook et al. (1992)
\end{tabular}

67. For all products in the sample surveyed, efficacy derived from clinical trials was the primary source of data scrutinised for effectiveness assessment, often supplemented by a systematic review of the literature. However, assessments did not always lead to similar results, especially in the assessment of 
added therapeutic value (see later). In the case of a cancer product for instance, the Canadian Common Drug review found in 2007 that the level of evidence on effectiveness was insufficient while the French Transparency Commission issued a positive recommendation based on available evidence in 2006.

68. Some countries are now requesting companies to collect information on safety and/or effectiveness after listing. Though observational studies do not provide the highest level of evidence, progress achieved in study design and countries' interest for health outcomes observed in real life suggest that they might play a greater role in the future. In the case of cabazitaxel for instance, the French Transparency Commission initially considered that the medicine only brought a minor therapeutic benefit over comparators (ASMR IV). However, the commission re-assessed the medicine to include results of an observational study (realised on a cohort of patients receiving the drug through a temporary authorisation) and concluded that the therapeutic improvement was higher (modest improvement - ASMR III).

\section{The choice of comparator to assess added therapeutic value}

69. The relative efficacy, relative effectiveness and added therapeutic value of a drug depend on the intervention this drug is compared with. Therefore, the choice of comparator is a crucial element of the assessment. Many countries or institutions provide clear guidance for the selection of the appropriate comparator for the assessment of clinical benefit of the new drugs (see table 9). For the sample of products analysed in this study, countries most often refer to the same comparator (which can be placebo or best supportive care). However, direct comparisons with comparators are not always available from clinical trials. In such cases, indirect comparisons are used to derive incremental health gains.

Table 9. The choice of relevant comparator to assess added therapeutic benefit or incremental costeffectiveness ratio

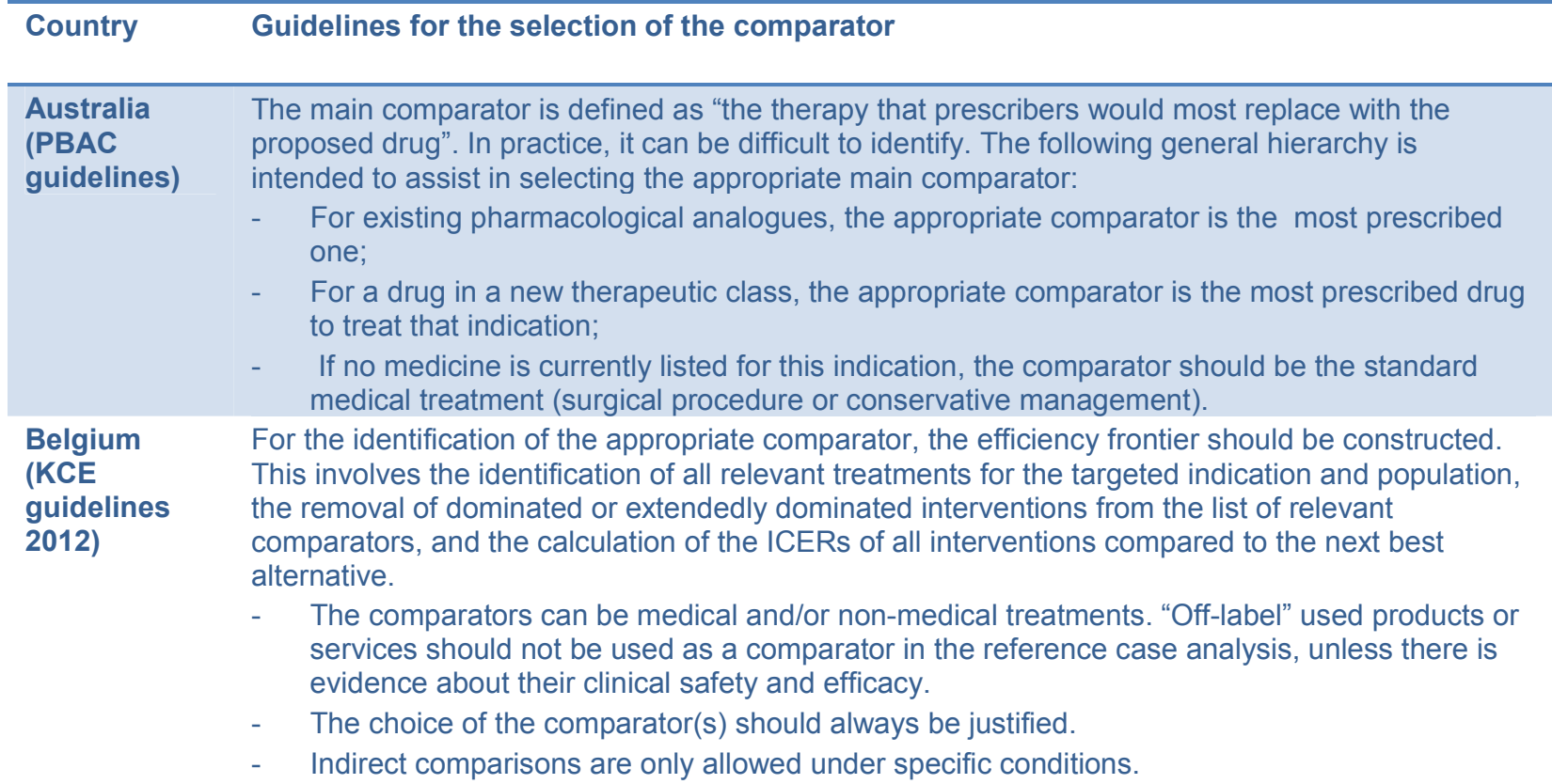

Canada

(CADTH guidelines 2013)
The new therapy should be compared with the accepted therapy (existing practice), where accepted treatment would be the single most prevalent clinical practice (if there is one that is dominant). Where generic versions of the accepted therapies exist, the price of the generic drug should be used. All other reasonable alternative therapies should be at least discussed in the report. 
DELSA/HEA/WD/HWP(2013)4

\begin{tabular}{|c|c|}
\hline Country & Guidelines for the selection of the comparator \\
\hline $\begin{array}{l}\text { France } \\
\text { (Country } \\
\text { profile) }\end{array}$ & $\begin{array}{l}\text { The Transparency Commission must identify all products of the reference therapeutic class, as } \\
\text { well as other products with similar therapeutic objectives, and where possible, identify the most } \\
\text { prescribed competitor, the last included in the positive list and the product with the cheapest } \\
\text { treatment cost. In practice however, therapeutic improvement (AMSR) is not assessed against all } \\
\text { medicines or other therapies listed but against the best available and reimbursed treatment. }\end{array}$ \\
\hline $\begin{array}{l}\text { Germany } \\
\text { (G-BA } \\
\text { website) }\end{array}$ & $\begin{array}{l}\text { For medicines with new active ingredients, additional benefit is assessed for each indication, by } \\
\text { comparison to the "appropriate comparator" as defined by law: } \\
\text { - } \quad \text { The comparator must be authorised for the specific indication assessed; } \\
\text { - If the comparator is a non-medical treatment, it must be deliverable within the framework of } \\
\text { the health insurance in Germany; } \\
\text { - Preference should be given to therapeutic alternatives whose patient-relevant benefits have } \\
\text { already been assessed by the G-BA. } \\
\text { - The comparator should be considered as an appropriate therapy according to the generally } \\
\text { accepted state of medical knowledge. } \\
\text { - If there are several alternatives, the cheapest must be chosen (medicines subject to reference } \\
\text { prices should be preferred when possible). }\end{array}$ \\
\hline Italy & No guidelines \\
\hline Japan & Information not available \\
\hline Korea & Information not available \\
\hline $\begin{array}{l}\text { Norway } \\
\text { (NOMA, } \\
\text { 2012) }\end{array}$ & $\begin{array}{l}\text { The comparator(s) must be the most relevant treatment option(s) within the Norwegian context. } \\
\text { These will often be current established practice (according to the relevant specialist association, } \\
\text { for example) and/or the treatment whose use is most widespread. The alternatives may consist of } \\
\text { other forms of treatment than drugs (e.g. surgery) and even take the form of prevention, curative } \\
\text { treatment, palliative treatment or watchful waiting. Comparison with "no treatment" alone will be } \\
\text { accepted only in exceptional cases. If there are several potential alternative treatments and no } \\
\text { certainty about which of them is the most widely used, the applicant should include more than one. } \\
\text { The comparator(s) should be the one (those) most likely to be partially or wholly replaced, typically } \\
\text { established practice and/or the most widespread. If it is not clear whether this (these) is (are) cost- } \\
\text { effective compared with other relevant comparators or with no treatment, then all these options } \\
\text { should be included. If neither of the aforementioned comparators are the one(s) recommended by } \\
\text { the national clinical guidelines, then this (these) should be used as well. }\end{array}$ \\
\hline $\begin{array}{l}\text { Spain } \\
\text { (country } \\
\text { profile) }\end{array}$ & Current therapeutic alternatives \\
\hline $\begin{array}{l}\text { Sweden } \\
\text { (TLV } \\
\text { guidelines } \\
\text { 2008) }\end{array}$ & $\begin{array}{l}\text { The most appropriate alternative treatment (e.g. the most used). This could be a drug treatment, } \\
\text { another treatment or no treatment at all. In making calculations, the reference point should be a } \\
\text { treatment applicable in the Swedish health system. If existing randomised clinical trials do not offer } \\
\text { a relevant treatment alternative for Swedish conditions, the analysis should be supplemented by a } \\
\text { model calculation. The calculations carried out should be shown so that the assumptions and } \\
\text { procedure are evident. }\end{array}$ \\
\hline $\begin{array}{l}\text { Netherlands } \\
(\mathrm{CVZ}, 2006)\end{array}$ & $\begin{array}{l}\text { Standard treatment, i.e. the treatment regarded in daily practice as the first-choice, for which } \\
\text { effectiveness has been proved. If there is no "standard treatment", the usual treatment may be } \\
\text { considered. This can be either a medical or non-medical treatment. }\end{array}$ \\
\hline $\begin{array}{l}\text { UK (NICE } \\
\text { guidelines } \\
\text { 2008) }\end{array}$ & $\begin{array}{l}\text { Therapies routinely used in the NHS, including technologies regarded as current best practice } \\
\text { (including no intervention). }\end{array}$ \\
\hline
\end{tabular}

Source: Country profiles and national guidelines for assessment

\section{The consideration of costs and budget impact}

70. Obviously, the cost of new technologies is an important component of value-based pricing. In countries that do not use economic evaluation, the consideration of costs is almost always limited to the acquisition cost (or price) of the medicine. In countries using economic evaluation, a larger set of costs and 
cost-savings is in principle considered. The following paragraphs describe the types of costs considered by case-study countries. Budget impact is less directly related to value-based pricing, but obviously plays a role. This role is explored below.

\section{Costs considered in assessment for reimbursement or pricing}

71. Most case-study countries consider costs related to the use of a new medicine at one stage or another of the pricing and reimbursement process. Countries that do not use formal economic evaluation only take into account the costs of the medicine, at the time of price setting or price negotiation (France, Italy).

72. Countries using economic evaluation usually -though not always- consider other categories of costs, depending on the perspective adopted (see table 10). Costs can be classified into four categories:

- Direct medical costs, including the cost of the product itself and associated medical acts;

- Indirect medical costs (medical costs not related to the disease treated by the technology);

- $\quad$ Direct non-medical costs (e.g. transports, time for patients); and

- Indirect non-medical costs (e.g. loss in labour market productivity, sickness leave).

73. Assessment bodies in England and Wales and in Scotland only consider costs for public payers. NICE guidelines indicate, as a general principle, that potential direct and indirect resource costs for the NHS should be included, as well as the implications for spending on personal social services (PSS). However the Reference Case for submissions to NICE's Technology's Appraisals Programme states that in situations where costs outside this perspective are considered to be 'significant', they should also be presented alongside the Reference Case analysis. The document also states that these costs should include direct costs to the patients and their carers' and costs to other public sector agencies but normally not productivity losses.

74. In Canada, guidelines for economic evaluation published by the Canadian Agency for drugs and technologies in health accept several perspectives. The preferred perspective is the perspective of the publicly funded health care system, which includes direct costs for publicly funded health care system and publicly funded services outside the health system (such as home help or income transfer payments such as disability benefits). Direct costs to patients and their relatives (e.g. OOP payments, travel costs, net from income transfer payments received) might be considered. A wider social perspective may be accepted including lost productivity or costs for the employer but these costs must be reported separately (CADTH, 2006). A similar approach is adopted in Australia.

75. Norway and Sweden have adopted a societal perspective to assess both costs and benefits. According to Swedish guidelines, all relevant costs and revenues related to the treatment of the disease should be considered, irrespective of the payer (country council, local authority, state, patient, relatives etc.) or the beneficiary (TLV, 2008). Wider social impacts are incorporated in estimates of costs per QALY gained. Benefits considered are for example gains in worker productivity due to any reductions in sick leave. One issue with the societal perspective is the difficulty in valuing non-market resources in monetary terms, notably time for participants, patients and relatives. Concerning the valuation of costs, the Swedish pharmaceutical board recommended the human capital approach, which in theory might value all uses of time (Sculpher, 2001). Hence, the utility of leisure, education or retirement should be valued, but in practice estimates often only include market production until retirement age valued as wages. An alternative is the so called friction cost method (Koopmanschap et al, 1995) that only considers temporary 
(during a friction period) costs that are due to reduced working capacity. Equity concerns can arise from the practice of valuing the costs at market wages, which differ between population groups. This could be mitigated by the use of average wages (Drummond et al, 2005). Similarly, the implication that there is no social utility in time for individuals above the age of retirement is in essence a policy choice, and can be questioned.

76. Comparisons of guidelines for submissions and economic evaluation with information collected for our sample of products, suggest that countries offering choice to applicants on the perspective to adopt (Australia, Canada, NICE) most often only consider direct medical costs for the public payer in their assessment. Among the products surveyed for this study, non-medical costs were considered only in a limited number of cases (e.g. boceprevir for Hepatitis C). Norway and Sweden used direct non-medical costs for dabigatran and sitagliptin. For sitagliptin, the Netherlands assessed the costs of sick days using the friction cost method. However, as mentioned above, as the sample is far from being exhaustive, these conclusions can only be considered as illustrative (see Table 10).

Table 10. The perspective adopted for economic evaluation and/or costs considered in case-study countries

\begin{tabular}{|c|c|c|}
\hline Country & $\begin{array}{l}\text { Perspective adopted for pharmaco-economic } \\
\text { evaluation and costs to be considered } \\
\text { (according to guidelines) }\end{array}$ & $\begin{array}{c}\text { Costs considered in the sample of } \\
\text { drugs selected }\end{array}$ \\
\hline Australia & $\begin{array}{l}\text { Perspective adopted: public payer } \\
\text { Direct medical costs, social services, indirect } \\
\text { costs. Changes in productive capacity as an } \\
\text { outcome of therapy are not encouraged in } \\
\text { submission to the PBAC (PBAC, 2008). }\end{array}$ & $\begin{array}{l}\text { Direct medical costs only, most often } \\
\text { limited to the cost of the medicine. } \\
\text { For cancer drug sunitinib, the following } \\
\text { costs were also considered in assessments } \\
\text { for listing for GIST: costs of the } \\
\text { management of adverse events; diagnostic } \\
\text { imaging costs, acute progression } \\
\text { management costs and palliative care } \\
\text { costs. }\end{array}$ \\
\hline Belgium & $\begin{array}{l}\text { Economic evaluation is required for products in } \\
\text { class } 1 \text { (with added therapeutic value) and may } \\
\text { be considered for other applications. } \\
\text { Perspective adopted: "all health care payers". } \\
\text { Only direct medical costs (e.g. health services, } \\
\text { medications, hospitalisations). If productivity } \\
\text { losses, non-health care costs and/or unrelated } \\
\text { health care costs are deemed important for a } \\
\text { specific treatment, they may be presented in a } \\
\text { separate analysis (KCE guidelines 2012). }\end{array}$ & $\begin{array}{l}\text { Direct medical costs only, which can } \\
\text { include costs of hospitalisation where } \\
\text { needed, costs of adverse events, etc... }\end{array}$ \\
\hline Canada & $\begin{array}{l}\text { Perspective adopted: several possibilities but } \\
\text { have to be justified, and results presented } \\
\text { separately } \\
\text { Direct health care costs: costs of treatment } \\
\text { (administration of drug, monitoring, other costs } \\
\text { induced through use of the drug like treatment of } \\
\text { adverse events or complications; costs that may } \\
\text { be impacted by treatment like specify surgery or } \\
\text { in-hospital stay) and costs incurred beyond } \\
\text { treatment (medical costs like cost of treating } \\
\text { disease, complications with treatment). } \\
\text { Non-health care resources and costs, where } \\
\text { relevant. These include patient's time (treatment } \\
\text { time and loss of productivity), caregiver time and } \\
\text { out-of-pocket costs (including travel expenses, } \\
\text { child care etc.) (patient and caregiver time must } \\
\text { be converted to costs) } \\
\text { Source: CADTH (2011) }\end{array}$ & $\begin{array}{l}\text { Direct medical costs only (most often costs } \\
\text { of the drug itself) }\end{array}$ \\
\hline
\end{tabular}




\section{DELSA/HEA/WD/HWP(2013)4}

\begin{tabular}{|c|c|c|}
\hline Country & $\begin{array}{c}\text { Perspective adopted for pharmaco-economic } \\
\text { evaluation and costs to be considered } \\
\text { (according to guidelines) }\end{array}$ & $\begin{array}{c}\text { Costs considered in the sample of } \\
\text { drugs selected }\end{array}$ \\
\hline Denmark & $\begin{array}{l}\text { Perspective: socio-economic } \\
\text { All relevant costs, regardless whether they are } \\
\text { direct, indirect or intangible. } \\
\text { Indirect costs should be indicated separately and } \\
\text { the human capital method is recommended. }\end{array}$ & Only direct medical costs included \\
\hline Italy & No official guidelines & $\begin{array}{l}\text { Direct and indirect medical costs included } \\
\text { when economic evaluation is performed. }\end{array}$ \\
\hline Korea & $\begin{array}{l}\text { Perspective: societal or payer, to be justified } \\
\text { Source: Yim et al (2012). }\end{array}$ & Information not available. \\
\hline Netherlands & $\begin{array}{l}\text { Perspective: societal, considering costs and } \\
\text { savings for public payers, patients, patients' } \\
\text { relatives, other payers, employers, etc. } \\
\text { Costs considered: direct medical and non- } \\
\text { medical costs; indirect costs due to productivity } \\
\text { losses } \\
\text { Source: CVZ (2006). }\end{array}$ & $\begin{array}{l}\text { For sitagliptin, consideration of costs of } \\
\text { sick days using the friction cost method. }\end{array}$ \\
\hline Norway & $\begin{array}{l}\text { Perspective: limited societal } \\
\text { All relevant costs borne by society and National } \\
\text { Insurance should be included and be presented } \\
\text { separately. } \\
\text { Source: Norwegian Medicines Agency (2005) }\end{array}$ & $\begin{array}{l}\text { Direct medical and non-medical costs } \\
\text { included. } \\
\text { e.g. direct non-medical costs considered } \\
\text { for dabigatran and sitagliptin. }\end{array}$ \\
\hline Spain & No official guidelines for supplier submission. & $\begin{array}{l}\text { Direct medical costs only, most often } \\
\text { limited to the cost of the drug }\end{array}$ \\
\hline Sweden & $\begin{array}{l}\text { Perspective adopted: societal } \\
\text { Direct costs, Indirect costs } \\
\text { (production loss and sickness should be included } \\
\text { and estimated by human capital approach) } \\
\text { Source: Pharmaceutical Benefits Board (2003) }\end{array}$ & $\begin{array}{l}\text { All costs included for } 4 \text { drugs ( } 1 \text { Direct } \\
\text { medical, } 1 \text { direct and indirect medical) } \\
\text { (details not available) } \\
\text { Consideration of direct non-medical costs } \\
\text { for dabigatran and sitagliptin. } \\
\text { Explicit exclusion of non-medical costs in } \\
\text { the CUA for sunitinib, justified by the fact } \\
\text { that production loss are likely to be } \\
\text { marginal since the disease mainly affects } \\
\text { older people. }\end{array}$ \\
\hline $\begin{array}{l}\text { UK England } \\
\& \text { Wales }\end{array}$ & $\begin{array}{l}\text { Potential direct and indirect resource costs for } \\
\text { the NHS and PSS that would be expected. } \\
\text { Source: NICE (2008) }\end{array}$ & $\begin{array}{l}\text { Mainly direct medical costs included (direct } \\
\text { non-medical costs in one case) }\end{array}$ \\
\hline UK, Scotland & $\begin{array}{l}\text { Direct health care resources, patient resources } \\
\text { Source: Scottish Medicine Consortium }\end{array}$ & $\begin{array}{l}\text { For Ranibizumab, costs considered are: } \\
\text { drug costs, costs of administrating the } \\
\text { drug, follow-up costs and costs of people } \\
\text { turning blind. }\end{array}$ \\
\hline France & $\begin{array}{l}\text { Pharmaco-economic evaluation is not (yet) } \\
\text { required/used in reimbursement and pricing } \\
\text { process but will be for very innovative drugs from } \\
\text { October } 2013 \text {. } \\
\text { Guidelines recently published by the HAS } \\
\text { recommend the adoption of an "all payers" } \\
\text { perspective. } \\
\text { The Pricing Committee is supposed to consider } \\
\text { daily cost of treatment of comparators and can } \\
\text { take into accounts savings/costs for health } \\
\text { insurance. }\end{array}$ & $\begin{array}{l}\text { No product has been subject to economic } \\
\text { evaluation yet. }\end{array}$ \\
\hline
\end{tabular}




\begin{tabular}{|c|c|c|}
\hline Country & $\begin{array}{l}\text { Perspective adopted for pharmaco-economic } \\
\text { evaluation and costs to be considered } \\
\text { (according to guidelines) }\end{array}$ & $\begin{array}{c}\text { Costs considered in the sample of } \\
\text { drugs selected }\end{array}$ \\
\hline Germany & $\begin{array}{l}\text { Pharmaco-economic evaluation is not } \\
\text { systematically used but assessment reports of } \\
\text { the G-BA (and IQWiG) include information on } \\
\text { (additional) costs of treatments. } \\
\text { Perspective adopted for economic assessment } \\
\text { performed by IQWiG: social health insurance and } \\
\text { patients } \\
\text { Direct costs: monetary value of resources that } \\
\text { are consumed through the provision of a specific } \\
\text { health service and which are reimbursed by the } \\
\text { social health insurance or partly covered by } \\
\text { patients. } \\
\text { Direct non-medical costs (e.g. transport costs, } \\
\text { home help) should be included in pertinent } \\
\text { cases. } \\
\text { Indirect medical costs are not primarily } \\
\text { considered. Costs of productivity losses (due to } \\
\text { morbidity) may be assessed separately is they } \\
\text { are substantially affected by the new technology. } \\
\text { Source: IQWiG (2009) }\end{array}$ & $\begin{array}{l}\text { None of the selected product was subject } \\
\text { to economic evaluation. }\end{array}$ \\
\hline
\end{tabular}

\section{The consideration of budget impact}

77. Some countries explicitly consider budget impact in the R\&P process, with specific decision rules applying for medicines with high budget impact. Australia explicitly considers the impact of any decision on the public budget to inform reimbursement decisions. There is no limit beyond which a medicine will not be reimbursed, although there used to be a budget impact threshold beyond which the Ministry of Finance and the Cabinet were responsible for the decision. Due to current pressure on public spending, they are now consulted for all decisions.

78. In Norway, the Norwegian Medicine Agency must consult the Ministry of health for applications with an expected budget impact exceeding NOK 5 million in the $5^{\text {th }}$ year after marketing. In Belgium, budget impact is explicitly considered. Both Minister of Finance and Minister of Budget are required to provide advice to the Ministry of Social Affairs before listing. In a few occasions, the former recommended to not list a medicine with a positive recommendation from reimbursement expert committee and the Minister of Social Affairs followed this advice (KCE, 2010). In the Netherlands, the Health Insurance Board (CVZ) considers budget impact when making reimbursement decisions, but costeffective medicines are only rarely not approved for reimbursement for budgetary reasons. In Spain, budget impact is one of the criteria considered for deciding on reimbursement status.

79. In Canada, budget impact is considered by managers of public drug plans rather than by the expert committee of the Common Drug Review. The guidelines for budget impact assessment published by the federal pricing review board (PMPRB) for pharmaceutical companies, committees and managers of federal, provincial and territorial drug plans in 2007 recommend to consider only drug costs, including costs or savings associated with other drugs likely to be affected by listing of the new drug (PMPRB, 2007). The inter-territorial expert committee responsible for the evaluation of oncology drugs analyses the feasibility of adoption of new medicines in health systems, including budget impact. It recommends the consideration "net budget impact", i.e. costs of the drug itself and costs for other products and services related to its use, such as companion testing technologies (pERC, 2011). 
80. Sweden does not consider budget impact as a relevant criterion to make reimbursement decisions. The cost-effectiveness threshold and disease severity are the only criteria used. However, county councils can impose further restrictions to the use of a medicine due to financial restrictions.

81. In another group of countries, budget impact is not explicitly considered in the R\&P process, but pharmaceutical companies are requested to provide information on expected sales or consumption in the years following listing. In Denmark, this information must be included in applications for reimbursement, while in France, the information is included in application for pricing decisions. The pricing committee considers expected volumes of sales of the new product at the time of price negotiation to use its purchasing power. It sometimes uses volume-price agreements to obtain further discounts if volumes of sales taken as the basis for price negotiation are exceeded. In Germany, companies are requested to provide total costs for statutory health insurance in their application for benefit assessment, for use at the time of price negotiation.

82. In Italy, budget impact is one of the criteria that are used for the reimbursement decision and in price negotiations. Budget impact is also used for post-marketing assessments. In the budget impact analysis, all aspects linked to the usage of the product are considered, including possible savings against other forms of treatment, in the hospital setting, for example.

\section{The value of innovativeness}

83. Many R\&P policies have been designed with the objective to encourage pharmaceutical R\&D and "innovative" drugs are usually granted price premiums. However, the extent to which this criterion is taken into account in individual decisions related to R\&P is difficult to assess.

\section{What do new technologies get for added therapeutic value?}

84. Case-study countries all have a system in place to assess a pharmaceutical's added value, with the objective to allow a price premium for medicines with added therapeutic value. By definition, added therapeutic value is considered in all countries using economic assessment based on incremental costeffectiveness or cost-utility ratios. In these countries, estimation of cost-effectiveness or cost-utility is only undertaken if the new drug brings benefits for patients. Otherwise, cost-minimisation is used and the new drug will be included in the national formulary or positive list if its cost is lower than those of comparator(s).

85. Other countries have adopted classifications to rate the level of added therapeutic value of new products (see Table 11). For instance, the French transparency commission uses a five-level scale to rate clinical benefits of a new medicine (ASMR for Amélioration du service médical rendu). Medicines with an ASMR I rating are considered to offer major therapeutic progress, while drugs with other ASMR levels are less innovative. In Germany, the Federal Joint Committee assesses the additional therapeutic benefit using 6 categories: three of them refer to actual and measurable additional benefits, another category recognizes the existence of an additional benefit which cannot be quantifiable; the two other categories include drugs with no additional benefit or even less clinical benefit than comparator. In Italy, the degree of innovativeness of new products is assessed through a score assigned according to the availability of preexisting treatments and the therapeutic benefit. Principal and surrogate clinical endpoints are used to cluster the new product in one of the following categories: a) Major benefits on clinical end-points (reduction of mortality and morbidity) or on validated surrogate end-points; b) Partial benefit on the disease (clinical end-points or validated surrogate end-points) or limited evidence of a major benefit (nonconclusive results) or c) Minor or temporary benefit on some aspects of the disease (for example, partial symptomatic relief in a serious disease). 
86. Added therapeutic value is used as an explicit criterion for price regulation or negotiation in several countries. In Canada, the PMPRB classifies new patented medicines into four categories according to their therapeutic improvement to determine which test should apply to identify "excessive prices" at the federal level. France uses its 5-category classification to determine the rules applicable in price negotiations. In both countries, the more innovative drugs are benchmarked against prices in foreign countries, while the less innovative drugs are benchmarked against prices of comparator drugs in the internal market. The rule is based on the assumption that "international benchmarking" - with an appropriate set of countries- is more advantageous for new products than therapeutic referencing. However, in Canada, actual prices paid by public plans may be negotiated at lower level than maximum price defined at the federal level. In France, new medicines with ASMR I to III and considered by the High Authority in Health to be efficient benefit from a price guarantee of 5 years. This means that the listing price will remain the same over this period, though the company may have to pay rebates to health insurance in pre-defined and product-specific circumstances.

87. In Japan, new and innovative medicines can obtain a price premium over their competitors according to established rules. Very innovative medicines can pretend to a $70 \%$ to $120 \%$ price premium, while less innovative ones can obtain $35 \%$ to $60 \%$ premium. A medicine can also obtain a price premium of $5 \%$ to $20 \%$ if it is the first approved in its therapeutic indication for paediatric use, and a premium of $10 \%$ to $20 \%$ for "marketability" if the targeted population is very small (see JPMA, 2012 and country profile for more details).

Table 11. Assessment of added therapeutic value and implications

\begin{tabular}{|c|c|c|}
\hline Country & Assessment / Classification & Implication \\
\hline Australia & $\begin{array}{l}\text { Assessment of the number of QALY } \\
\text { gained }\end{array}$ & $\begin{array}{l}\text { Use of CEA or CUA (otherwise CMA) } \\
\text { Reasonableness of ICER assessed against } \\
\text { threshold }\end{array}$ \\
\hline $\begin{array}{l}\text { Belgium } \\
\text { (CMR) }\end{array}$ & $\begin{array}{l}\text { Class 1: added therapeutic value } \\
\text { Class 2: analogous or similar } \\
\text { therapeutic value } \\
\text { Class } 3 \text { : generics/copies (same } \\
\text { active ingredient) }\end{array}$ & $\begin{array}{l}\text { Class } 1 \text { drugs are entitled to negotiate a price above } \\
\text { the comparator's price }\end{array}$ \\
\hline $\begin{array}{l}\text { Canada } \\
\text { (PMPRB) }\end{array}$ & $\begin{array}{l}\text { Four classes for new patented } \\
\text { products: } \\
\text { Breakthrough; } \\
\text { Substantial Improvement; } \\
\text { Moderate Improvement; } \\
\text { Slight or No Improvement }\end{array}$ & $\begin{array}{l}\text { Maximum selling prices are determined by } \\
\text { reference to international benchmarking for } \\
\text { breakthrough innovations. For other drugs, } \\
\text { maximum prices are set by reference to the price of } \\
\text { competitors in the Canadian market. }\end{array}$ \\
\hline $\begin{array}{l}\text { Canada } \\
\text { (public drug } \\
\text { plans) }\end{array}$ & $\begin{array}{l}\text { Assessment of the number of QALY } \\
\text { gained }\end{array}$ & Use of pharmaco-economics to make decisions. \\
\hline Denmark & $\begin{array}{l}\text { No assessment/classification. Health } \\
\text { gains in natural units }\end{array}$ & \\
\hline $\begin{array}{l}\text { France } \\
\text { (HAS) }\end{array}$ & $\begin{array}{l}\text { ASMR I: Major improvement } \\
\text { ASMR II: Significant improvement } \\
\text { ASMR III: Modest improvement } \\
\text { ASMR IV: Minor improvement } \\
\text { ASMR V: No improvement }\end{array}$ & $\begin{array}{l}\text { Medicines with ASMR I to III are entitled to a price } \\
\text { premium, determined by the manufacturer and } \\
\text { benchmarked to foreign prices. Idem for medicines } \\
\text { with ASMR IV with limited market potential. }\end{array}$ \\
\hline $\begin{array}{l}\text { Germany } \\
\text { (G-BA) }\end{array}$ & $\begin{array}{l}\text { Considerable additional benefit } \\
\text { Significant additional benefit } \\
\text { Small additional benefit } \\
\text { Additional benefit but not quantifiable } \\
\text { No evidence of additional benefit } \\
\text { Less benefit than comparator }\end{array}$ & $\begin{array}{l}\text { Medicines with some additional benefit are not } \\
\text { clustered in reference price groups and are given a } \\
\text { price premium over comparators. The degree of } \\
\text { innovation is referred to in the negotiation process. }\end{array}$ \\
\hline
\end{tabular}


DELSA/HEA/WD/HWP(2013)4

\begin{tabular}{|c|c|c|}
\hline Country & Assessment / Classification & Implication \\
\hline Italy $^{(1)}$ & $\begin{array}{l}\text { Important, } \\
\text { Moderate } \\
\text { Modest innovation }\end{array}$ & $\begin{array}{l}\text { Price advantages for innovative drugs (no formal } \\
\text { rule) }\end{array}$ \\
\hline Japan & $\begin{array}{l}\text { Innovativeness } \\
\text { Usefulness I } \\
\text { Usefulness II } \\
\text { Paediatric use } \\
\text { Marketability I } \\
\text { Marketability II }\end{array}$ & $\begin{array}{l}\text { Price premium for each category (over price of } \\
\text { comparator): } \\
70-120 \% \\
35-60 \% \\
5-30 \% \\
5-20 \% \\
10-20 \% \\
5 \%\end{array}$ \\
\hline Korea & Number of QALY gained & Funding decisions based on cost-effectiveness \\
\hline Netherlands & $\begin{array}{l}\text { Annex 1A: similar therapeutic value } \\
\text { Annex 1B: added therapeutic value }\end{array}$ & $\begin{array}{l}\text { Annex 1B drugs are entitled to a price premium } \\
\text { (evidence on Pharmacoeconomics and budget } \\
\text { impact required) }\end{array}$ \\
\hline Norway & $\begin{array}{l}\text { Assessment of the number of QALY } \\
\text { gained }\end{array}$ & $\begin{array}{l}\text { Use of CEA or CUA } \\
\text { Reasonableness of ICER assessed against } \\
\text { threshold }\end{array}$ \\
\hline Spain & $\begin{array}{l}\text { Classification of therapeutic value: } \\
\text { Significant } \\
\text { Moderate } \\
\text { Low } \\
\text { No interest }\end{array}$ & $\begin{array}{l}\text { Price premium of } 10-20 \% \text { if a drug has a significant } \\
\text { or moderate added therapeutic value }\end{array}$ \\
\hline Sweden & $\begin{array}{l}\text { Assessment of the number of QALY } \\
\text { gained }\end{array}$ & Price (premium) based on cost-effectiveness ratio \\
\hline $\begin{array}{l}\text { United } \\
\text { Kingdom }\end{array}$ & $\begin{array}{l}\text { Assessment of the number of QALY } \\
\text { gained }\end{array}$ & $\begin{array}{l}\text { Reasonable additional costs for QALYs gained/ } \\
\text { incremental cost effectiveness ratio }\end{array}$ \\
\hline
\end{tabular}

Note: (1) Italy announced it will replace this classification in three categories by a score of innovation from September 2013.

Source: Adapted from KCE (2010), completed with country profiles

\section{The assessment of added therapeutic value is not always consistent across countries}

88. The analysis of assessments conducted for the sample of products shows that the assessment of the existence and level of added therapeutic value is not necessarily consistent across countries. For instance, the added therapeutic value of fingolimod was assessed differently by case-study countries. While the Netherlands and Sweden found that the drug did not bring any therapeutic improvement, other countries found a small benefit, at least for some sub-populations (see Box 4). 


\section{Box 4. The assessment of added therapeutic value differs across countries: the example of fingolimod}

Committees in charge of assessment of added therapeutic value or additional benefit do not always agree on the degree of innovativeness of a new medicine. For instance, the therapeutic value of fingolimod for the treatment of multiple sclerosis was assessed by a number of countries, with different results (see table below). Germany and Sweden found that the drug had no added therapeutic value while Australia, Belgium, France and the United Kingdom found some.

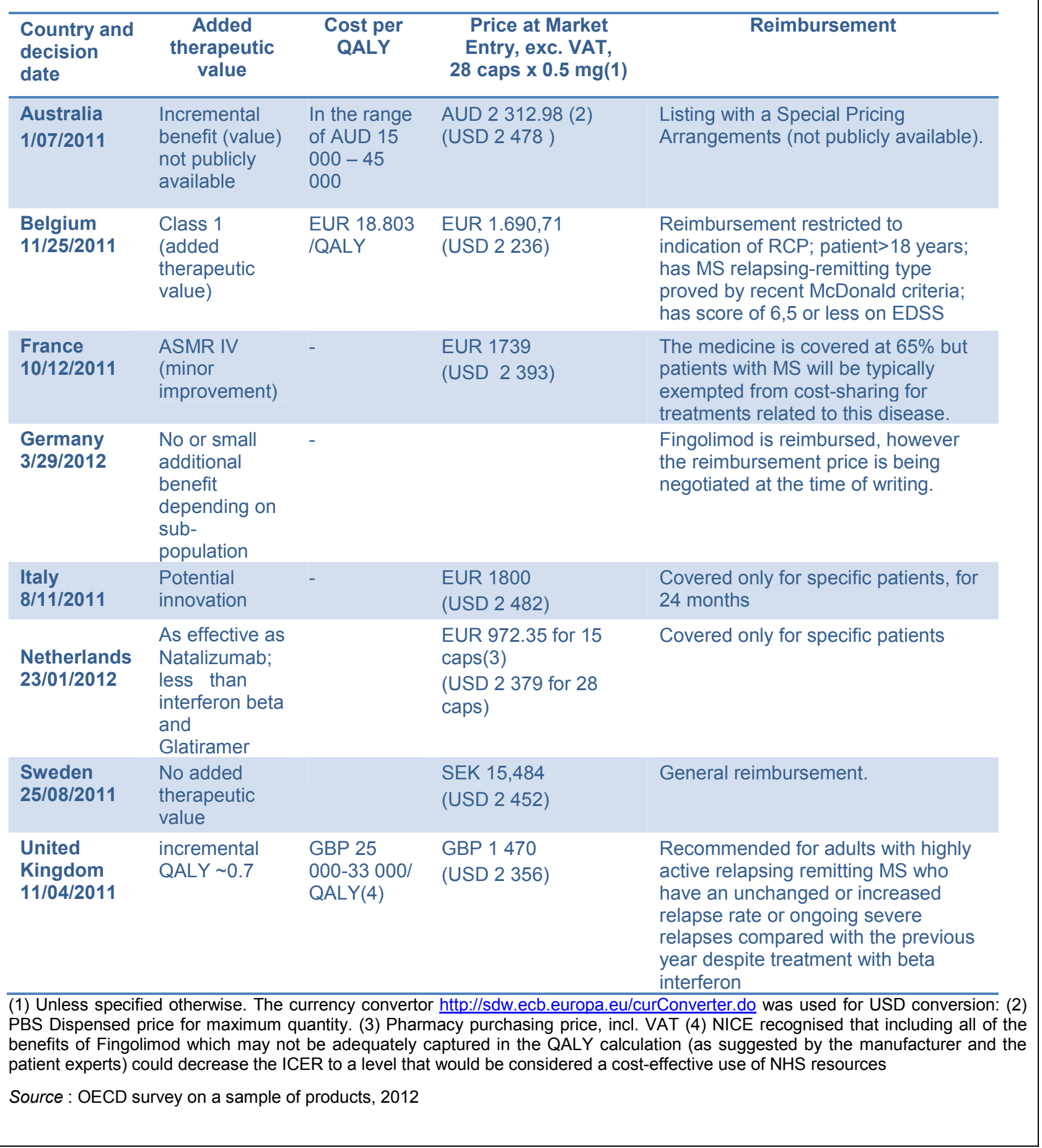


89. In principle, clinical benefits could be the most evidence-based and transferable part of the assessment of pharmaceutical products. Some stakeholders suggest that a single assessment -for instance for all European countries- could avoid duplication of work by national agencies and inconsistencies across countries. The European network for Health Technology Assessment ${ }^{5}$ has been elaborating guidelines on methodologies used for this assessment. This might be a first step towards a European assessment of clinical benefits, if decision-makers decide to take this route.

\section{Innovation "beyond added therapeutic value" is generally not considered}

90. Italy is the only country that mentions pharmacological or technological innovation "[that is] not a therapeutic advantage over existing products" as a criterion explicitly taken into account in the pricing process. However, this criterion is only one of several dimensions considered for scoring the degree of innovation of new products and respective weights of the multiple dimensions in the global score are not specified. It is therefore necessary to take concrete examples to measure the impact of this criterion on the regulated price. No other country explicitly considers "innovation" that does not translate into therapeutic improvement for patients in the assessment or decision-making process.

\section{Positive changes in the process of care may be an exception}

91. Changes in the process of care could be considered as a valuable benefit when the use of a new drug is more comfortable for patients and/or for caregivers. Some examples of such benefits could be replacing an injection by an oral treatment, allowing ingestion of a single dose per day, etc. Such benefits are rarely formally taken into account in economic evaluation, unless the supplier can show a link between this change and the final end-point. The French Transparency Commission for instance considers improvements in the mode of delivery in the rating of added therapeutic value if the expected impact on compliance has a proven clinical value. However, the weight given to this parameter is unknown.

92. Changes in the process of care that affect the costs of treatments, for instance by allowing treatment in ambulatory care instead of hospitalisation will typically be considered in the costing part of the evaluation (as costs saved or added).

93. Fingolimod (Gilenya ${ }^{\circledR}$ ), a drug for the treatment of relapsing remitting multiple sclerosis (marketed in 2011), could be an example where changes in the process of care were considered. Australia, Canada, Spain, Sweden and United Kingdom consider the new route of administration (oral treatment) an improvement over the comparator (natalizumab injection in Spain). Changes in the process of care were considered in the assessment of Dabigatran (Pradaxa ${ }^{\circledR}$ ) for the first indication -prevention of venous thromboembolic events in adult patients who have undergone major operating surgery the lower limb (elective total hip or knee replacement). See box below.

5. $\quad$ http://www.eunethta.eu/ 


\section{Box 5. How improvement in the process of care is taken into account : the example of dabigatran}

Dabigatran was first approved for the prevention of venous thromboembolic events in adult patients who have undergone major operating surgery on the lower limb (elective total hip or knee replacement). While its competitors were injectable medicines, dabigatran is an oral treatment, thereby offering more comfort for patients and potential savings in administration costs. A few months after market entry, dabigatran was approved for a second indication: the prevention of stroke and systemic embolism (SSE) in patient with non-valvular atrial fibrillation for whom anticoagulation is appropriate. This extension of indications widened the target population. For example in France, the Transparency Commission estimated that the targeted population was 158764 for the first indication and 500,000 patients for the second indication.

\section{A price premium over competitors at market entry}

The majority of countries using economic evaluation for the assessment of dabigatran, decided to use a costminimisation analysis (Australia, Belgium, the Netherlands, Norway and Spain) since dabigatran was not more effective than Enoxaparin, a low molecular weight heparin (LMWH) used as comparator. However, Australia, Belgium, the Netherlands and Spain recognised that dabigatran had an additional benefit with respect to the low-molecular weight heparins because of its oral administration form.

In 2008, in France, the Transparency Commission recommended the reimbursement of dabigatran in inpatient and ambulatory care for its first indication (with a $65 \%$ reimbursement rate in ambulatory care). The Commission considered that dabigatran had no added therapeutic value over Lovenox (ASMR V), but the medicine obtained a price premium of around $60 \%$ per DDD over its comparator.

When dabigatran was first assessed by the PBAC in Australia, in March 2009, PBAC deferred its decision to give the applicant an opportunity to compare dabigatran with rivaroxaban, another new oral therapy available for the same patient population. However in November 2009, PBAC recommended dabigratran (without change of comparator in the application), with a $49 \%$ price premium over enoxaparin, in consideration of savings in costs associated with the administration of enoxaprin.

In Belgium, in April 2009, dabigatran was listed in class 1 for reimbursement (drugs with added therapeutic benefit) with a price premium of $0,7 €$ Euros per day over the price of LMWH. In Spain in 2009, dabigatran received a $20 \%$ price premium over the price of all LMWH.

In the Netherlands, dabigatran is listed in annex 1B and thus reimbursed at the price proposed by the manufacturer. In Sweden, the TLV used a CEA and accepted dabigatran with a higher price than the cheapest option because it saved hospital visits, resulting in a net return for health care.

In the United Kingdom, NICE assessed dabigatran for its first indication in 2008 with a CEA and found only small incremental benefits over LMWH. The institute considered that dabigatran was as cost-effective, in terms of use of NHS resources, as LMWH or fondaparinux in the prevention of venous thrombo-embolism.

In Italy, dabigatran has been reimbursed for its first indication since November 2008 and can only be used in hospitals (class $\mathrm{H}$ ). The listed price is subject to a mandatory discount for the public sector. AIFA set a cap of expenditure at 3.2 million in the 24 months following the contract, beyond which the company had to refund any excess.

In Norway, dabigatran was initially reimbursed only for patients for whom the use of injections is not recommended, but this restriction was withdrawn later. In Canada, in 2009, the CUA submitted by the manufacturer reported differences in QALYs that favoured enoxaparin (although very slightly). There were some cost savings associated with dabigatran use compared with enoxaparin, however they were not considered sufficient to offset the higher incidence of venous thrombosis seen in the trial.

\section{Some price reductions when market size increases}

In Australia, PBAC recommended listing of dabigatran for its second indication in March 2011, with a cost per QALY below AUD 15000, without change in price. In the Netherlands, dabigatran was listed for its second indication because it was considered cost-effective compared to treatment with vitamin $\mathrm{K}$ antagonists (VKA). The applicant reported a health gain of 0.22 QALY with dabigatran-treated patients compared to VKA treatment. 
In France, in 2012, the Transparency Commission recommended reimbursement for the second indication for dabigatran (at $65 \%$ ) but considered that the medicine has no added therapeutic value over competitors (ASMR V). The list price did not change, in spite of a much larger target population.

In the United Kingdom, in March 2012, the second indication was approved and considered cost-effective with an incremental cost per QALY of about GBP 18000 and the price decreased by $40 \%$. Moreover the manufacturer announced a price reduction by 13\% from 1st April 2012.

In Spain, the assessment of dabigatran for its second indication in October 2011 led to a price reduction of $40 \%$ in terms of daily-treatment-cost, to the lowest price in Europe.

In Sweden, the TLV recommended listing of dabigatran for the second indication in 2011 because of an improvement of 0,12 QALY and an acceptable cost per QALY (in the range of SEK 535000 - 360 000). After the second indication was approved the purchasing price of dabigatran decreased by $38 \%$.

In Canada, in 2011, the CDR recommended dabigatran for listing in its second indication. Dabigatran is covered ${ }^{1}$ either partially or fully in Quebec and Nova Scotia. In Belgium, dabigatran is listed for this second indication under a Managed Entry Agreement, whose content is confidential.

Source : OECD survey on a sample of products

${ }^{1}$ This coverage could be restricted, accessible through specialized programs or available under the province's general health care coverage program. All formulary searches were conducted on April 23, 2012 and were based on the information available on the website for each province.

\section{How are wider social benefits valued?}

94. By definition, economic evaluation from a societal perspective takes into account "wider social benefits". Gains in working days or in the productivity for the patient or his/her relatives will be typically taken into account. Such benefits are often expressed in monetary units and considered in the costing part (i.e. deduced from costs generated by the treatment). They can also be considered as benefits in costbenefit analyses, where both costs and benefits are expressed in monetary units. However, this is not the type of analysis preferred by the countries studied.

95. The implications of these considerations in terms of reimbursement or pricing decisions are expected to play an important role in some cases. Johannesson and colleagues provide estimates of the impact of adopting a societal perspective on incremental cost-effectiveness ratios (ICER) for two pathologies: Alzheimer's' disease and multiple sclerosis. For Alzheimer's disease, a review of 16 studies from different countries shows that direct medical costs account for 10 to $56 \%$ of all costs (depending on the context and study), the remainder being split between formal non-medical care and informal care. These variations reflect differences in organization of care but also in methods used to assess costs (especially the costs of informal care). In these studies, utility for caregivers is rarely taken into account. It was, however, included in the NICE appraisal of cholinesterase inhibitors, in which a utility increment of 0.06 (on a $0-1$ scale) was added to patient utility (Johannesson et al., 2009). The authors then simulate a VBP or acceptable price for a treatment (assuming an ICER threshold of SEK 600,000) depending on the perspective adopted. The acceptable price ranges from SEK 18,700 (when only direct medical costs are considered) to SEK 45,400 (when social costs are considered). For multiple sclerosis (MS), non-healthcare costs account for the majority of costs generated by the disease. On average in Europe, medicines account for $20 \%$ of total spending, outpatient care for $11 \%$, inpatient for $11 \%$ while costs related to early retirement and informal care account for respectively $24 \%$ and $25 \%$ of total costs). Because the disease does not reduce life-span, MS may have the highest cost per patient over the life-cycle. However, ICER computed for MS treatments rarely meet current cost-effectiveness thresholds. The authors simulated that adopting a societal perspective would reduce the ICER by $35-40 \%$. 
96. Only a few case-study countries use a societal perspective for economic evaluation: this is the case of Denmark, the Netherlands and Sweden, while Norway adopts of "limited societal perspective". Korea accepts both societal and payer perspectives and asks the applicant to justify its approach. According to an assessment of 51 pharmaco-economic analysis submitted for coverage decisions between 2005 and 2009, two-third of submissions adopted a societal perspective (Yim, 2012).

97. The present study failed to identify any remarkable effect of the consideration of "wider social benefit" on the outcomes from reimbursement or pricing policies for the sample of products surveyed. In Sweden, the treatment for multiple sclerosis fingolimod is recognised as having a wider social benefit, such as gains in productivity and spare time due to easier drug administration. In the United Kingdom during the assessment process of fingolimod (Gilenya ${ }^{\circledR}$ ), the reduced need for care from family and the possibility that patients may return to the workforce were discussed as wider benefits. For this specific product, however, there is no evidence that the consideration of wider social benefit led to a higher price than in other countries (see box 4).

98. The explicit consideration of wider social benefits is more difficult in countries that do not use economic evaluation. In France, the "benefit in terms of public health" aims to assess benefits of the new drug for the whole population (not limited to patients). It is measured along three dimensions: health outcomes produced at the population level (which depends on the number of patients with the disease and the effectiveness of the treatment); the fact that the new product covers an unmet medical need; and its impact on the health system (resources saved or displaced within the health system). The second dimension is expected to favour treatments for orphan diseases and the third dimension is only optionally considered by the Transparency Commission.

99. These observations, however, do not allow drawing definitive conclusions on the impact of considering societal benefits. The sample of selected product is too small to be considered as representative.

\section{Is there a cost-effectiveness threshold?}

100. The issue of cost-effectiveness thresholds is only relevant in countries using economic evaluation. The use of economic evaluation itself only makes sense if there is some indication of a level beyond which a technology will not be considered cost-effective. However, most countries have been reluctant to establish and publish a definitive cost-effectiveness threshold for decision-making in health care. The National Institute of Clinical Excellence in England published some guidance and indicated a range of incremental cost-effectiveness ratios. In other countries, studies analysing past decisions have tried to infer cost-effectiveness thresholds, often without being able to identify a definitive threshold (see $\mathrm{KCE}, 2008$ and table 12). Conclusions of these studies and of more recent ones are presented below and illustrated by examples of decisions made for the sample of surveyed products.

101. In Australia, there is no explicit threshold. A previous study showed that between 1994 and 2003, the highest cost per QALY accepted was AUD 52400 , but noted that $41 \%$ of product/indications submitted with a lower level were not listed (Henry et al., 2005). A more recent study analysed the outcome of the assessment of submissions to PBAC for product-indication between July 2005 and November 2009: about 59\% of these received a positive recommendation for listing (with or without restrictions) and $41 \%$ of decisions were "deferred" or negative. Among assessments including an ICER value (about $50 \%$ of all assessments), the percentage of positive recommendations decreased when the ICER increased: $51 \%$ of submissions with an ICER inferior to AUD 45000 were accepted, against 33\% when the ICER was in the AUD 45000 - 75000 range and 16\% beyond AUD 75000 (Mauskopf et al., 2013). Since a few years, PBAC summary reports do no longer publish the value of the ICERs but instead 
indicate the range in which the value is included: AUD 15000 - 45000 per QALY; 45000 - 75 000; 75 000-105 000; or 105 000-200 000.This makes the identification of an ICER threshold more difficult.

102. In Canada, Rocchi et al. (2008) studied all recommendations made by CDEC between 2003 and 2007 and found that medicines were accepted when less costly than alternatives or with an ICER up to CAD 80000 per QALY while medicines were rejected with ICER ranging from CAD 31000 to 137000 per QALY. The overlap between the two categories indicates that other criteria are taken into account.

103. In Korea, the HIRA, responsible for appraisal did not publish any ICER threshold. It decided to take the GDP/capita as a reference value for cost-effectiveness, but considers other criteria to make decisions, such as disease severity, budget impact, coverage in other countries, and innovation. Yim and colleagues (2012) studied all submissions for coverage including an economic evaluation between 2005 and 2009 (51 submissions) and observed an implicit threshold of USD 28000 per QALY (with a societal perspective). The study also revealed that ICERs assessed with a high level of uncertainty were less likely to lead to positive recommendations.

104. In Sweden there is no explicit threshold value. However, a study of applications for reimbursement over the period October 2002 to October 2007 showed a correlation between disease severity and willingness to pay for a QALY. On average, the cost/QALY of accepted applications is EUR 35000 but the Pharmaceutical benefit board has accepted costs per QALY in the area of EUR 100000 for more severe conditions. A high degree of uncertainty in the cost-effectiveness estimate does not seem to reduce the willingness to pay for a QALY. Instead it is highly correlated with restrictions in the reimbursement status or with follow up data being requested (Hugosson \& Engstrom, 2008).

105. NICE set a range for the ICER threshold: from GBP 20000 to GBP 30000 , with guidelines on how other factors should be taken into account to make decisions within this range (KCE, 2008). Interventions with an ICER below GBP 20000 should be accepted unless there are major doubts about the plausibility of estimates. For interventions with an ICER between GBP 20000 and GBP 30 000, other factors should be taken into account, such as the degree of uncertainty of estimates, added benefits of an innovative new technology that are not adequately captured by QALYs, and the potential misrepresentation of QALYs gained by the HRQoL tool (KCE, 2008). Since recently, medicines meeting specific criteria can be accepted with cost per QALY higher than GBP 30000 (see section on disease severity). 
Table 12. Explicit and implicit ICER thresholds and values observed in our sample of products

\begin{tabular}{|c|c|}
\hline Country & Existence of a threshold and implicit values (1) \\
\hline Australia & $\begin{array}{l}\text { No explicit threshold. Implicit threshold estimated at AUD } 52400 \text { (USD } 35095 \text { ) in 1994-2003, but } \\
\text { rejections below this threshold. Between } 2005 \text { and 2009, 33\% of drugs with an ICER between } \\
\text { AUD } 45000 \text { (USD } 30 \text { 139) and AUD } 75000 \text { (USD } 50 \text { 232) were accepted and } 16 \% \text { of drugs with } \\
\text { ICER> AUD } 75000 \text { (USD } 50 \text { 232) were accepted. }\end{array}$ \\
\hline & $\begin{array}{l}\text { In our sample, listing for product/indications with ICER values over AUD } 75000 \text { (USD } 50232 \text { ) } \\
\text { were always rejected and ICER over } 45000 \text { (USD 30139) were only accepted in a few cases, } \\
\text { e.g. Sunitinib was listed for gastro-intestinal tumour because of a high clinical need and } \\
\text { bevacizumab was listed for colorectal cancer above this threshold. Eculizumab was accepted } \\
\text { with a (likely) higher ICER but as part of the Life Saving Drug Program. }\end{array}$ \\
\hline
\end{tabular}

In our sample, the reimbursement commission generally considered that medicines with cost per QALY higher than EUR 80000 (USD 92 314) should not be reimbursed. However, Bevacizumab was listed for breast cancer with an ICER > EUR 100000 (USD 115 158).

Canada $\quad$ No explicit threshold. Implicit threshold estimated at CAD 80000 (USD 64 879) in 2003-2007, but some drugs were rejected below this threshold (Rocchi et al, 2008).

Korea No explicit threshold, but GDP per capita used as a "reference value" (USD 26000 in 2007). Implicit threshold of USD 28000 observed between 2005 and 2009 (Yim et al, 2012).

Netherlands The Council for Public Health and Health care suggests an absolute maximum ICER threshold value of EUR 80000 (USD 9 4904) / QALY, for severe diseases. However, orphan medicines have been adopted beyond this threshold.

Norway $\quad$ No explicit threshold

Listing of sunitinib for GIST was rejected with an ICER of NOK 476000 (USD 52 338) / QALY, but listing for $1^{\text {st }}$ line treatment of renal cancer was accepted with an ICER of NOK 501000 (USD 54 295) / QALY because the committee considered that the ICER was over-estimated.

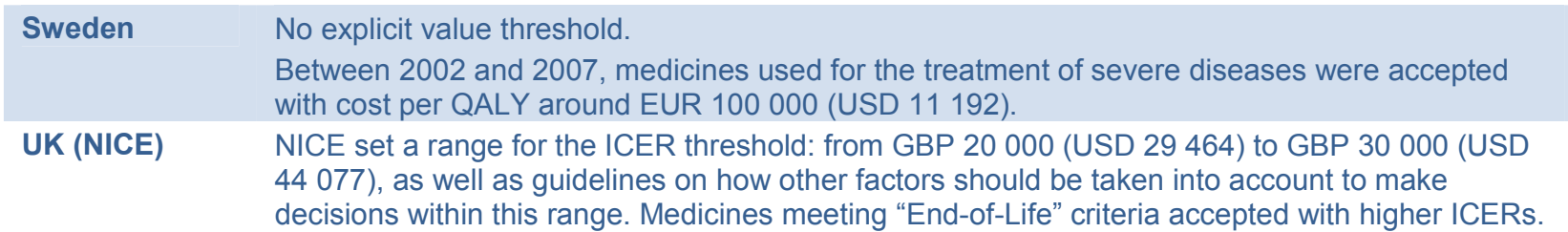

Note: in this table, national currencies have been converted in USD using purchasing power parities conversion rates of 2012. Although this approach is not fully satisfactory, no better alternative was identified.

Source: KCE (2008) and assessment reports.

106. The heterogeneity of recommendations for reimbursement made by assessment bodies in several countries has been analysed in several studies (see Wilsdon and Serota, 2011 for a review). The extent to which these differences come from economic rather than clinical consideration is not always easy to determine. In our sample, recommendations to not fund a medicine were more common in countries using economic evaluation than in countries founding their recommendations on clinical benefit only. However, negative recommendations were often followed by re-submissions of the application, with a restricted set of indications, with a lower price or with new evidence, which were finally accepted. 


\section{Are treatments for severe or rare diseases more valued than others?}

107. The document posted by the English Department of Health for consultation proposes to establish a reference cost-effectiveness threshold and higher thresholds for severe or rare diseases. This issue at stake here is the balance between efficiency and equity, with different possible conceptions of equity. This has already been the subject of many debates and academic research and a gap seems to emerge between the recommendations of academic researchers and practices observed in the health sector.

108. The Netherlands has devoted a lot of attention to this question and expert groups have proposed the use of "proportional shortfalls" to weight QALYs. This method combines two competing principles considered for equity purpose: the principle of fair innings (everyone should experience the same quantity of healthy life, which implies for instance that treatment for children should be prioritised over treatments for old people) and the principle of expected health (priority should be given to treatments expected to provide the highest health benefits to their population targets). The proportional shortfall is defined for a population target for a treatment as the ratio of the amount of QALYs lost in absence of treatment to the amount of QALYs this population could expect in absence of the disease. Using the principle of proportional shortfalls to make decisions implies to give priority to patients who lose the greatest proportion of their expected life expectancy due to a specific illness, if untreated (van de Wetering et al., 2013). Experts recognise however, that the application of this principle in decision making is not straight forward.

109. Although the debate has been more explicitly formalised in some countries using economic evaluation to inform their decisions, it is not absent in other countries, where pharmaceutical companies also claim high prices for drugs designed to treat severe and rare diseases.

\section{Treatments for severe diseases are more valued}

110. In our sample of countries, the severity of the ailment treated is considered with different approaches and consequences on R\&P. In France, the severity of the disease is taken into account in the assessment of the therapeutic value, which in principle guides the reimbursement level. Drugs for severe diseases are typically fully reimbursed by health insurance while other drugs are only partially reimbursed by health insurance.

111. A common finding is that oncology products are accepted at higher ICERs than treatments for other diseases. According to Rocchi and colleagues (2008), the chair of the Ontario expert review committee suggested that the ICER threshold for oncology drugs was higher than for other medicines (CAD 75000 instead of CAD 50 000). Similarly, oncology drugs were accepted with much higher ICER values than other medicines by NICE and by the SCM in Scotland. In Scotland, oncology drugs were accepted with ICERs twice as large as those of other drugs (Rocchi et al., 2008).

112. In the Netherlands, the principle for health technology assessment states that patients with the highest need should be given priority. This principle can only apply to the appraisal phase since the economic evaluation does not allow a different weighting. In Canada, disease severity is not explicitly considered, neither in the pan-Canadian assessment of new products nor in price regulation at the federal level. However, a new entity was recently created to assess separately cancer drugs. The new institution (pCODR) is too recent to allow interpretations of its decisions.

113. In Sweden, severity is explicitly taken into account as one criterion for decision making. ICER accepted for medicines treating severe diseases are usually higher than those accepted for treatments for mild symptoms with no impact on life expectancy. This was confirmed by a study by Hugosson and 
Engstrom (2008) on past decisions. However, there are no pre-defined thresholds and judgements are made on a case by case basis by the TLV board.

114. In Australia, PBAC can resort to the "rule of rescue" in exceptional circumstances. This rule might influence a decision, which would be negative due to a high ICER and other relevant criteria, if four conditions are met: (i) there is no alternative (pharmacological or not); (ii) the medical condition is severe, progressive and expected to lead to premature death; (iii) the medical condition applies to only a small number of patients; and (iv) the proposed drug provides a worthwhile clinical improvement sufficient to qualify as a rescue from the medical condition. PBAC guidelines specify that "the more severe the condition, or the younger the age at which a person with the condition might die, or the closer a person with the condition is to death, the more influential the rule of rescue might be in the consideration by PBAC", and also that drugs targeted to smaller groups of patients and greater health improvements are more likely to benefit from the rule of rescue (PBAC, 2008).

115. In England and Wales, NICE originally excluded the "rule of rescue" from the list of criteria considered relevant for decisions. However, the Institute published new guidance for the appraisal of lifeextending, end-of-life treatment (NICE $(2008,2009)$. These new guidelines allow, in principle, funding of some treatments whose ICER is above the usual GBP 30000 (\$PPP 44 076,6)/QALY threshold, provided that these treatments have the following characteristics:

- Treatments indicated for patients with a short life expectancy, normally less than 24 months;

- There is sufficient evidence that the treatment offers an extension to life, normally at least three additional months, compared to current NHS treatments;

- The treatment is licensed or otherwise indicated, for a small patient population.

116. In these circumstances, the appraisal committee is expected to consider the impact of giving greater weight to QALYs achieved in the later stages of terminal diseases in the ICER and to assess the magnitude of the additional weight needed to fall within the current threshold range. Any guidance produced using this supplementary advice should be reviewed within two years.

117. The analysis of our sample of products shows that some products/indications were funded in spite of very high costs per QALY, because there was a clinical need and no alternative. This provision, however, does not automatically apply to any type of cancer for instance (see box 6). NICE in England and Wales and the Norwegian agency have made different decisions concerning two indications of a same oncology drug with similar ICER. 


\section{Box 6. The consideration of disease severity in the sample of products surveyed}

In England, NICE assessed the oral oncology drug Sunitinib for three different indications: as a second line treatment for Gastrointestinal stromal tumor (GIST), as a first line treatment for metastatic renal cancer, and as a second line treatment for renal cancer. The ICER was estimated by NICE at GBP 31 800/QALY for GIST, "Iess than GBP 50000 " for the $1^{\text {st }}$ line treatment of renal cancer and not disclosed for the second line treatment of renal cancer. NICE considered that the use of sunitinib as a second line treatment in renal cancer did not meet the NICE "end-of-life criteria" and did not recommend its use but issued a positive recommendation for the two other indications, with Patient Access Agreements. NICE did not recommend the use of cabazitaxel in the treatment of hormone refractory metastatic prostate cancer with an ICER of GBP 87500.

The Norwegian agency also assessed sunitinib for each of these indications. ICER were assessed at NOK 476 000 for GIST, NOK 501000 for $1^{\text {st }}$ line treatment of renal cancer and NOK 491000 for $2^{\text {nd }}$ line treatment of renal cancer. However, due to uncertainties in the estimate provided for the third indication, only the two first indications were approved for funding.

Source : OECD survey

\section{Treatments for rare diseases are also often more valued}

118. Orphan drugs have received a lot of attention from decision-makers and already benefit from a set of advantages (including notably longer market-exclusivity) aimed to encourage research and development of medicines for markets that would probably not be profitable without these incentives. However, pharmaceutical companies continue to market orphan drugs at very high prices.

119. The first advantage procured because of the "rarity" of the disease treated in terms of value is that assessment bodies are more flexible about the type and level of evidence provided in companies' applications for funding. This flexibility is explicitly announced by Australia for instance.

120. A second type of advantage exists in countries like France or Italy, where recommendations are made on the grounds of clinical benefits and clinical needs, before entering into price negotiations. In such cases, decision-makers are expected to reach an agreement on price with the manufacturer in order to enforce the positive recommendation. This provides a significant amount of leverage for the manufacturer in price negotiations, which can be reinforced by the opinion expressed by the Ministry of Health participating in pricing committees. In Italy, most of the orphan drugs are included in the positive list because, by definition, they cover an unmet need, and this is one of the conditions to be included in the positive list. In France, orphan drugs are typically covered. In assessments of the Transparency Commission, rarity (together with clinical need, i.e. the non-existence of alternative treatment), is explicitly considered.

121. Countries using economic evaluation have sometimes adapted general rules to favour the funding of orphan drugs with high cost per QALY. In Australia, for instance, rarity positively influences the application of the rule of rescue. In Sweden, a greater uncertainty is accepted in cost-effectiveness studies if there is no possible way of acquiring data due to small patient groups (KCE, 2009). However, the rarity of the disease itself does not justify the acceptance of the higher ICER: the disease treated has to be severe to justify a high ICER. In Belgium, applications for orphan medicine reimbursement are not required to include an economic evaluation.

122. These medicines may be funded through special programs rather than included in the general positive list. In Australia, the Life Saving Drugs Program provides subsidised access for eligible patients to 
expensive life-saving medicines for very rare life-threatening conditions that are not included in the positive list. During 2010-2011, nine drugs were funded for 210 patients with seven types of disorders.

123. In Norway, by contrast, medicines treating severe illnesses and orphan medicines are not supposed to be treated differently.

124. The orphan medicine eculizumab is the most expensive medicine of our sample. Only four assessment reports mention ICER values for this drug: the Australian PBAC reports a cost of AUD 200 000 per death avoided within two years; the Canadian CDEC reports CAD 2.4 million per QALY; the Canadian INESSS (for Quebec) reports of cost per life-year saved ranging from CAD 1 to 2.8 million and the Swedish TLV measured the sensitivity of the cost-per-QALY to hypothetical discounts on list price. At the list price, the treatment costs SEK 5 million per QALY. Other countries report cost per patient and per year of EUR 350000 or more. Australia funded the medicine through its Life Saving Drug Program. While CDEC did not recommend funding of eculizumab, some provinces (e.g. Ontario) funded the drug through special access programs. Quebec refused to list eculizumab. In Sweden, the drug is not recognised costeffective but other factors may be taken into account for listing at county level. In other European countries included in this study, the medicine was listed in spite of high costs per patient.

\section{Paying for value through product-specific agreements}

125. In some circumstances, payers want to be sure they do not pay "too much" for a given product and know this cannot be guaranteed by just setting or negotiating a price and/or reimbursement conditions. On their side, pharmaceutical companies are interested in product-specific agreements likely to speed or allow market access while preserving the integrity of their 'list price' (the price benchmarked by other payers). Since the 1990s, payers and companies have been developing product-specific agreements to address a number of issues, which can all be considered as "value-related" issues:

- Uncertainties about clinical efficacy or clinical effectiveness;

- Uncertainties about cost-effectiveness;

- Uncertainties about budget impact.

126. Several authors and reports have proposed taxonomies and typologies to classify product-specific agreements, which could arguably all be included in the broad categories of "risk-sharing" or "managed entry" agreements (see for instance IMS, 2009, Espin J et al. 2011; de Pouvourville and Montgrédien, 2012; Klemp et al., 2011; Walker et al., 2012). This report considers three broad categories.

Product-specific agreements aiming to reduce uncertainties in effectiveness or cost-effectiveness, without performance-based provisions.

127. Coverage with evidence developments (CED) schemes belong to this category since they link coverage of a medicine to supplementary data collection to reduce uncertainties about health outcomes achieved in clinical trials (efficacy) or in real life (effectiveness). Depending on the objective of the study, CED agreements cover the medicine "only in research" or for all patients eligible to treatment. These two types of agreements differ in the type of data to be collected and in the "irrecoverable" costs they generate. Typically, in England and Wales, CED schemes provide coverage only for patients included in clinical trials. In Sweden, these schemes provide coverage in exchange for information on the actual use of the product (e.g. obesity treatments), on long-term effects on morbidity and mortality (e.g. cholesterol products), on quality of life (e.g. insulin detemir), and/or on cost effectiveness (e.g. treatment for Parkinson's disease, vaccine for cervical cancer) (Carlson et al., 2010). Italy also developed web-based 


\section{DELSA/HEA/WD/HWP(2013)4}

"Registries", mainly for innovative oncologic and orphan drugs, with the aim to collect information about rational and appropriate use of specific medicines in a single database; to monitor the related consumption and expenditure; and to provide information needed for risk-sharing agreements.

128. These agreements aim to inform coverage and pricing decision, which may be in turn be affected by new available information, but they do not necessarily include provisions linking explicitly the performance of the product (in terms of efficacy, effectiveness or cost-effectiveness) to future decisions in terms of coverage or pricing.

Performance-based agreements, aiming to reduce uncertainties about cost-effectiveness, linking the price paid by payers to the performance of the product.

129. These agreements are typically signed when there is a high level of uncertainty about the benefits claimed by the manufacturer. When health benefits are potentially high, the third-party payer agrees to fund the new treatment but asks to be (at least partly) refunded by the company if claimed benefits are not observed in the real life.

130. Performance-based agreements link third-party payments for the medicine to outcomes observed either at individual level (for each patient) or at the aggregate level (for the whole population treated). Outcomes to be assessed can be defined in terms of clinical endpoints (e.g. clinical response, improvement in quality of life) or in terms of cost-utility (the cost/QALY gained should not exceed a certain threshold).

131. The agreement signed by the English NHS with several manufacturers in 2002 for multiple sclerosis treatments is the most famous example, but other examples exist. For instance, in Germany, a health insurance fund signed an agreement with Novartis to obtain a refund of a patient's treatment for osteoporosis if an osteoporosis-related fracture occurs. In England, Janssen Cilag agreed to refund treatment of multiple myelomia for patients who do not respond positively after four cycles of treatments. In England again, companies producing treatments for multiple sclerosis agreed to reduce the price of their products in order to maintain an average cost/QALY at GBP 36000 (IMS, 2009). In France, the coverage of a treatment for schizophrenia claimed to improve compliance was approved under the condition that the company monitors compliance in real life and will refund a part of social security spending if compliance targets are not met. Italy signed several agreements according to the "Payment by Results" scheme, used in particular for oncology drugs (Garattini and Casadei, 2011). Box 7 provides examples of such agreements for the sample of products analysed in this study.

\section{Financial agreements aiming to control budget impact or ensure value-based funding.}

132. Financial agreements aiming to control budget impact typically link price reductions or rebates to volumes sold or indications of inappropriate use. France typically uses this type of agreements, negotiated in confidentiality with the Economic Committee of Health Products. Italy also use price-volume agreements but these agreements are sometimes public (e.g. rebates to be paid by manufacturers to each region for dabigatran have been published in the Official Bulletin).

133. They can also take the form of "dose capping" as observed in some agreements signed under the Patient Access Scheme in England and Wales. For instance, the original PAS agreement for Lucentis ${ }^{\circledR}$ limited funding by the NHS to 14 injections per eye and per patient and the manufacturer had to pay following treatments where needed. Such agreements have been introduced at the regional level In Sweden. For instance, the Stockholm County Council signed an agreement in April 2008 (initially valid for one year but extended) whereby if patients with advanced cancer exceeded an accumulated dose of 10000 $\mathrm{mg}$ of bevacizumab, the additional costs would be fully covered by the company. Other regions in Sweden have also been offered similar schemes (Adamski, 2010). These agreements can be viewed as alternatives 
to funding restrictions to a limited number of treatments, beyond which the patient is left untreated. The value for payers is the same but the value for patients is higher. Administration costs of these schemes, however, should not be neglected.

134. Financial agreements may also be used to reduce the price paid for one product or one indication without affecting the product's list price. Cost-sharing scheme used in Italy or "free stock agreements" used in England and Wales enter in this category. The supplier pays a share of the price or the full price of the first cycles of treatments and third-party payers pay for the following cycles when the clinical response is positive.

135. A last type of financial arrangement only consists of rebates/discounts on the list price. These are not real "risk-sharing agreements". From the payer's point of view, they might be useful to consider in order to discriminate the price of a medicine across several indications with very different costeffectiveness ratios (see later). In other cases, these agreements mainly aim to preserve the list price from the consequences of international benchmarking -from the manufacturer's perspective-.

136. The majority of countries surveyed in this study use product-specific agreements, with the notable exceptions of Denmark, Norway and Spain. In some countries, like France and Belgium, the existence and the content of product-specific agreements are confidential and thus not observable (with a few exceptions). For other countries, information collected for the sample of products surveyed shows interesting differences in approaches adopted to limit budget impact or ensure value-for-money of pharmaceutical spending (see box 7). A single agreement may include several provisions responding to different objectives.

\section{Box 7. Product-specific agreements in the sample of products surveyed}

Information on risk-sharing agreements is not always publicly available. In France, product-specific agreements exist for some products but their existence and their content are confidential. Risk-sharing agreements exist in Belgium for innovative products initially refused by the Reimbursement Commission, but their content is partially confidential. Information collected through the survey on product-specific agreements is reported below.

\begin{tabular}{|c|c|}
\hline \multirow{4}{*}{$\begin{array}{l}\text { Bevacizumab } \\
\text { (Avastin) - } \\
\text { Oncology }\end{array}$} & $\begin{array}{l}\text { In Australia, the pricing authority signed special pricing arrangements, whose content is } \\
\text { not publicly available }\end{array}$ \\
\hline & $\begin{array}{l}\text { Germany: an agreement was signed between the company and several SHI funds } \\
\text { according to which patients were allowed to receive bevacizumab + placlitaxel for breast } \\
\text { cancer and metastatic renal cell carcinoma, to assess survival gains in real life. The } \\
\text { company was supposed to refund part of all costs beyond a certain dose threshold, } \\
\text { which was in fact rarely met. }\end{array}$ \\
\hline & $\begin{array}{l}\text { Italy (AIFA): the medicine is reimbursed for its } 4 \text { indications through combination of cost- } \\
\text { sharing (50\% after } 6 \text { weeks) and dose capping at } 11000 \mathrm{mg} / \mathrm{year}\end{array}$ \\
\hline & $\begin{array}{l}\text { Sweden (Stockholm): costs for an accumulated dose per patient beyond } 10000 \mathrm{mg} \text { paid } \\
\text { by the manufacturer. }\end{array}$ \\
\hline \multirow[t]{3}{*}{$\begin{array}{l}\text { Cetuximab } \\
\text { (Erbitux) - } \\
\text { Oncology }\end{array}$} & $\begin{array}{l}\text { England (NICE): PAS for first line treatment of metastatic colorectal cancer (MCC): } 16 \% \\
\text { rebate on the amount Cetuximab used on a per patient basis } \\
\text { (NICE recommended the use of cetuximab in combination with radiotherapy for the } \\
\text { treatment of locally advanced squamous cell cancer of the head and neck, without PAS, } \\
\text { but did not recommend use in the treatment of recurrent and/or metastatic squamous } \\
\text { cell cancer of the head and neck). }\end{array}$ \\
\hline & $\begin{array}{l}\text { Scotland (SMC): PAS for the treatment of metastatic colorectal cancer in combination } \\
\text { with chemotherapy for a selection of patients: undisclosed discount on acquisition costs }\end{array}$ \\
\hline & $\begin{array}{l}\text { Italy (AIFA): Risk-Sharing for treatment of metastatic colorectal cancer (MCC): } 50 \% \\
\text { reimbursement in case of therapeutic failure within } 2 \text { months/ } 8 \text { weeks of treatment and } \\
\text { Payment by results for the treatment of recurrent and/or metastatic squamous cell } \\
\text { cancer of the head and neck: full reimbursement in case of therapeutic failure within } 6 \\
\text { weeks of treatment. }\end{array}$ \\
\hline
\end{tabular}




\begin{tabular}{|c|c|}
\hline \multirow[t]{4}{*}{$\begin{array}{l}\text { Sunitinib (Sutent) - } \\
\text { Oncology }\end{array}$} & $\begin{array}{l}\text { England (NICE): PAS for treatment of advanced or metastatic renal cell carcinoma } \\
\text { (RCC) or gastro-intestinal stromal tumours (GIST), the manufacturer offers the first cycle } \\
\text { of treatment with sunitinib free of charge to the NHS. }\end{array}$ \\
\hline & $\begin{array}{l}\text { Scotland (SMC): PAS for treatment of gastrointestinal stromal tumour (GIST): } \\
\text { Each patient receives one cycle of sunitinib free of charge. }\end{array}$ \\
\hline & $\begin{array}{l}\text { Italy (AIFA) - Cost sharing for treatment of advanced or metastatic renal cell carcinoma } \\
\text { (RCC): the company provides the first treatment cycle for free; } \\
\text {-Sunitinib is recommended for the treatment of gastrointestinal stromal tumour (GIST) }\end{array}$ \\
\hline & $\begin{array}{l}\text { In Australia the pricing authority signed special pricing arrangements, but its content is } \\
\text { not publicly available }\end{array}$ \\
\hline \multirow{2}{*}{$\begin{array}{l}\text { Fingolimod } \\
\text { (Gilenya) - Multiple } \\
\text { sclerosis }\end{array}$} & $\begin{array}{l}\text { In Australia the pricing authority signed special pricing arrangements, but its content is } \\
\text { not publicly available }\end{array}$ \\
\hline & $\begin{array}{l}\text { England (NICE): The manufacturer provides a discount on the list price of fingolimod. } \\
\text { The size of the discount is commercial in confidence. }\end{array}$ \\
\hline \multirow[t]{4}{*}{$\begin{array}{l}\text { Ranibizumab - } \\
\text { Lucentis } \\
\text { (age-related } \\
\text { macular } \\
\text { degeneration) }\end{array}$} & $\begin{array}{l}\text { England (NICE): in a first PAS agreement signed in 2008, the cost of ranibizumab } \\
\text { beyond } 14 \text { injections in each treated eye was met by the manufacturer. The most recent } \\
\text { agreement proposed by the company and signed in } 2012 \text { consists in an undisclosed } \\
\text { discount. }\end{array}$ \\
\hline & Scotland (SMC): PAS, simple discount, kept confidential. \\
\hline & $\begin{array}{l}\text { Italy (AIFA): Payment by result, i.e. full reimbursement in case of therapeutic failure } \\
\text { within } 3 \text { months of treatment ( } 3 \text { injections) }\end{array}$ \\
\hline & $\begin{array}{l}\text { In Australia the pricing authority signed a special pricing arrangement, but its content is } \\
\text { not publicly available }\end{array}$ \\
\hline $\begin{array}{l}\text { Dabigatran } \\
\text { (Pradaxa) }\end{array}$ & $\begin{array}{l}\text { Italy (AIFA): Manufacturer is required to pay back the treatment costs exceeding the } \\
\text { expenditure ceiling of EUR } 3.2 \text { million in the } 24 \text { months following the decision. }\end{array}$ \\
\hline \multirow{2}{*}{$\begin{array}{l}\text { Eculizumab - } \\
\text { (Soliris) Orphan } \\
\text { drug }\end{array}$} & $\begin{array}{l}\text { France (2008): budget ceiling beyond which the company agreed to provide the } \\
\text { medicine free of charge }\end{array}$ \\
\hline & Italy (AIFA): the manufacturer pays for the two initial packages; \\
\hline \multirow{2}{*}{$\begin{array}{l}\text { Sitagliptin/metformi } \\
\text { n } \\
\text { (Type } 2 \text { diabetes, to } \\
\text { improve the control } \\
\text { of blood glucose } \\
\text { levels) }\end{array}$} & $\begin{array}{l}\text { France (CEPS)*: Performance-based agreement: the product is claimed to ensure a } \\
\text { more durable control of glycemia than another association (metformin/sulfamides). If this } \\
\text { result is not demonstrated in the observational study, the price will be reduced and the } \\
\text { company will pay a rebate to compensate the price premium granted. }\end{array}$ \\
\hline & Italy (AIFA): Price-volume agreement with pay-back from manufacturers. \\
\hline \multicolumn{2}{|c|}{$\begin{array}{l}\text { Note: *This type of agreement is in principle confidential but was disclosed by the President of CEPS (quoted in de Pouvourville G } \\
\text { and L. Mongrédien (2012) }\end{array}$} \\
\hline \multicolumn{2}{|c|}{ Sources : OECD survey, Espin et al., 2011; Pugatch et al., 2010} \\
\hline
\end{tabular}

\section{What happens when products have different indications with very different benefits?}

137. Experts and stakeholders advocating for value-based pricing have often raised the problem of pricing drugs with several indications with very different cost-effectiveness. In response to the questions raised by the English Department of Health on this matter, economists from York University showed that the best solution in such cases was to price the medicines at a unique price, set at the average of ICERs (Claxton et al., 2011). From a practical point of view, it seems also more convenient and involves less need for a complex monitoring system.

138. Where prices are regulated, products usually do have a unique listed price, which does not vary across indications. This is the case in France, Italy or Belgium, but also in Australia, where the Australian Pricing authority sets an average price, based on expected volumes for each indication.

139. However, the existence of product-specific agreements, when used only for certain indications of a product, is a way to use price discrimination across indications (see box 7). In Italy for instance, sunitinib is reimbursed at the listed price for the GIST indication, but subject of a cost-sharing agreement reducing its price when used in the treatment of renal carcinoma. 


\section{How does international benchmarking interfere with value-based pricing?}

140. International benchmarking or external reference price (ERP) has been widely used in OECD countries to regulate the prices or reimbursement prices of pharmaceuticals (OECD, 2008; Leopold et al., 2012). Eleven case-study countries currently benchmark their prices -or at least some of them- against prices in other countries: Belgium, Canada, Denmark, France, Germany, Italy, Japan, Korea, the Netherlands, Norway and Spain. In these countries, international benchmarking is either used as the main criterion or as supportive information for price setting. Australia, Sweden and the United Kingdom do not use ERP. In 2009, Denmark decided to introduce ERP only for new medicines in the hospital sector. Since 2011, Germany uses ERP as supportive information for innovative medicines for the price review after one year (see table 13).

Table 13. International price benchmarking in OECD countries

\begin{tabular}{|c|c|c|c|c|}
\hline \multirow[t]{2}{*}{ Countries } & \multicolumn{2}{|c|}{ International benchmarking } & \multicolumn{2}{|c|}{ Calculation of reference price } \\
\hline & Adoption depth of EPR & Scope & Price basis & Calculation \\
\hline Australia & \multicolumn{4}{|l|}{ Not used } \\
\hline Belgium & Supportive information & All medicines & Ex-factory & $\begin{array}{l}\text { Average of all } \\
\text { countries }\end{array}$ \\
\hline Canada & Main criterion & $\begin{array}{l}\text { Innovative patented } \\
\text { medicines }\end{array}$ & Ex-factory & Median price \\
\hline Denmark & Main criterion & New hospital drugs & & $\begin{array}{l}\text { The price should not } \\
\text { exceed the average } \\
\text { prices comparable } \\
\text { European countries }\end{array}$ \\
\hline France & Main criterion & Innovative medicines & Ex-factory & $\begin{array}{l}\text { Price should be } \\
\text { consistent with } \\
\text { prices of foreign } \\
\text { countries }\end{array}$ \\
\hline Germany & \multicolumn{4}{|l|}{ Supportive information } \\
\hline Italy & Supportive information & Reimbursed medicines & Ex-factory & $\begin{array}{l}\text { Average of all } \\
\text { countries }\end{array}$ \\
\hline Japan & Supportive information & Reimbursed medicines & List price & $\begin{array}{l}\text { Average of } 4 \\
\text { countries }\end{array}$ \\
\hline Korea & $\begin{array}{l}\text { One of the criteria for } \\
\text { price negotiation }\end{array}$ & Reimbursed medicines & n.a. & $\begin{array}{l}80 \% \text { or less of the } \\
\text { lowest among the } \\
\text { prices when there } \\
\text { are no more than } 3 \\
\text { countries that can } \\
\text { be compared }\end{array}$ \\
\hline Netherlands & Main criterion & Prescription-only-medicines & Pharmacy retail & $\begin{array}{l}\text { Average of all } \\
\text { countries }\end{array}$ \\
\hline Norway & Main criterion & Prescription-only-medicines & Pharmacy retail & $\begin{array}{l}\text { Average of } 3 \\
\text { countries }\end{array}$ \\
\hline Spain & Main criterion & Innovative medicines & Ex-factory & $\begin{array}{l}\text { Not pre-defined, } \\
\text { often in Euro zone. }\end{array}$ \\
\hline Sweden & \multicolumn{4}{|c|}{ Not used (abolished in 2002) } \\
\hline $\begin{array}{l}\text { United } \\
\text { Kingdom }\end{array}$ & \multicolumn{4}{|l|}{ Not used } \\
\hline
\end{tabular}


141. Table 14 below shows the composition of the baskets of countries for each case-study country using EPR. Italy, Korea and Spain do not specify the countries in the basket and decide on an ad hoc basis. In Italy, EPR is used only as supportive tool when setting drug prices of new medicines and the countries basket is not specified. However, from March 2011, reference prices for off-patent drugs have been set referring to prices observed in Germany, United Kingdom, France and Spain. Spain refers to all countries using the Euro. Korea refers to some OECD countries but also to other countries.

142. Some countries define detailed methodologies for the calculation of reference prices and the most common procedure used is to take the average of prices observed in countries included in the basket (Belgium, Italy and the Netherlands). Norway defines the average of the three lowest priced countries as the reference price and Korea refers to the lowest among the prices when there are no more than 3 countries that can be compared and sets the price at $80 \%$ or less of this price. In France, prices are only required to be "consistent" with prices in comparator countries, which leave room for case-by-case negotiations between authorities and manufacturers.

143. International benchmarking continues to play an important role in price regulation, at least in some market segments. At first sight, this strategy does not seem completely consistent with the idea of paying for value. There are many reasons for the "value" of new products to differ across countries, because of the perspective adopted to assess value (payer vs. societal) but also because of differences in the use and prices of other health care inputs. This would imply different willingness-to-pay and different prices across countries, which appear contradictory with international benchmarking. However, the way international benchmarking is used (supportive information), the choice of countries included in the basket, and the way the foreign-based reference prices are computed, is likely to allow some flexibility when setting or negotiating prices. Nevertheless, the increased use of value-based pricing in the most referenced countries will clearly have an impact on prices paid elsewhere. 
Table 14. International benchmarking for price regulation ${ }^{6,7}$

\begin{tabular}{|c|c|c|c|c|c|c|c|c|c|c|c|c|c|c|}
\hline $\begin{array}{l}\text { Case-study } \\
\text { countries }\end{array}$ & $\begin{array}{l}\frac{\pi}{\pi} \\
\frac{\pi}{2} \\
\frac{0}{2} \\
\frac{0}{4}\end{array}$ & $\frac{5}{\frac{5}{5}}$ & $\begin{array}{l}\frac{\mathbb{N}}{0} \\
\underset{\mathbb{N}}{\mathbb{N}} \\
\mathcal{J}\end{array}$ & ํㅗㅀ & 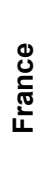 & 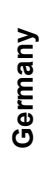 & $\underset{ \pm}{\stackrel{\lambda}{ \pm}}$ & $\begin{array}{l}\text { 동 } \\
\stackrel{\circ}{\frac{0}{\sigma}}\end{array}$ & $\begin{array}{l}\mathbb{d} \\
\dot{0}\end{array}$ & $\begin{array}{l}\frac{n}{0} \\
\frac{c}{c} \\
\frac{D}{2} \\
\frac{d}{c} \\
\stackrel{ \pm}{2}\end{array}$ & $\begin{array}{l}\text { ते } \\
\text { zo } \\
\mathbf{z}\end{array}$ & 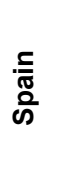 & $\begin{array}{l}\frac{c}{0} \\
\frac{0}{0} \\
\sum_{\infty}^{\circ}\end{array}$ & 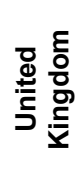 \\
\hline \multicolumn{15}{|l|}{ Austria } \\
\hline Belgium & & - & & & & & & & & & & & & \\
\hline \multicolumn{15}{|l|}{ Czech Republic } \\
\hline Denmark & & & & - & & & & & & & & & & \\
\hline \multicolumn{15}{|l|}{ Estonia } \\
\hline \multicolumn{15}{|l|}{ Finland } \\
\hline \multicolumn{15}{|l|}{ Hungary } \\
\hline \multicolumn{15}{|l|}{ Ireland } \\
\hline Italy & & & & & & & - & & & & & & & \\
\hline \multicolumn{15}{|l|}{ Latvia } \\
\hline \multicolumn{15}{|l|}{ Lithuania } \\
\hline \multicolumn{15}{|l|}{ Luxembourg } \\
\hline \multicolumn{15}{|l|}{ Malta } \\
\hline Netherlands & & & & & & & & & & - & & & & \\
\hline \multicolumn{15}{|l|}{ New Zealand } \\
\hline \multicolumn{15}{|l|}{ Switzerland } \\
\hline United Kingdom & & & & & & & & & & & & & & - \\
\hline United States & & & & & & & & & & & & & & \\
\hline
\end{tabular}

Note: Spain has not defined the basket of countries, but usually refers to countries within the Eurozone. Italy and Korea have not defined the basket of countries they refer to and act on an ad hoc basis.

Source: Leopold et al. (2012) and country profiles

6. Note by Turkey: The information in this document with reference to « Cyprus » relates to the southern part of the Island. There is no single authority representing both Turkish and Greek Cypriot people on the Island. Turkey recognizes the Turkish Republic of Northern Cyprus (TRNC). Until a lasting and equitable solution is found within the context of the United Nations, Turkey shall preserve its position concerning the "Cyprus issue".

7. Note by all the European Union Member States of the OECD and the European Commission: The Republic of Cyprus is recognised by all members of the United Nations with the exception of Turkey. The information in this document relates to the area under the effective control of the Government of the Republic of Cyprus." 


\section{CONCLUSIONS}

144. The main objective of this report was to explore value-based pricing for pharmaceuticals. In principle, value-based pricing (VBP) can offer better value-for-money for purchasers of pharmaceuticals. It also gives clear signals to pharmaceutical companies that they will be rewarded if their products address the priorities of the purchasers, so in the longer run may reorient pharmaceutical innovation in a more costeffective direction. However, it is easier to talk of rewarding 'value' than it is actually to do so. Is it value to the purchaser that should be the basis of decisions (i.e. some combination of the increase in health and the reduction in other health spending) or the value to society (which would also take into account increased labour force productivity of those who are less sick and those who no longer care for others, amongst other things)? Is there 'value' in innovation itself? Countries which use value-based pricing for pharmaceuticals do not make the same choices as to how to determine value. Furthermore, countries which do not have value-based pricing per se may take into account some of the elements used in economic assessments of value in making their decisions. This report attempts to shed light on what impact these different choices make to reimbursement decisions and prices.

145. Ideally this would be done by comparing actual prices paid for a set of pharmaceuticals. However, unsurprisingly, gathering information on actual prices paid by purchasers in case-study countries was not possible in many cases. For products used in inpatient care and financed through hospital payments (i.e. not on top of DRG- or other types of hospital payments), prices are most often not regulated at all but negotiated between purchasers and suppliers. Canada is an exception, as it regulates the maximum selling price of all patented products, but prices actually paid by hospitals are however not known even there. For other products in our sample, the existence of so called risk-sharing agreements, publicly available or confidential in nature, often makes it impossible to determine the average price actually paid by purchasers.

146. This report nevertheless does answer some of the questions raised in the objectives of the study. The first, and by no means trivial, conclusion is that the type of health outcomes considered by assessment bodies and decision-makers to inform or make decisions on reimbursement seem to have more in common with each other than differences. Of course countries would prefer that these outcomes were final endpoints such as overall survival, but in practice, assessment bodies can only rely on information available at the time of assessment and often accept surrogate markers to formulate recommendations. They require, however, that a clear link is established between surrogate markers and final outcomes. When cost-effectiveness plays a crucial role in the recommendation, incremental cost-effectiveness ratios always take the form of incremental cost per QALY gained, which means that overall, years of life gained, as assessed in clinical trials or derived from modelling, is the main outcome of interest.

147. One substantial difference between the case-study countries is whether they take into account utility for patients as a measure of outcome. Typically, countries using economic evaluation consider utility (Australia, Canada, Sweden, Norway and the United Kingdom) while other countries (e.g. France or Italy) do not. This is expected to have an impact on reimbursement decisions, price levels and relative prices of different categories of products. From the sample of countries and products scrutinized, it was not possible to identify such an impact.

148. Countries show different attitudes towards uncertainty and those using economic evaluation seem more likely to reject applications for funding when they consider that the level of uncertainty pertaining to 
efficacy, effectiveness or even costs is too high. One of the great advantages of economic evaluations is that they most often include sensitivity analyses which make risks linked to uncertainty more explicit. In the absence of economic evaluation, decision-makers may have little means for assessing risk in any formal way, and so - perhaps - underestimate its extent.

149. Although there are, in theory, relatively large differences in the definition of what should be included in 'value' and what should be excluded across countries; in practice it is not obvious that these make a substantial difference to the outcomes of the decision-making process. Several case-study countries conduct economic analysis from a societal perspective, which might be expected to enhance the assessed value of clinically-effective products. However, in practice the wider social perspective is often not included. Among the sample of products scrutinised, the consideration of indirect non-medical costs was rare, except in Sweden, and its real impact on price impossible to determine.

150. Many countries see value-based pricing as a way of promoting real innovation, as opposed to marginal adaptation of existing products. This study therefore attempted to document which aspects of innovation are considered in practice. The added therapeutic value of new products is the key element taken into account to grant a price premium over competitors or allow incremental costs. Changes in the process of care have been explicitly considered by several countries, as an advantage for patients in at least two cases in our sample of products, though without impact on the final endpoint. In one case, the change in the process of care generating savings for public payers justified a premium over the price of the comparator. Apart from that, we found no evidence that innovation "beyond therapeutic value" is considered in practice to make reimbursement or price decisions. This might, of course, be simply because the sample of products chosen did not capture all the nuances of the decision-making process. Perhaps other products have benefitted from the wider considerations being taken into account.

151. Another question addressed by this study is whether disease severity or rarity receives particular attention, justifying higher prices or incremental cost-effectiveness ratios (ICER) in case-study countries. The answer is clearly that they do. Countries using economic evaluation usually accept higher ICERs when there is a high clinical need. ICERs accepted may be twice as large as the usual (implicit) ICER thresholds in some occasions. While some countries have explicitly defined criteria that should be taken into account (e.g. NICE with the end-of-life criteria), others do not seem to have pre-defined rules. Countries that do not use economic evaluations are also more likely to accept high prices in similar circumstances.

152. Countries have so far been reluctant to set a definitive cost-effectiveness threshold. It is easy to understand why. If they were to announce a cost-effectiveness threshold, companies would have incentives to adjust their price in order to meet this threshold in all circumstances. This could involve reductions in prices (broadly, a good thing for consumers) for some products, but also increasing prices for others. Hence, setting a threshold and announcing it publicly would be a major step to take. In addition, analysts do not agree on how such a threshold should be set and some of them suggest that it should not be determined from first principles, but instead be set empirically, by reference to the current allocation of money in the health system.

153. When medicines are approved for several indications which display very different costeffectiveness ratios, countries have adopted different attitudes. Most often, the price of the medicine is unique and countries make a "yes or no" decision for each indication. The price is often set at a level considered acceptable at the time of the first decision (for the first indication(s) reimbursed) and subsequently it is not reviewed when new indications are assessed for reimbursement purposes. In fact, if the new indication is not considered to be worth funding at this price, it may be rejected or it may be funded through a product-specific agreement equivalent to a price discount. This practice creates a sort of price discrimination across market segments defined for each indication, together with safeguards (for the company) that the discounted price will only be used for less beneficial indication. On the other hand, if 
the new indication is more cost-effective for the payer than the original usage (i.e. it has a lower cost per QALY gained), the application is accepted at the existing price. The price may even be reduced if the targeted population increases significantly.

154. This illustrates a more general point: for health systems as well as for pharmaceutical companies, price is not the only component of value. Very often, decision-makers have to trade-off prices against potential market sizes and are willing to extend indications in exchange for a lower price as long as benefits for patients are clearly showed. Negotiations of this type seem more likely to occur in systems not using a formal evaluation process.

155. The timing of assessment for recommendation or decision is likely to influence value. In a majority of case-study countries, applications for funding are assessed before effective market entry, which allows more flexibility for decision-makers, at least to reject decisions. In countries where the medicine has been marketed, it is more difficult to make hard decisions because of the endowment effect -the fact that doctors and patients are aware of the existence of a treatment and willing to use it at any price.

156. The conclusions listed so far relate more to differences in the practical implementation of valuebased pricing. However, there are of course potentially more systemic effects from such changes to the pricing system. One such potential impact is on countries which continue to price their pharmaceuticals on the basis of the price charged in other markets. As more reference countries move towards value-based pricing, their assessments of value will in effect be 'exported' to those countries using them as a reference. However, to the extent that 'value' is very much system-specific - depending on the particular cost structures of a health system - the use of reference pricing by country A of value-based prices in country B does not mean that country B will necessarily have prices which reflect value to country B.

157. Even this conclusion assumes that value-based pricing actually makes a difference to prices eventually charged. On this, the verdict is not yet clear. It is not yet possible to say that VBP is making a large difference compared to pricing decisions elsewhere. In part this may be because many of the features which VBP could be taking into account and which might make a large difference to the assessed value of medicines - such as a societal perspective - in practice seem to be being used very sparingly. This highlights a related issue, that the actual operation of VBP schemes is often relatively obscure. The practice of VBP often appears to be more of an art than a science. This flexibility in interpretation of VBP will inevitably reduce the impact of the introduction of VBP in the approach of pharmaceutical companies to innovation in the future. If they cannot be sure that, say, the societal effects of a new drug will be taken into account, they will put less weight on developing new products which might have such an impact. To that extent, VBP will be less effective in delivering its goals of balancing current costs with appropriate incentives for future innovation. There is a case for greater clarity and hence certainty in the application of VBP - otherwise, its potential benefits over a less structured negotiation process are far from apparent. 


\section{REFERENCES}

Adamski, J. (2010), Risk sharing arrangements for pharmaceuticals: potential considerations and recommendations for European payers. Adamski, J. et al. BMC Health Services Research 2010, $10: 153$

Bagshaw, S. and R. Bellomo (2008), The need to reform our assessment of evidence from clinical trials: A commentary. Philos Ethics Humanit Med. 2008; 3: 23

Department of Health (2010), A new value-based approach to the pricing of branded medicines - $A$ consultation, Department of Health, London

de Pouvourville, G. and L. Mongrédien (2012), L'accès au marché remboursé pour les medicaments: les contrats de partage des risqué fondés sur les resultants", ESSEC Business School, Collège des économistes de la santé.

Drummond, M.F. et al. (2005), Methods for the economic evaluation of health care programmes, Drummond M. F., et al., Oxford University Press, 2005

CADTH (2006), Guidelines for the economic evaluation of health technologies: Canada, Third Edition, Canadian Agency for Drugs and Technologies in Health, Ottawa.

CADTH (2009), Addendum to CADTH's Guidelines for the economic evaluation of health technologies: Specific guidance for oncology products, Canadian Agency for Drugs and Technologies in Health, Ottawa.

CADTH (2011), Common Drug Review Submission Guidelines for Manufacturers - November 2011 Submission guidelines for $1^{\text {st }}$ treatment for disease/disorder or $1^{\text {st }}$ to be listed - Canadian Agency for Drugs and Technologies in Health, Ottawa http://www.cadth.ca/media/cdr/process/CDR_Submission_Guidelines_e.pdf

Carlson, J.J. et al. (2010), "Linking Payment to Health Outcomes: A Taxonomy and Examination of Performance-based Reimbursement Schemes Between Health Care Payers and Manufacturers", Health Policy, in press.

Claxton, K. (2007), OFT, VBP: QED?, Health Economics 16(6): 545-558.

Claxton, K et al. (2008), Value based pricing for NHS drugs: an opportunity not to be missed? British Medical Journal 336: 251-254.

Claxton, K., M. Sculpher and S. Carroll (2011), Value-based pricing for pharmaceuticals: its role, specification and prospects in a newly devolved NHS, CHE Research Paper No. 60, Centre for Health Economics, University of York.

CVZ (2006), Guidelines for pharmacoeconomic research, updated version. College voor zorgverzekeringen, Diemen - March 2006 


\section{DELSA/HEA/WD/HWP(2013)4}

Espin, J., J. Rovira and L. García (2011), Experiences and impact of European Risk-sharing Schemes focusing on oncology medicines, Andalusian School of Public Health, Granada

Garattini, L. and G. Casadei (2011), Risk sharing agreements: what lessons from Italy? International Journal of Technology Assessment in Health Care. 2011 Apr;27(2):169-72.

Haute Autorité en Santé (2011), Choix méthodologiques pour l'évaluation économique à la HAS - Guide méthodologique, Haute Autorité de santé, Paris.

Health Affairs (2010), Designing Insurance To Improve Value In Health Care, Vol. 29; N¹1.

Henry, D.A., S. Hill, R. Hill, and A. Harris (2005), Drug Prices and Value for Money - The Australian Pharmaceutical Benefits Scheme, JAMA, Vol. 294, No. 20, pp. 2630-2632.

Hinterhuber, A. (2008), Customer value-based pricing strategies: why companies resist, Journal of Business Strategy, Vol. 29, No. 4, pp. 41-50.

Hugosson, K, and A. Engstrom (2008). Threshold value for a QALY - correlation with disease severity and decision uncertainty. Pharmaceutical Benefits Board, Solna, Sweden. Poster presented at ISPOR 13th Annual international meeting, Toronto.

Hurley, J. (2000), An overview of the normative economics of the health sector, Chapter 2 in Handbook of Health Economics, Vol. 1, pp 55-118, Elsevier

Husereau, D. and C. Cameron (2011) Value-Based Pricing of Pharmaceuticals in Canada: Opportunities to Expand the Role of Health Technology, Canadian Health Services Research Foundation, Paper No. 5.

Institute of Medicine (2010), Evaluation of Biomarkers and Surrogate Endpoints in Chronic Disease, Academy Press.

IQWiG (2009), General Methods for the Assessment of the Relation of Benefits to Costs - Version 1.0 dated 19/11/2009, German national institute for quality and efficiency in health care.

Johannesson, M. et al. (2009), Why should economic evaluations of medical innovation have a societal perspective?, OHE Briefing, No. 51, Office of Health Economics, London.

KCE (2008), Threshold values for cost-effectiveness in health care, KCE reports $100 \mathrm{C}$, Belgian Health Care Knowledge Centre, Brussels.

KCE (2008), Guidelines for pharmacoeconomic evaluations in Belgium, KCE reports 78C

KCE (2009), Policies for Orphan Diseases and Orphan Drugs, Belgian Health Care Knowledge Centre, $\mathrm{KCE}$ reports $112 \mathrm{C}$

Koopmanschap, M.A., et al. (1995), The friction cost method for measuring indirect costs of disease. Journal of Health Economics 14, 171189

Le Polain, M., M. Franken, M. Koopmanschap and I. Cleemput (2010), "Drug reimbursement systems: international comparison and policy recommendations", KCE reports 147C, Belgian Health Care Knowledge Centre. 
Leopold, C. et al. (2012), Differences in external price referencing in Europe: a descriptive overview Health Policy, 104(1):50-60

Liozu, S. et al. (2011), The conceptualization of value-based pricing in industrial firms, Journal of Revenue and Pricing Management, Vol. 11, No. 1, 12-34

Mauskopf, J. et al. (2011), Differences among formulary submission guidelines: Implications for health technology assessment, International Journal of Technology Assessment in Health Care, Vol. 27, pp 261-270

NICE (2008), Guide to the Methods of Technology Appraisals (June 2008), National Institute for Health and Clinical Excellence.

NICE (2008), Social Value Judgements: Principles for the Development of NICE Guidance, NICE, London.

NICE (2009), Appraising Life-extending, end-of-life Treatments, NICE, London.

The Norwegian Medicines Control Authority (2005), Norwegian Guidelines for Pharmacoeconomic Analysis in Connection with Applications for Reimbursement.

OECD (2008), Pharmaceutical pricing in a global market, Organisation for Economic Cooperation and development, Paris.

OECD (2010), Value for money in health spending, OECD, Paris.

OFT - Office of Fair Trading (2007), The Pharmaceutical Price Regulation Scheme - An OFT market study, OFT, London.

Paris, V., M. Devaux and L. Wei (2010), Health Institutional Characteristics: A Survey of 29 OECD Countries, OECD Health Working Papers, No. 50.

PBAC (2008), Guidelines for Preparing Submissions to the Pharmaceutical Benefits Advisory Committee December 2008, Pharmaceutical Benefits Advisory Committee ${ }^{8}$

pERC (2011); pCODR Expert Review Committee Deliberative Framework. March 2011

Petticrew, M. and H. Roberts (2003) Evidence, hierarchies, and typologies: horses for courses. J Epidemiol Community Health, Vol. 57, No. 7, pp. 527-529

Pharmaceutical Benefits Board (2003), General guidelines for economic evaluations from the Pharmaceutical Benefits Board (2003) -

http://www.ispor.org/peguidelines/source/Guidelines in_Sweden.pdf

Pugatch, M., P. Healy and R. Chu (2010), Sharing the Burden: Could risk-sharing change the way we pay for healthcare?, The Stokholm Network, London.

8.

http://www.health.gov.au/internet/main/publishing.nsf/content/AECB791C29482920CA25724400188EDB \$\$File/PBAC4.3.2.pdf 
Rocchi, A. et al. (2008), The Role of Economic Evidence in Canadian Oncology Reimbursement DecisionMaking:To Lambda and Beyond, Value in Health, Vol. 11; No. 4., pp. 771-83

Scottish Medicines Consortium (2007), Guidance to Manufacturers for Completion of New Product Assessment Form (NPAF) - Revised June 2007, PartC: Guidance NPAF Economic Sections (Sections 6 and 7).

Sculpher, M. (2001), The role and estimation of productivity costs in economic evaluation. In: Drummond M, McGuire A (eds). Economic evaluation in health care - Merging theory with practice. Oxford: Oxford University Press

Sorenson, C., M. Drummond and P. Kanavos (2008), Ensuring value for money in health care: the role of health technology assessment in the European Union, European Observatory on Health Systems and Policies, Copenhagen.

van de Wettering, E.J., E.A. Stolk, N.J.A. van Exel and W.B.F. Brouwer (2013), Balancing equity and efficiency in the Dutch basic benefits package using the principle of proportional shortfalls, European Journal of Health Economics, Vol. 14, pp. 107-115.

Walker, S., M. Sculpher, K. Claxton and S. Palmer (2012), Coverage with evidence development, only in research, risk sharing or patient access scheme? A framework for coverage decisions, Value in Health, Vol. 15, pp. 570-579.

Wilsdon, T. and A. Serota (2011), A comparative role and impact of health technology assessment, Charles River Associates, London

Yim, E.S. et al. (2012), Assessment of pharmacoeconomic evaluations submitted for reimbursement in Korea, Value in Health, Supplement, pp. 104-110. 


\section{ANNEX 1: BACKGROUND INFORMATION ON CASE-STUDY COUNTRIES*}

158. This annex describes the environment in which reimbursement and pricing policies take place in case-study countries. It presents data on pharmaceutical expenditure trends and financing, as well as information on user participation to pharmaceutical costs.

\section{Trends in pharmaceutical spending ${ }^{9}$}

159. In 2010, OECD countries devoted on average $16.7 \%$ of their health expenditure to pharmaceuticals (see Figure 1). Wide variations exist across countries, with expenditures for pharmaceuticals accounting for more than $25 \%$ of total health spending in Hungary, Mexico, the Slovak Republic and Turkey, and for less than $10 \%$ in countries like Switzerland, the Netherlands, New-Zealand, Demark and Norway. As a share of GDP, pharmaceutical spending is particularly high in Hungary, the Slovak Republic, Greece and the United States where it exceeds $2 \%$. By contrast, it only accounts for just over $0.6 \%$ of GDP in Norway and Luxembourg. Case-study countries are different in term of pharmaceutical expenditure but none of them belong to the very high-spending group.

160. When OECD countries are ranked according to spending per capita, the relative position of casestudy countries is slightly different: while Denmark and Norway remain in the low-spending group, Canada, Germany, France and Belgium emerge as high spenders (See Figure 2). In 2010, the OECD average per capita pharmaceutical spending was of USD\$PPP 480. The United States was by far the highest spender, with a spending level twice as large as the OECD average, followed by Canada. Casestudy countries display various levels of spending, from relatively high (Germany, France, Japan, Belgium), to relatively low (Norway and Denmark).

161. All OECD countries use a mix of public and private sources to pay for health care and pharmaceuticals but financing patterns vary widely across OECD countries (Figure 3). For pharmaceuticals, the share of public financing in total expenditures ranged from $19 \%$ in Mexico to $84 \%$ in Luxembourg in 2010. The public sector remains the major source of pharmaceutical financing in all OECD countries except in Mexico, the United States, Canada, Poland, Iceland, Hungary, Italy and Estonia. Casestudy countries represent different levels of public sector interventions since public financing accounts from 70 to $79 \%$ of pharmaceutical spending in Spain, Japan, Germany and the Netherlands, from 60 to $69 \%$ in Portugal, Belgium, France and Switzerland, from 50 to $59 \%$ in Denmark, Australia, Norway, Sweden and Korea, and less than $50 \%$ in Italy (48\%) and Canada (38\%). Private financing includes both private health insurance payments and households' out-of-pocket payments, which can be distinguished in almost all countries in health expenditure data. Private health insurance plays a significant role in the United States, Canada, Slovenia and France. Out-of-pocket expenditures include both expenditures for non-reimbursed medicines (self-medication or non-reimbursable prescription drugs) and users' charges for drugs covered by public or private health insurance.

The statistical data for Israel are supplied by and under the responsibility of the relevant Israeli authorities. The use of such data by the OECD is without prejudice to the status of the Golan Heights, East Jerusalem and Israeli settlements in the West Bank under the terms of international law.

In the system of health accounts, pharmaceutical expenditure refers to expenditures for pharmaceuticals and other medical non-durable dispensed to outpatients. It includes prescribed medicines, over-the-counter medicines, as well as a range of medical non-durables such as bandages or elastic stockings. It does not include spending for pharmaceuticals dispensed in in-patient care. 
162. Between 2005 and 2010, real pharmaceutical expenditure growth has been lower, on average, than real health expenditure growth in OECD countries. From 2009 to 2010, the growth in pharmaceutical spending was negative $(-4.4 \%)$ for the first time (see table 14). Case-study countries are characterised by different patterns of pharmaceutical expenditure growth.

Figure 1. Pharmaceutical spending as a share of total health expenditure and GDP, 2010

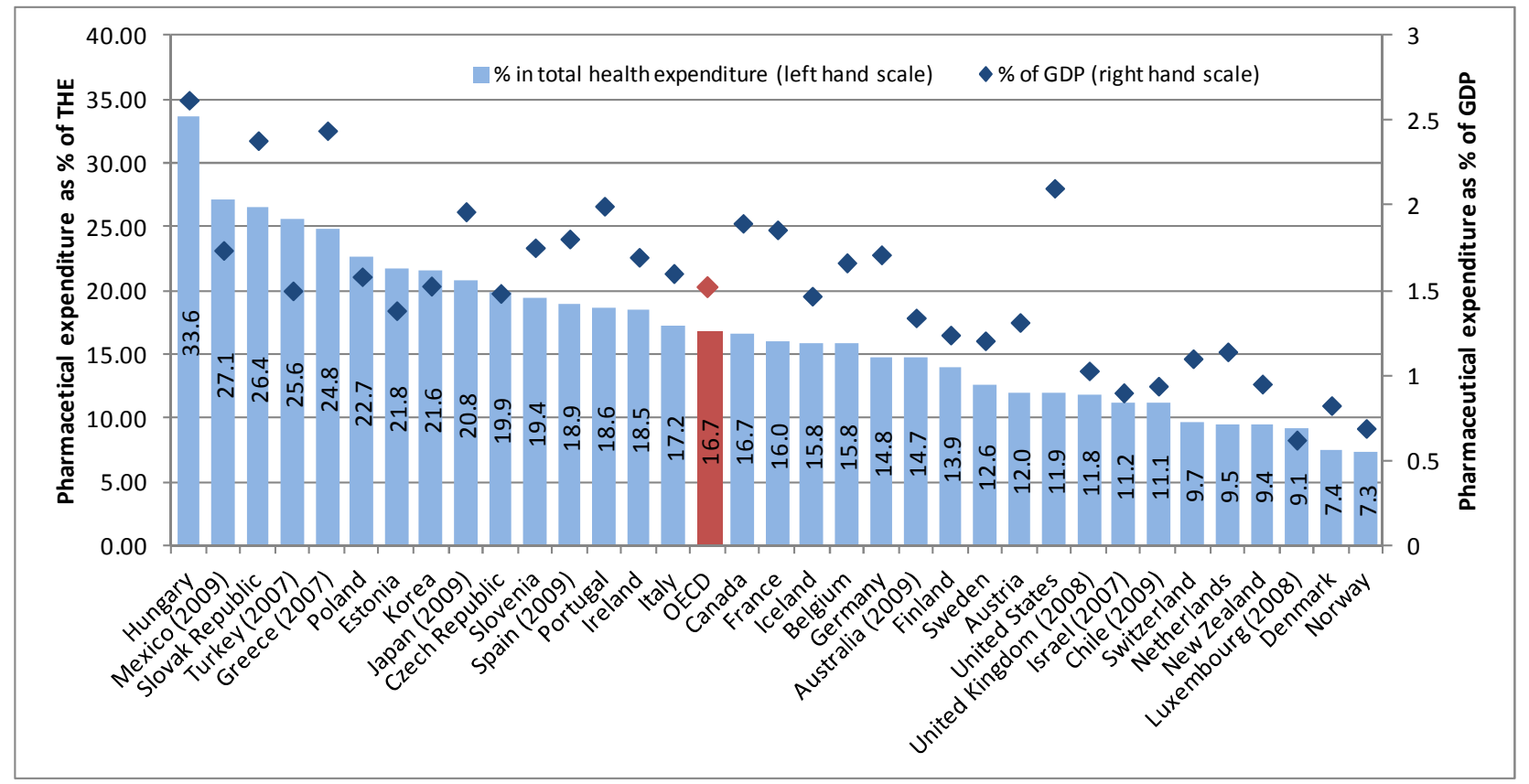

Source: OECD (2011), WHO-NHA database and OECD Secretariat's estimates. 
Figure 2. Per capita pharmaceutical spending, 2010

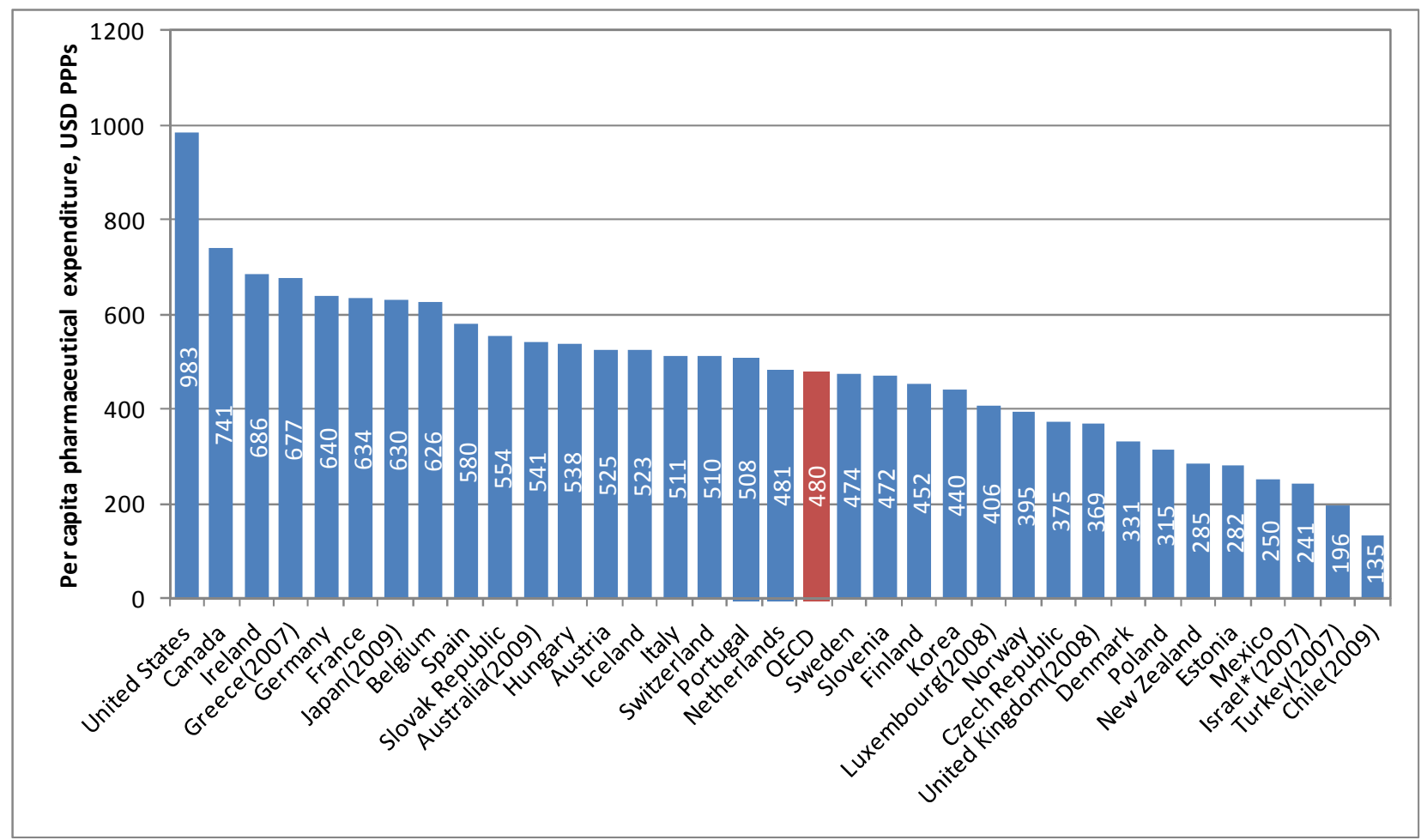

Source: OECD (2011), WHO-NHA database and OECD Secretariat's estimates.

Figure 3. Pharmaceutical spending funding, 2010

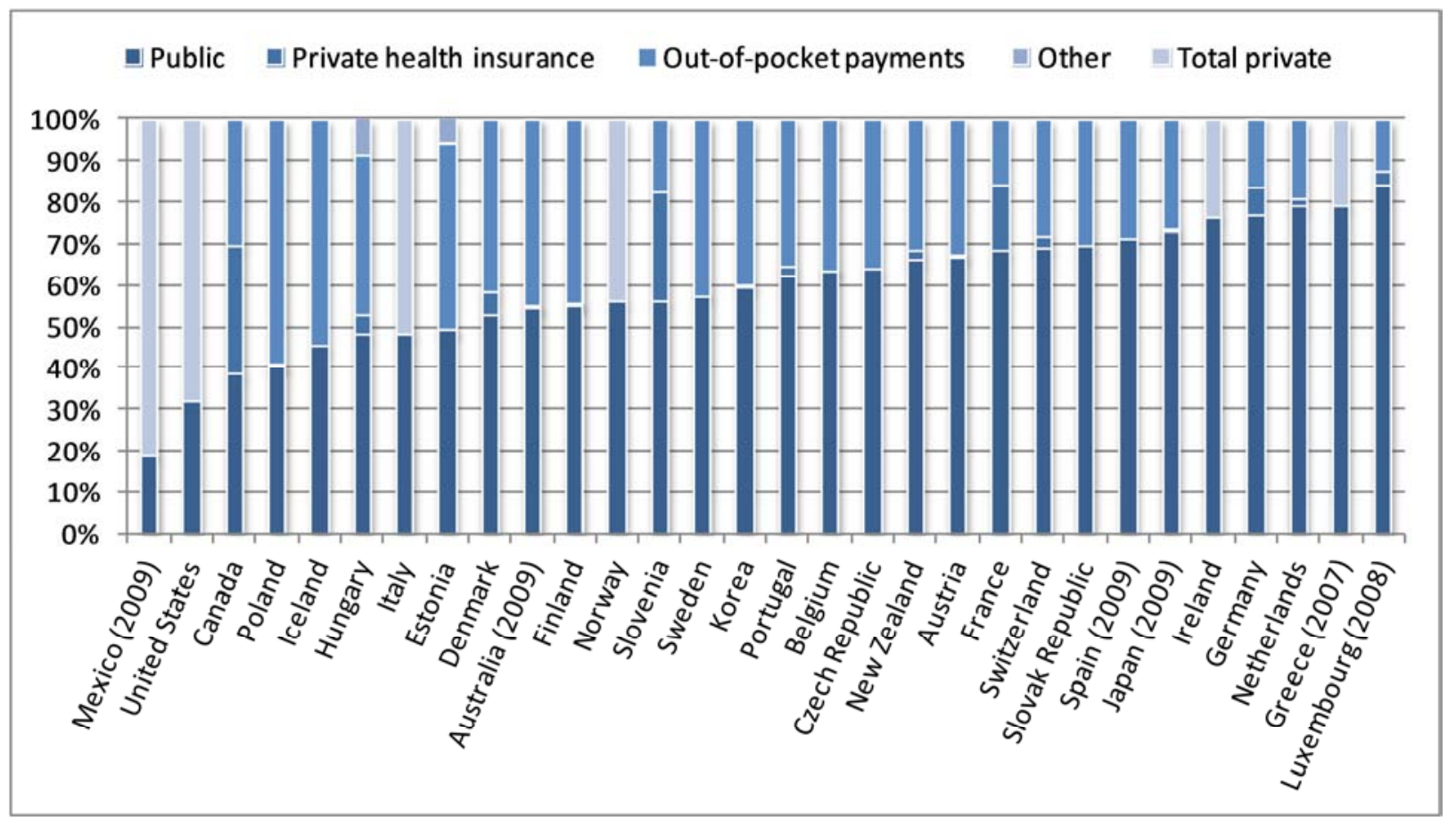

Source: OECD (2011), WHO-NHA database and OECD Secretariat's estimates. 
Table 15. Annual growth in real total health expenditure and real pharmaceutical expenditure 2005-2009

\begin{tabular}{|c|c|c|c|c|c|c|c|c|c|c|}
\hline \multirow[b]{2}{*}{ Country } & \multicolumn{5}{|c|}{ Total health expenditure } & \multicolumn{5}{|c|}{$\begin{array}{l}\text { Total expenditures on pharmaceuticals and medical } \\
\text { non-durables }\end{array}$} \\
\hline & $\begin{array}{l}2005- \\
2006 \\
\end{array}$ & $\begin{array}{l}2006- \\
2007 \\
\end{array}$ & $\begin{array}{l}2007- \\
2008 \\
\end{array}$ & $\begin{array}{l}2008= \\
2009 \\
\end{array}$ & $\begin{array}{l}2009- \\
2010 \\
\end{array}$ & $\begin{array}{l}2005- \\
2006\end{array}$ & $\begin{array}{l}2006- \\
2007\end{array}$ & $\begin{array}{l}2007- \\
2008\end{array}$ & $\begin{array}{l}2008- \\
2009\end{array}$ & $\begin{array}{l}2009- \\
2010\end{array}$ \\
\hline Australia & $3.9 \%$ & $4.1 \%$ & $4.6 \%$ & $6.4 \%$ & $\mathrm{~N} / \mathrm{A}$ & $4.0 \%$ & $4.2 \%$ & $6.4 \%$ & $7.6 \%$ & N/A \\
\hline Austria & $1.7 \%$ & $4.2 \%$ & $3.6 \%$ & $2.7 \%$ & $0.4 \%$ & $2.7 \%$ & $5.7 \%$ & $4.0 \%$ & $-5.1 \%$ & $-1.1 \%$ \\
\hline Belgium & $-2.5 \%$ & $3.2 \%$ & $5.0 \%$ & $3.7 \%$ & $1.1 \%$ & $-2.3 \%$ & $2.6 \%$ & $4.4 \%$ & $0.9 \%$ & $-0.3 \%$ \\
\hline Canada & $4.3 \%$ & $2.9 \%$ & $3.0 \%$ & $8.0 \%$ & $3.0 \%$ & $5.4 \%$ & $2.1 \%$ & $1.4 \%$ & $8.0 \%$ & $1.2 \%$ \\
\hline $\begin{array}{l}\text { Chile } \\
\text { Czech }\end{array}$ & $0.3 \%$ & $9.0 \%$ & $12.8 \%$ & $10.5 \%$ & $-0.8 \%$ & $-6.2 \%$ & $2.0 \%$ & $13.0 \%$ & $0.9 \%$ & N/A \\
\hline Republic & $3.3 \%$ & $3.0 \%$ & $7.8 \%$ & $11.7 \%$ & $-4.1 \%$ & $-5.1 \%$ & $-2.8 \%$ & $2.3 \%$ & $6.2 \%$ & $-1.5 \%$ \\
\hline Denmark & $5.0 \%$ & $2.2 \%$ & $1.2 \%$ & $5.9 \%$ & $-1.7 \%$ & $6.4 \%$ & $4.8 \%$ & $-5.0 \%$ & $-2.9 \%$ & $-0.5 \%$ \\
\hline Estonia & $10.0 \%$ & $10.6 \%$ & $12.6 \%$ & $-0.5 \%$ & $-7.3 \%$ & $8.3 \%$ & $0.7 \%$ & $8.9 \%$ & $12.8 \%$ & $-14.0 \%$ \\
\hline Finland & $3.4 \%$ & $1.5 \%$ & $3.5 \%$ & $1.1 \%$ & $0.9 \%$ & $-5.1 \%$ & $2.5 \%$ & $3.4 \%$ & $-2.7 \%$ & $-1.3 \%$ \\
\hline France & $1.9 \%$ & $2.1 \%$ & $-0.9 \%$ & $3.3 \%$ & $1.3 \%$ & $-0.5 \%$ & $2.8 \%$ & $-1.4 \%$ & $1.6 \%$ & $0.5 \%$ \\
\hline Germany & $2.0 \%$ & $1.7 \%$ & $3.2 \%$ & $4.1 \%$ & $2.6 \%$ & $0.1 \%$ & $3.6 \%$ & $3.1 \%$ & $3.3 \%$ & $1.7 \%$ \\
\hline Greece & $6.4 \%$ & $4.0 \%$ & $3.0 \%$ & $0.9 \%$ & $-6.5 \%$ & $12.3 \%$ & $13.9 \%$ & N/A & N/A & $\mathrm{N} / \mathrm{A}$ \\
\hline Hungary & $1.6 \%$ & $-7.0 \%$ & $-1.9 \%$ & $-3.4 \%$ & $2.0 \%$ & $3.7 \%$ & $-8.2 \%$ & $-0.1 \%$ & $0.9 \%$ & $5.5 \%$ \\
\hline Iceland & $1.2 \%$ & $5.5 \%$ & $1.6 \%$ & $-1.4 \%$ & $-7.5 \%$ & $-0.3 \%$ & $0.3 \%$ & $9.7 \%$ & $6.0 \%$ & $-6.6 \%$ \\
\hline Ireland & $4.8 \%$ & $8.0 \%$ & $11.3 \%$ & $3.5 \%$ & $-7.6 \%$ & $10.2 \%$ & $8.7 \%$ & $11.2 \%$ & $1.1 \%$ & $1.8 \%$ \\
\hline Israel & $1.4 \%$ & $5.3 \%$ & $5.3 \%$ & $-1.8 \%$ & N/A & N/A & $\mathrm{N} / \mathrm{A}$ & N/A & N/A & N/A \\
\hline Italy & $3.0 \%$ & $-2.1 \%$ & $1.7 \%$ & $-1.0 \%$ & $1.5 \%$ & $1.2 \%$ & $-4.5 \%$ & $-4.5 \%$ & $-3.6 \%$ & $-0.9 \%$ \\
\hline Japan & $1.7 \%$ & $2.4 \%$ & $2.7 \%$ & $4.2 \%$ & N/A & $0.3 \%$ & $4.4 \%$ & $0.3 \%$ & $11.5 \%$ & $\mathrm{~N} / \mathrm{A}$ \\
\hline Korea & $12.3 \%$ & $9.5 \%$ & $4.8 \%$ & $7.5 \%$ & $8.5 \%$ & $10.4 \%$ & $4.5 \%$ & $4.0 \%$ & $4.2 \%$ & $4.2 \%$ \\
\hline Luxembourg & $2.4 \%$ & $-1.9 \%$ & $-3.8 \%$ & $10.1 \%$ & N/A & $-1.6 \%$ & $1.2 \%$ & $-3.2 \%$ & N/A & $\mathrm{N} / \mathrm{A}$ \\
\hline Mexico & $1.7 \%$ & $5.1 \%$ & $2.4 \%$ & $2.8 \%$ & $1.5 \%$ & $5.3 \%$ & $12.7 \%$ & $2.7 \%$ & $-1.6 \%$ & $\mathrm{~N} / \mathrm{A}$ \\
\hline $\begin{array}{l}\text { Netherlands } \\
\text { New }\end{array}$ & $2.3 \%$ & $15.7 \%$ & $3.6 \%$ & $4.1 \%$ & $2.5 \%$ & N/A & $N / A$ & $-1.2 \%$ & $1.8 \%$ & $0.7 \%$ \\
\hline Zealand & $7.3 \%$ & $-0.4 \%$ & $7.4 \%$ & $8.6 \%$ & $3.4 \%$ & $13.4 \%$ & $-8.4 \%$ & $0.0 \%$ & $7.0 \%$ & $2.3 \%$ \\
\hline Norway & $-2.8 \%$ & $4.8 \%$ & $-2.2 \%$ & $12.5 \%$ & $-3.1 \%$ & $-7.0 \%$ & $-2.7 \%$ & $-8.4 \%$ & $8.5 \%$ & $-2.3 \%$ \\
\hline Poland & $6.0 \%$ & $9.1 \%$ & $14.3 \%$ & $6.5 \%$ & $0.6 \%$ & $2.9 \%$ & $-0.4 \%$ & $5.7 \%$ & $6.2 \%$ & $-0.5 \%$ \\
\hline $\begin{array}{l}\text { Portugal } \\
\text { Slovak }\end{array}$ & $-1.7 \%$ & $2.0 \%$ & $2.2 \%$ & $2.8 \%$ & $0.6 \%$ & $0.6 \%$ & $1.1 \%$ & $-1.3 \%$ & $-2.0 \%$ & $-3.3 \%$ \\
\hline Republic & $13.0 \%$ & $16.6 \%$ & $9.4 \%$ & $8.5 \%$ & $2.6 \%$ & $5.5 \%$ & $9.6 \%$ & $8.1 \%$ & $4.3 \%$ & $2.2 \%$ \\
\hline Slovenia & $4.9 \%$ & $1.2 \%$ & $9.8 \%$ & $2.8 \%$ & $-1.6 \%$ & $2.8 \%$ & $-2.4 \%$ & $3.1 \%$ & $3.7 \%$ & $2.6 \%$ \\
\hline Spain & $4.9 \%$ & $5.2 \%$ & $6.6 \%$ & $2.8 \%$ & N/A & $0.5 \%$ & $2.3 \%$ & $4.4 \%$ & $3.9 \%$ & $\mathrm{~N} / \mathrm{A}$ \\
\hline Sweden & $3.0 \%$ & $3.0 \%$ & $2.9 \%$ & $2.3 \%$ & $2.0 \%$ & $3.3 \%$ & $0.6 \%$ & $1.4 \%$ & $1.1 \%$ & $1.1 \%$ \\
\hline Switzerland & $-0.6 \%$ & $2.1 \%$ & $3.3 \%$ & $4.2 \%$ & $2.4 \%$ & $-2.7 \%$ & $1.2 \%$ & $1.6 \%$ & $4.2 \%$ & $-2.1 \%$ \\
\hline $\begin{array}{l}\text { Turkey } \\
\text { United }\end{array}$ & $14.0 \%$ & $8.7 \%$ & $1.3 \%$ & $\mathrm{~N} / \mathrm{A}$ & N/A & N/A & N/A & $\mathrm{N} / \mathrm{A}$ & N/A & $\mathrm{N} / \mathrm{A}$ \\
\hline $\begin{array}{l}\text { Kingdom } \\
\text { United }\end{array}$ & $5.3 \%$ & $3.7 \%$ & $2.2 \%$ & $7.0 \%$ & $0.2 \%$ & $1.0 \%$ & $2.0 \%$ & $-0.6 \%$ & $\mathrm{~N} / \mathrm{A}$ & N/A \\
\hline States & $3.3 \%$ & $3.3 \%$ & $2.4 \%$ & $2.7 \%$ & $2.7 \%$ & $5.3 \%$ & $2.5 \%$ & $1.0 \%$ & $3.7 \%$ & $0.2 \%$ \\
\hline OECD & $3.8 \%$ & $4.4 \%$ & $4.3 \%$ & $4.3 \%$ & $0.0 \%$ & $2.4 \%$ & $2.1 \%$ & $2.4 \%$ & $3.2 \%$ & $-4.4 \%$ \\
\hline
\end{tabular}

Source: OECD (2011), WHO-NHA database and OECD Secretariat's estimates. 


\section{User participation to the costs of pharmaceutical care}

163. In all case-study countries, patients have to contribute to the costs of out-patient pharmaceuticals (see Table 14). In seven out of fourteen countries, this contribution takes the form of a co-insurance rate, which can vary across drug categories (France, Belgium) or decreases when cumulative spending for patients increases (Norway and Sweden). In France, it is combined with a small co-payment. In three countries, patients have to pay a deductible before getting any reimbursement: this deductible only pertains to pharmaceutical spending in Denmark and Sweden, but to all health care services in the Netherlands. In three countries (Australia, Italy and the United Kingdom), patients pay a fixed prescription charge. In Canada, the nature and extent of co-payments vary widely across drug plans. In addition to these copayments, many case-study countries have a reference price system, in which patients have to pay for any difference between the price of the product and the reference price. In all countries, co-payments are waved or reduced for people with high medical needs or in poor economic circumstances. 
DELSA/HEA/WD/HWP(2013)4

Table 16. Patient contributions to the costs of reimbursed pharmaceuticals in 2012

\begin{tabular}{|c|c|}
\hline $\begin{array}{l}\text { Case-study } \\
\text { countries }\end{array}$ & Cost-sharing requirements \\
\hline Australia & Copayment of AUS $\$ 35.40$ per prescription, reduced for pensioners and veterans to AUS $\$ 5.80$ \\
\hline Belgium & $\begin{array}{l}\text { Co-insurance rate, with different levels across categories, with a cap per prescription. } \\
\text { Co-insurance rate is } 0 \% \text { for vital pharmaceuticals, } 25 \% \text { for therapeutically important drugs; } 50 \% \\
\text { for pharmaceuticals for symptomatic treatment, } 60 \% \text { for influenza vaccines and antihistamines } \\
\text { and } 80 \% \text { for contraceptive medicines. }\end{array}$ \\
\hline Canada & Copayments are specific to each drug plan. \\
\hline Denmark & $\begin{array}{l}\text { Deductible of DKK } 820 \text { and decreasing co-insurance rate linked to accumulated OOP spending } \\
\text { in one year. Reimbursement rate is } 50 \% \text { up to DKK } 1340 \text { DKK, then } 75 \% \text { up to DKK } 2885 \text {, then } \\
85 \% \text { up to } 3370 \text { DKK. Beyond that level, the patient can apply for } 100 \% \text { reimbursement for the } \\
\text { rest of the year. }\end{array}$ \\
\hline France & $\begin{array}{l}\text { Co-insurance rates of } 35 \%, 70 \% \text { or } 85 \% \text { depending on drug categories }+ \text { copayment of } € 50 / R x \\
\text { capped to EUR } 50 \text { per year. Exemptions for some categories of patients and full reimbursement } \\
\text { for some drugs. }\end{array}$ \\
\hline Germany & $10 \%$ co-insurance (with a minimum of $€ 5$ and a maximum of $€ 10$ per prescription). \\
\hline Italy & $\begin{array}{l}\text { Copayments per prescription set at regional level, with possible adjustments for population } \\
\text { categories (e.g. based on specific clinical condition, age and income) }\end{array}$ \\
\hline Japan & $30 \%$ co-insurance rate \\
\hline Korea & Co-insurance rates, varying with the level of referral of the facility. \\
\hline Netherland & $\begin{array}{l}\text { Deductible + maximum reimbursement for drugs in list } 1 \mathrm{~A} \text {, full reimbursement for drugs in list } 1 \mathrm{~B} \\
\text { and conditional reimbursement (i.e. restricted to certain conditions of use, for specific categories } \\
\text { of patients) for drugs in list } 2 \text {. }\end{array}$ \\
\hline Norway & $\begin{array}{l}\text { Co-insurance rate of } 38 \% \text {, capped to NOK } 520(€ 66.4) \text { per prescription. In addition, patients' } \\
\text { copayments are capped to an annual ceiling of NOK } 1,880(€ 240) \text {. }\end{array}$ \\
\hline Spain & $\begin{array}{l}\text { Co-insurance rate of about } 40 \% \text { of costs, reduced to } 10 \% \text { (and capped to } € 2.64 / \text { pack) for } \\
\text { chronically ill patients. Exemptions exist for some categories of patients (e.g. pensioners and } \\
\text { their dependents, treatments for workplace injuries) }\end{array}$ \\
\hline Sweden & $\begin{array}{l}\text { Deductible (SEK 900) and then a decreasing co-insurance rate. The participation is capped at } \\
\text { SEK } 1,800 \text { per year, beyond which the patient receives a "free card". }\end{array}$ \\
\hline United Kingdom & $\begin{array}{l}\text { Copayment is } £ 7.65 \text { per prescription, but a number of patients are entitled to free prescriptions } \\
\text { (i.e. under } 16 \text { and over } 60 \text { patients, pregnant women, patients with a specified medical condition) }\end{array}$ \\
\hline
\end{tabular}




\section{OECD HEALTH WORKING PAPERS TO CHECK WITH LAST PAPER}

A full list of the papers in this series can be found on the OECD website: http://www.oecd.org/health/workingpapers

No. 62 HEALTH WORKFORCE PLANNING IN OECD COUNTRIES: A REVIEW OF 26 PROJECTION MODELS FROM 18 COUNTRIES (2013) Tomoko Ono, Gaetan Lafortune and Michael Schoenstein

No. 61 INTERNATIONAL VARIATIONS IN A SELECTED NUMBER OF SURGICAL PROCEDURES (2013) Klim McPherson, Giorgia Gon, Maggie Scott

No. 60 HEALTH SPENDING GROWTH AT ZERO: WHICH COUNTRIES, WHICH SECTORS ARE MOST AFFECTED? (2013) David Morgan and Roberto Astolfi

No. 59 A COMPARATIVE ANALYSIS OF HEALTH FORECASTING METHODS (2012) Roberto Astolfi, Luca Lorenzoni, Jillian Oderkirk

No. 58 INCOME-RELATED INEQUALITIES IN HEALTH SERVICE UTILISATION IN 19 OECD COUNTRIES, 2008-09 (2012) Marion Devaux and Michael de Looper

No. 57 THE IMPACT OF PAY INCREASES ON NURSES' LABOUR MARKET: A REVIEW OF EVIDENCE FROM FOUR OECD COUNTRIES (2011) James Buchan and Steven Black

No. 56 DESCRIPTION OF ALTERNATIVE APPROACHES TO MEASURE AND PLACE A VALUE ON HOSPITAL PRODUCTS IN SEVEN OECD COUNTRIES (2011) Luca Lorenzoni and Mark Pearson

No. 55 MORTALITY AMENABLE TO HEALTH CARE IN 31 OECD COUNTRIES: ESTIMATES AND METHODOLOGICAL ISSUES (2011) Juan G. Gay, Valerie Paris, Marion Devaux, Michael de Looper

No. 54 NURSES IN ADVANCED ROLES: A DESCRIPTION AND EVALUATION OF EXPERIENCES IN 12 DEVELOPED COUNTRIES (2010) Marie-Laure Delamaire and Gaetan Lafortune

No. 53 COMPARING PRICE LEVELS OF HOSPITAL SERVICE ACROSS COUNTRIES: RESULTS OF A PILOT STUDY (2010) Luca Lorenzoni

No. 52 GUIDELINES FOR IMPROVING THE COMPARABILITY AND AVAILABILITY OF PRIVATE HEALTH EXPENDITURES UNDER THE SYSTEM OF HEALTH ACCOUNTS FRAMEWORK (2010) Ravi P. Rannan-Eliya and Luca Lorenzoni

No. 51 EFFECTIVE WAYS TO REALISE POLICY REFORMS IN HEALTH SYSTEMS (2010) Jeremy Hurst

No. 50 HEALTH SYSTEMS INSTITUTIONAL CHARACTERISTICS A SURVEY OF 29 OECD COUNTRIES (2010) Valerie Paris, Marion Devaux and Lihan Wei

No. 49 THE CHALLENGE OF FINANCING HEALTH CARE IN THE CURRENT CRISIS (2010) Peter Scherer, Marion Devaux 
No. 48 IMPROVING LIFESTYLES, TACKLING OBESITY: THE HEALTH AND ECONOMIC IMPACT OF PREVENTION STRATEGIES (2009) Franco Sassi, Michele Cecchini, Jeremy Lauer and Dan Chisholm

No. 47 HEALTH CARE QUALITY INDICATORS PROJECT: PATIENT SAFETY INDICATORS REPORT 2009 (2009) Saskia Drösler, Patrick Romano, Lihan Wei; and ANNEX Saskia Drösler

No. 46 EDUCATION AND OBESITY IN FOUR OECD COUNTRIES (2009) Franco Sassi, Marion Devaux, Jody Church, Michele Cecchini and Francesca Borgonovi

No. 45 THE OBESITY EPIDEMIC: ANALYSIS OF PAST AND PROJECTED FUTURE TRENDS IN SELECTED OECD COUNTRIES (2009) Franco Sassi, Marion Devaux, Michele Cecchini and Elena Rusticelli

No. 44 THE LONG-TERM CARE WORKFORCE: OVERVIEW AND STRATEGIES TO ADAPT SUPPLY TO A GROWING DEMAND (2009) Rie Fujisawa and Francesca Colombo

No. 43 MEASURING DISPARITIES IN HEALTH STATUS AND IN ACCESS AND USE OF HEALTH CARE IN OECD COUNTRIES (2009) Michael de Looper and Gaetan Lafortune

No. 42 POLICIES FOR HEALTHY AGEING: AN OVERVIEW (2009) Howard Oxley

No. 41 THE REMUNERATION OF GENERAL PRACTITIONERS AND SPECIALISTS IN 14 OECD COUNTRIES: WHAT ARE THE FACTORS EXPLAINING VARIATIONS ACROSS COUNTRIES? (2008) Rie Fujisawa and Gaetan Lafortune

No. 40 INTERNATIONAL MOBILITY OF HEALTH PROFESSIONALS AND HEALTH WORKFORCE MANAGEMENT IN CANADA: MYTHS AND REALITIES (2008) Jean-Christophe Dumont, Pascal Zurn, Jody Church and Christine Le Thi

No. 39 PHARMACEUTICAL PRICING \& REIMBURSEMENT POLICIES IN GERMANY (2008) Valérie Paris and Elizabeth Docteur

No. 38 MIGRATION OF HEALTH WORKERS: THE UK PERSPECTIVE TO 2006 (2008) James Buchan, Susanna Baldwin and Miranda Munro

No. 37 THE US PHYSICIAN WORKFORCE: WHERE DO WE STAND? (2008) Richard A. Cooper

No. 36 MIGRATION POLICIES OF HEALTH PROFESSIONALS IN FRANCE (2008) Roland Cash and Philippe Ulmann

No. 35 NURSE WORKFORCE CHALLENGES IN THE UNITED STATES: IMPLICATIONS FOR POLICY (2008) Linda H. Aiken and Robyn Cheung

No. 34 MISMATCHES IN THE FORMAL SECTOR, EXPANSION OF THE INFORMAL SECTOR: IMMIGRATION OF HEALTH PROFESSIONALS TO ITALY (2008) Jonathan Chaloff

No. 33 HEALTH WORKFORCE AND INTERNATIONAL MIGRATION: CAN NEW ZEALAND COMPETE? (2008) Pascal Zurn and Jean-Christophe Dumont 


\section{RECENT RELATED OECD PUBLICATIONS}

A GOOD LIFE IN OLD AGE? MONITORING AND IMPROVING QUALITY IN LONG-TERM CARE (2013)

STRENGTHENING HEALTH INFORMATION INFRASTRUCTURE FOR HEALTH CARE QUALITY GOVERNANCE (2013)

WAITING TIME POLICIES IN THE HEALTH SECTOR, WHAT WORKS? (2013)

OECD REVIEWS OF HEALTH CARE QUALITY - DENMARK (2013)

OECD HEALTH DATA 2013

(Database available from http://www.oecd.org/els/health-systems/oecdhealthdata.htm)

HEALTH AT A GLANCE: ASIA/PACIFIC (2012)

HEALTH AT A GLANCE: EUROPE (2012)

OECD REVIEWS OF HEALTH SYSTEMS - RUSSIAN FEDERATION (2012)

OECD REVIEWS OF HEALTH CARE QUALITY - KOREA (2012)

OECD REVIEWS OF HEALTH CARE QUALITY - ISRAEL (2012)

SICK ON THE JOB? MYTHS AND REALITIES ABOUT MENTAL HEALTH AND WORK (2011)

OECD REVIEWS OF HEALTH SYSTEMS - SWITZERLAND (2011)

HEALTH AT A GLANCE 2011: OECD INDICATORS (2011)

See http://www.oecd.org/health/healthataglance for more information

HEALTH REFORM: MEETING THE CHALLENGE OF AGEING AND MULTIPLE MORBIDITIES (2011)

A SYSTEM OF HEALTH ACCOUNTS (2011)

HELP WANTED? PROVIDING AND PAYING FOR LONG-TERM CARE (2011)

IMPROVING VALUE IN HEALTH CARE: MEASURING QUALITY (2010)

VALUE FOR MONEY IN HEALTH SPENDING (2010)

OBESITY AND THE ECONOMICS OF PREVENTION: FIT NOT FAT(2010)

For a full list, consult the OECD On-Line Bookstore at www.oecd.org, or write for a free written catalogue to the following address:

OECD Publications Service

2, rue André-Pascal, 75775 PARIS CEDEX 16

or to the OECD Distributor in your country 